\title{
The antioxidant and anti-inflammatory activities of alkylresorcinols from rye bran
}

\author{
By \\ Julia Gliwa, B.Sc. \\ Master of Science \\ in \\ Chemistry \\ Carleton University \\ Ottawa, Ontario \\ (C) 2013 \\ Julia Gliwa
}

A thesis submitted to the Faculty of Graduate and Postdoctoral Affairs in partial fulfillment of the requirements for the degree of 


\begin{abstract}
Alkylresorcinols (ARs) are phenolic lipids, found in the bran layer of cereals such as rye. They are natural antioxidants that confer many health benefits. In this study, ARs were extracted from Hazlet rye bran and analyzed for their in vitro antioxidant and antiinflammatory activities and in vivo antiobesity and antioxidant activities. In vitro studies showed that rye bran ARs have higher antioxidant activity than those from wheat and oat bran. ARs also exhibited anti-inflammatory activity by inhibiting the inflammatory mediator nitric oxide (NO), and gene expression of iNOS and COX-2. ARs did not exhibit antiobesity activity in CF-1 mice fed a 60\% high fat (HF) diet but showed in vivo antioxidant activity in the liver using the oxygen radical absorbance capacity (ORAC) assay. In heart tissue, ARs exhibited higher antioxidant activity than the HF control diet, using the ORAC, superoxide dismutase (SOD), and glutathione assays, but results were not significant.
\end{abstract}




\section{Acknowledgements}

First and foremost I would like to thank my supervisors Drs. Hosseinian and Willmore for their guidance, patience, and support throughout my studies and mostly for their positive attitudes towards my results when I was ready to give up. Also, I want to thank Dr. Abizaid for generously supplying the mice for our study and always looking on the bright side when things didn't work out. A special thanks to Zack Patterson and Harry MacKay who spared me from lifelong trauma by helping with sacrificing the mice.

At this point I should also mention the 56 mice that had to give their lives for research purposes, especially numbers $11,18,19$, and 33 , who died before the end of the study.

I would like to thank all the past and present Hosseinian and Willmore lab members who are always willing to help and talked things through with me when my research didn't make sense.

Last but not least, a big thank you goes to my mom, grandparents, and great aunt who didn't just generously support me for the last 6 years, during my Bachelor and Masters Degree, but for the past 25 years of my life. Thanks for all the Christmas, Birthday and Easter care packages filled with chocolate and clothes. A special thanks also to my stepfather, without whom I would have never come to Canada in the first place.

To my husband Peter, there are so many things to thank you for, but mostly I want to thank you for always being there and listening to me ranting after many failed experiences almost made me quit science. 


\section{Table of Contents}

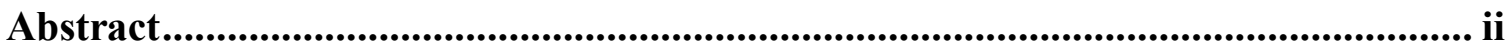

Acknowledgements ..................................................................................................... iii

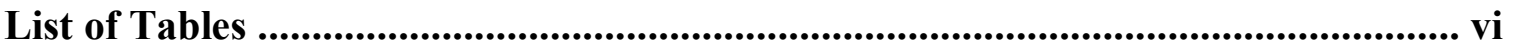

List of Figures ......................................................................................................... vii

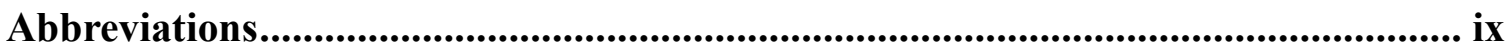

Chapter 1 - Introduction..............................................................................................1

1.1 Alkylresorcinols in cereal bran .................................................................1

1.2 Biosynthesis and role of ARs in plants .......................................................3

1.3 Intake, absorption and metabolism of ARs ...............................................5

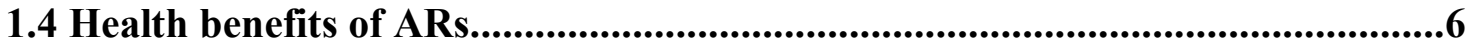

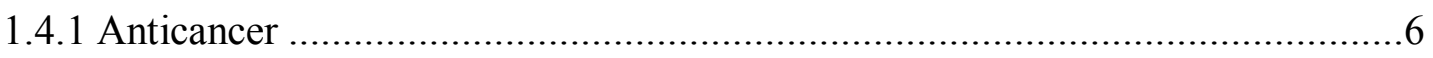

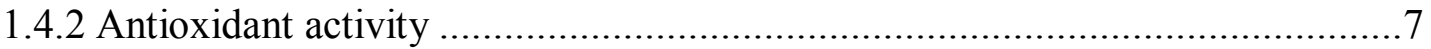

1.5 Antioxidant assays.......................................................................................10

1.5.1 Oxygen Radical Absorbance Capacity (ORAC) and ß-carotene bleaching

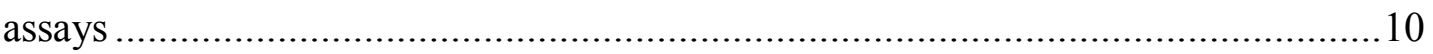

1.5.2 Glutathione and superoxide dismutase assays........................................... 11

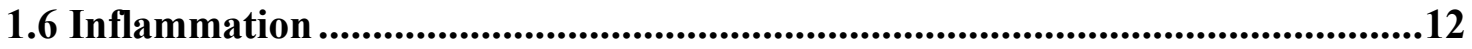

Chapter 2 - Extraction and characterization of alkylresorcinols and their antioxidant and anti-inflammatory activity in vitro .........................................14

2.1 Abstract

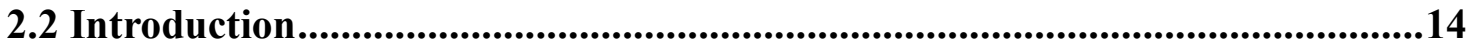

2.3 Materials and Methods .............................................................................17

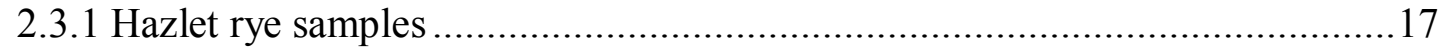

2.3.2 Extraction of ARs from Hazlet bran ........................................................ 17

2.3.3 High Performance Liquid Chromatography (HPLC) ................................. 17

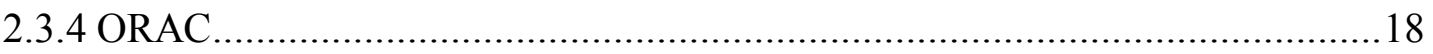

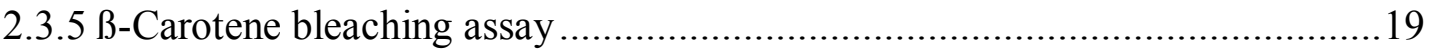

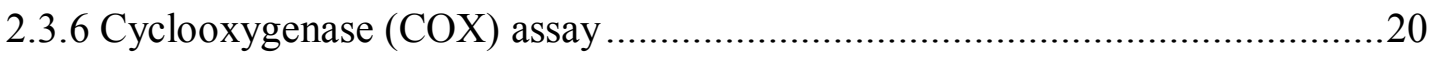

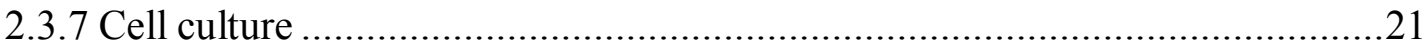

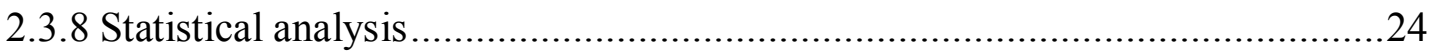

2.4 Results..........................................................................................................25

2.4.1 Characterization of AR homologues from Hazlet rye bran ..........................25

2.4.2 In vitro antioxidant activity of ARs from Hazlet rye bran ............................28

2.4.3 In vitro effect of rye bran ARs on COX-2 inhibition ......................................30

2.4.4 Effect of rye bran ARs on cytotoxicity on RAW 264.7 macrophages ..............31

2.4.5 Effect of rye bran ARs on LPS-induced NO production in RAW 264.7

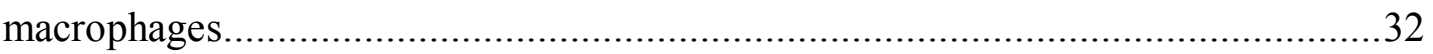


2.4.6 Effect of rye bran ARs on the protein expression of iNOS and COX-2 ...........34

2.4.7 Effect of rye bran ARs on the mRNA expression of iNOS and COX-2 ...........37

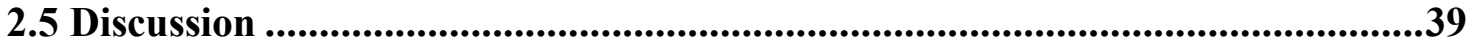

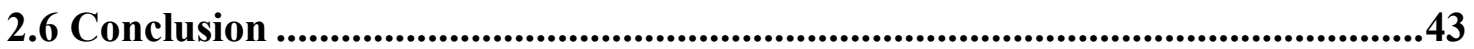

Chapter 3 - Effect of alkylresorcinols from Hazlet rye bran on antiobesity and antioxidant activity in mouse tissues.......................................................................45

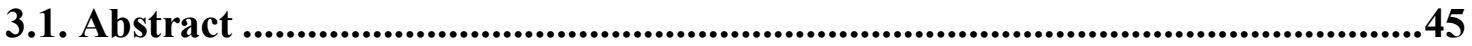

3.2. Introduction ....................................................................................................45

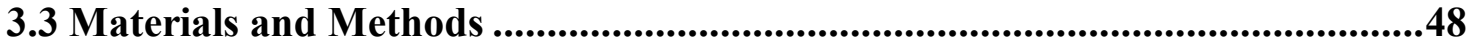

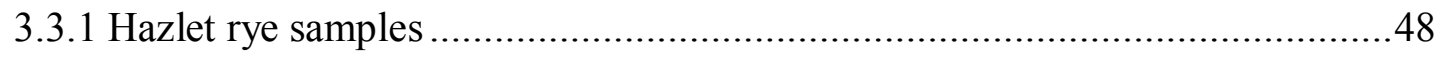

3.3.2 Extraction of ARs from Hazlet bran ....................................................... 48

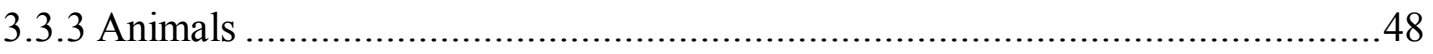

3.3.4 Tissue homogenization and protein determination.....................................51

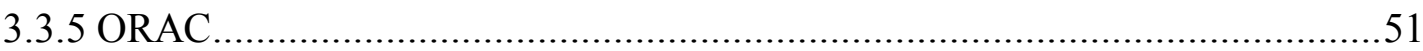

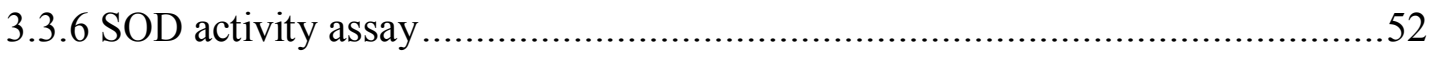

3.3.7 Determination of glutathione and glutathione disulfide ............................53

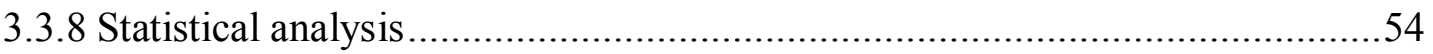

3.4 Results........................................................................................................554

3.4.1 Changes in body weight and caloric intake of control and treatment mice ......54

3.4.2 Blood glucose clearance in control and treatment mice after overnight fasting

3.4.3 Mouse carcass composition of control and treatment mice after a 3-month intervention period .......................................................................................6 60 3.4.4 Antioxidant activity in liver and heart tissue of control and treatment mice ....62

3.4.5 Glutathione levels in liver and heart tissue of control and treatment mice.......66

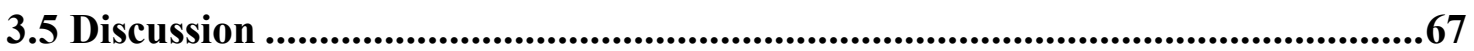

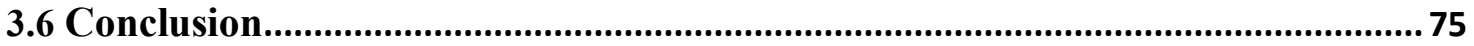

Chapter 4- Conclusion and Future Directions .......................................................76

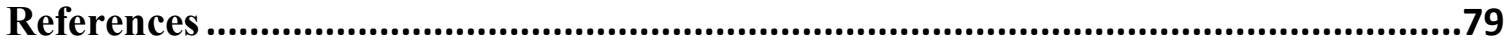




\section{List of Tables}

Table 1-1: Total contents and relative composition of alkylresorcinols in different milling

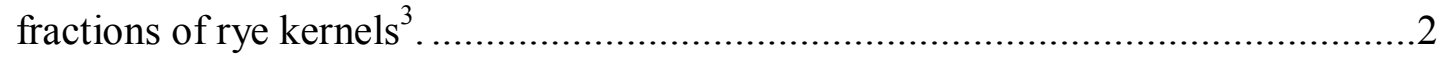




\section{List of Figures}

Figure 1-1: Chemical structure of alkylresorcinols. 1

Figure 1-2: Biosynthesis of alkylresorcinols and various triketide and tetraketide pyrones and pentaketide resorcylic acids, modified from $\mathrm{Yu}$ et al. ${ }^{14}$... .4

Figure 2-1: (A) HPLC chromatogram of AR homologues from a mixture of AR standards and (B) from Hazlet rye bran obtained with ultraviolet detection. (C) Total amount of AR homologues in Hazlet rye bran as determined with HPLC analysis. Results are expressed as mean values \pm SEM.

Figure 2-2: Antioxidant activity of AR extracts from Hazlet rye, wheat, and oat bran, determined by (A) ORAC in $\mu \mathrm{mol} \mathrm{TE} / \mathrm{g}$ of ARs and (B) $\beta$-carotene bleaching as \% Inhibition of $\beta$-carotene bleaching. Results are expressed as mean values $\pm \mathrm{SEM}$. Significantly different from Hazlet, ${ }^{*} \mathrm{P}<0.05,{ }^{*} * \mathrm{P}<0.01$

Figure 2-3: Inhibition of human recombinant COX-2 by AR extract from Hazlet rye bran.

Results are expressed as mean values \pm SEM. 30

Figure 2-4: Reduction of cellular metabolic activity of RAW 264.7 cells at increasing concentrations of AR extracts from Hazlet rye bran using the MTT assay. Results are expressed as mean values \pm SEM.

Figure 2-5: Inhibition on NO production in LPS-stimulated RAW 264.7 cells by AR extracts from Hazlet rye bran and oat bran. Results are expressed as mean values \pm SEM. Significantly different from the corresponding control (LPS, no treatment), $* \mathrm{P}<0.05,{ }^{*} * \mathrm{P}<0.01$

Figure 2-6: Inhibition of (a) iNOS and (b) COX-2 protein expression by AR extracts from Hazlet rye bran in LPS-stimulated RAW 264.7 cells. Results are expressed as mean values \pm SEM. Significantly different from the control (LPS, no treatment), ${ }^{*} \mathrm{P}<0.05$, $* * \mathrm{P}<0.01$ .36

Figure 2-7: Inhibition of (A) iNOS and (B) COX-2 mRNA expression by AR extracts from Hazlet rye bran in LPS-stimulated RAW 264.7 cells. Results are expressed as mean values \pm SEM. Significantly different from the control (LPS, no treatment), $* \mathrm{P}<0.05, * *<\mathrm{P}<0.01 \ldots$

Figure 3-1: (A) Body weight of control and treatment mice over 82 days. (B) Average body weight at the end of the treatment period $(c=a+b)$. (C) Average body weight 
gain $(\mathrm{c}=\mathrm{a}+\mathrm{b})$ and $(\mathrm{D})$ caloric intake per day of control and treatment miceover the course of the treatment period $(a=c, a=d, c \neq d)$. Mice were fed and weighted daily. Results are expressed as mean values \pm SEM.

Figure 3-2: Blood glucose levels of control and treatment mice obtained with the intraperitoneal glucose tolerance test after overnight fasting. Values were obtained

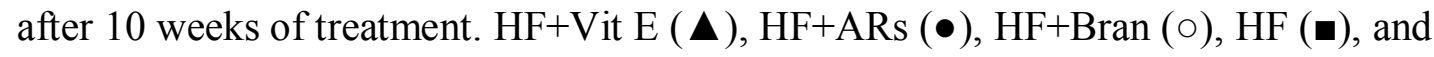
Chow ( $\square$ ). Results are expressed as mean values \pm SEM.

Figure 3-3: Blood glucose levels of control and treatment mice at time of death after overnight fasting. Values were obtained after 11 weeks of treatment. Results are expressed as mean values \pm SEM.

Figure 3-4: Mice carcass composition of control and treatment groups, obtain with the EchoMRI4in $1{ }^{\mathrm{TM}}$ mouse composition analyzer. (A)\% Fat Mass, (B) \% Lean mass $(\mathrm{c}=\mathrm{a}+\mathrm{b}),(\mathrm{C}) \%$ Water. Results are expressed as mean values \pm SEM.

Figure 3-5: Antioxidant activity of liver and heart tissue from control and treatment mice determined by the ORAC assay, expressed as (A) $\mu \mathrm{mol} \mathrm{TE} / \mathrm{mg}$ protein and (B) $\mu \mathrm{mol}$ $\mathrm{TE} / \mathrm{mg}$ wet weight. Results are expressed as mean values $\pm \mathrm{SEM}$.

Figure 3-6: Antioxidant activity of liver tissue from control and treatment mice determined by the (A) SOD activity assay (Units SOD/mg protein), and of liver and heart tissue from control and treatment mice determined by (B) the ratio of oxidized to reduced glutathione (GSSG/GSH). Results are expressed as mean values $\pm \mathrm{SEM}$.

Figure 3-7: Reduced glutathione levels in liver and heart tissue of control and treatment mice. Results are expressed as mean values \pm SEM. 


\section{Abbreviations}

AAFC- Agriculture and Agri-Food Canada

AAPH- 2,2`Azobis (2-methylpropionamidine) dihydrochloride

ADHP- 10-acetyl-3,7-dihydroxyphenoxazine

ARE- Antioxidant response element

ARs- Alkylresorcinols

ATCC-American type culture collection

AUC- Area under the curve

BCA- Bicinchoninic acid

BHA-Butylatedhydroxyanisole

BSA- Bovine serum albumin

COX-2- Cyclooxygenase-2

Cu/ZnSOD- Copper-zinc superoxide dismutase

DHBA-3,5-Dihydroxybenzoic acid

DHPPA- 3-(3,5-Dihydroxyphenyl)-propanoic acid

DM- Dry matter

DMEM- Dulbecco's modified eagle's medium

DMSO- Dimethyl sulfoxide

DNA- Deoxyribonucleic acid

DPPH- 2,2-Diphenyl-1-picrylhydrazyl

DTNB- 5,5'-Dithiobis-(2-nitrobenzoic acid)

DuP-697- 5-Bromo-2-(4-fluorophenyl)-3-(4-(methylsulfonyl)phenyl)-thiophene

ECSOD- Extracellular superoxide dismutase 
EDTA- Ethylenediaminetetraacetic acid

FA- Ferulica cid

GCL- $\gamma$-Glutamyl cysteine ligase

GR- Glutathione reductase

GSH- Reduced glutathione

GSSG- Glutathione disulfide (oxidized glutathione)

GTT- Glucose tolerance test

HF- High fat

HF+ARs- High fat and Alkylresorcinols

HF+Bran- High fat and rye bran

HF+Vit E- High fat and Vitamin E

HO-1- hemeoxygenase-1

HPLC- High performance liquid chromatography

IgG- Immunoglobulin

IL-1ß- Interleukin-1 beta

iNOS-Inducible nitric oxide synthase

Keap1-Kelch-like ECH-associated protein 1

LPS- Lipopolysaccharides

MAPK- Mitogen-activated protein kinases

MeSH- $\beta$-Mercaptoethanol

MnSOD- Manganese superoxide dismutase

MTT- 3-(4,5-Dimethylthiazol-2-yl)-2,5-diphenyltetrazolium bromide

NADH- Nicotinamide adenine dinucleotide 
NADPH- Nicotinamide adenine dinucleotide phosphate

NED- Naphthylenediaminedihydrochloride

NF-кB- Nuclear factor-kappa B

NO- Nitric oxide

NOS2- Inducible nitric oxide synthase

Nrf2- Nuclear factor (erythroid-derived 2)-like 2

ORAC- Oxygen radical absorbance capacity

PBS- Phosphate buffered saline

PGs- Prostaglandins

PVDF- Polyvinylidene fluoride

RNA- Ribonucleic acid

ROS- Reactive oxygen species

RT-PCR- Reverse transcriptase-polymerase chain reaction

SDS-PAGE- Sodium dodecyl sulfate-polyacrylamide gel electrophoresis

SOD- Superoxide dismutase

TBST- Tris-buffered saline-Tween

TE- Trolox equivalent

TNB- 5-Thionitrobenzoic acid

Trolox- 6-Hydroxy-2, 5, 7, 8-tetramethylchroman-2-carboxylic acid 


\section{Chapter 1 - General Introduction}

\subsection{Alkylresorcinols in cereal bran}

5-n-Alkylresorcinols are phenolic lipids, occurring mainly in higher plants, but also in fungi, algae, mosses and bacteria ${ }^{1}$. They are amphiphilic 1,3-dihydroxybenzene derivatives, with a hydrophilic benzene ring with two hydroxyl groups attached at meta position 1 and 3 and a hydrophobic alkyl chain at position 5 . This side chain can be saturated and unsaturated and is always odd numbered, ranging anywhere from 13 to 27 carbons ${ }^{2}$.

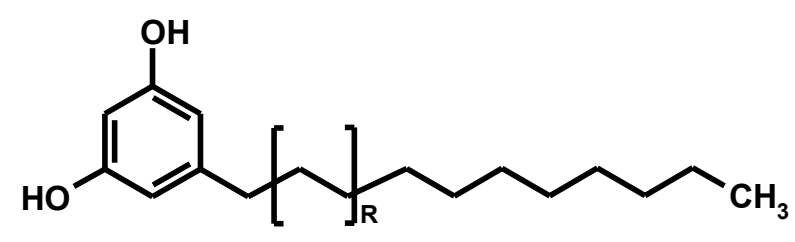

\section{Figure 1-1: Chemical structure of alkylresorcinols.}

ARs are mainly found in the bran of cereals such as rye (Secale cereale), wheat (Triticum spp.), triticale (Triticosecale) and barley (Hordeum vulgare). Low amounts are also found in the endosperm ${ }^{3}$. Rye and wheat show the highest levels of ARs in cereals consumed by humans, with $360-3200 \mu \mathrm{g} / \mathrm{g}$ of dry matter for rye and $317-1010 \mu \mathrm{g} / \mathrm{g}$ of dry matter for wheat (Triticum aestivum) ${ }^{4}$. The bran alone has an AR content of 2034$2753 \mu \mathrm{g} / \mathrm{g}^{5,6}$. More specifically, 99\% of ARs are located in the intermediate layer of the bran, including the hyaline layer, testa and pericarp ${ }^{7}$. 
Table 1-1: Total contents and relative composition of alkylresorcinols in different milling fractions of rye kernels ${ }^{3}$.

\begin{tabular}{llccccl}
\hline Percentage composition of alkylresorcinols \\
\hline Sample & $17: 0$ & $19: 0$ & $21: 0$ & $23: 0$ & $25: 0$ & $\begin{array}{l}\text { Total } \\
(\mu \mathrm{g} / \mathrm{g}\end{array}$ \\
& & & & & $\mathrm{DM})$ \\
\hline Whole Rye & 21 & 30 & 26 & 11 & 12 & 559 \\
Pericarp/testa & 18 & 26 & 24 & 15 & 17 & 958 \\
Aleurone & 21 & 29 & 26 & 11 & 13 & 2174 \\
Endosperm & 16 & 29 & 33 & 12 & 11 & 35 \\
\hline
\end{tabular}

The AR content in cereal product varies, with $\sim 230 \mu \mathrm{g} / \mathrm{g}$ DM in durum wheat $\operatorname{pasta}^{8}, 386-669 \mu \mathrm{g} / \mathrm{g}$ DM in soft rye bread, 237-350 $\mu \mathrm{g} / \mathrm{g} \mathrm{DM}$ in whole-grain bread ${ }^{5}$, 886-1007 $\mu \mathrm{g} / \mathrm{g}$ DM in rye crisp bread, and $222 \mu \mathrm{g} / \mathrm{g}$ DM in whole-grain wheat bread ${ }^{4}$.

ARs are present in cereals as different homologues, where the alkyl chain varies between 15 and 25 carbons. In rye, the predominant homologues are C17:0, C19:0, C21:0, C23:0, and C25:0, with $\mathrm{C} 19: 0$ being the most common homologue ${ }^{9,10}$, where C21:0 is more common in wheat and triticale and C25:0 is most common in barley ${ }^{4}$. Although saturated ARs are more common in cereals, unsaturated ARs, 5alkenylresorcinols $^{11}$, as well as keto- and hydroxyl derivatives have been found to be present in cereal grains at approximately $15-20 \%{ }^{12}$.

The rye cultivar used in this study is Hazlet winter rye. It is a cultivar of winter rye (Secale cereale L.) and was selected for large seed size, floret fertility and reduced plant height by two cycles of recurrent selection at the Semiarid Prairie Research Centre of Agriculture and Agri-Food Canada, Swift Current, $\mathrm{SK}^{13}$. 


\subsection{Biosynthesis and role of ARs in plants}

ARs are synthesized in plants by $2{ }^{`}$-oxoalkylresorcylic acid synthase (ORAS), a type III polyketide synthase, via the polyketide pathway ${ }^{14}$. In the proposed biosynthetic pathway, a fatty acyl-CoA starter unit reacts with malonyl coenzyme A three times to form a tetraketide intermediate ${ }^{15}$ by an aldol condensation-type reaction. The odd numbered side chain of ARs is the direct results of the fatty acid precursor ${ }^{16}$. This intermediate compound under goes an aldol condensation-type ring closure and hydrolysis to release the coenzyme A, to form and alkylresorcylic acid. This is followed by nonenzymatic decarboxylation, to yield 5-n-alkylresorcinols ${ }^{17}$. ORAS also synthesizes triketide and tetraketide pyrones and pentaketide resorcylic acids and resorcinols from the fatty acyl-CoA starter unit ${ }^{14}$.

ARs are secondary plant metabolites that are suggested to serve as phytoanticipins (defense) and allelochemicals. Antimicrobial activity of ARs in plants has been shown in in vitro assays and suggests adefensive role against plant pathogens ${ }^{18,19}$. A mixture of rye grain ARs has been shown to inhibit mycelia growth of Fusarium culmorum and strains of Rhizoctonia at concentrations between 160 and $260 \mu \mathrm{g} / \mathrm{mL}$ and $70-80 \mu \mathrm{g} / \mathrm{mL}$, respectively ${ }^{18}$. Additionally, the localization of ARs in the bran layer, which is the outer layer of the cereal kernel, suggests the role of a defense barrier to protect the seed ${ }^{3}$. 


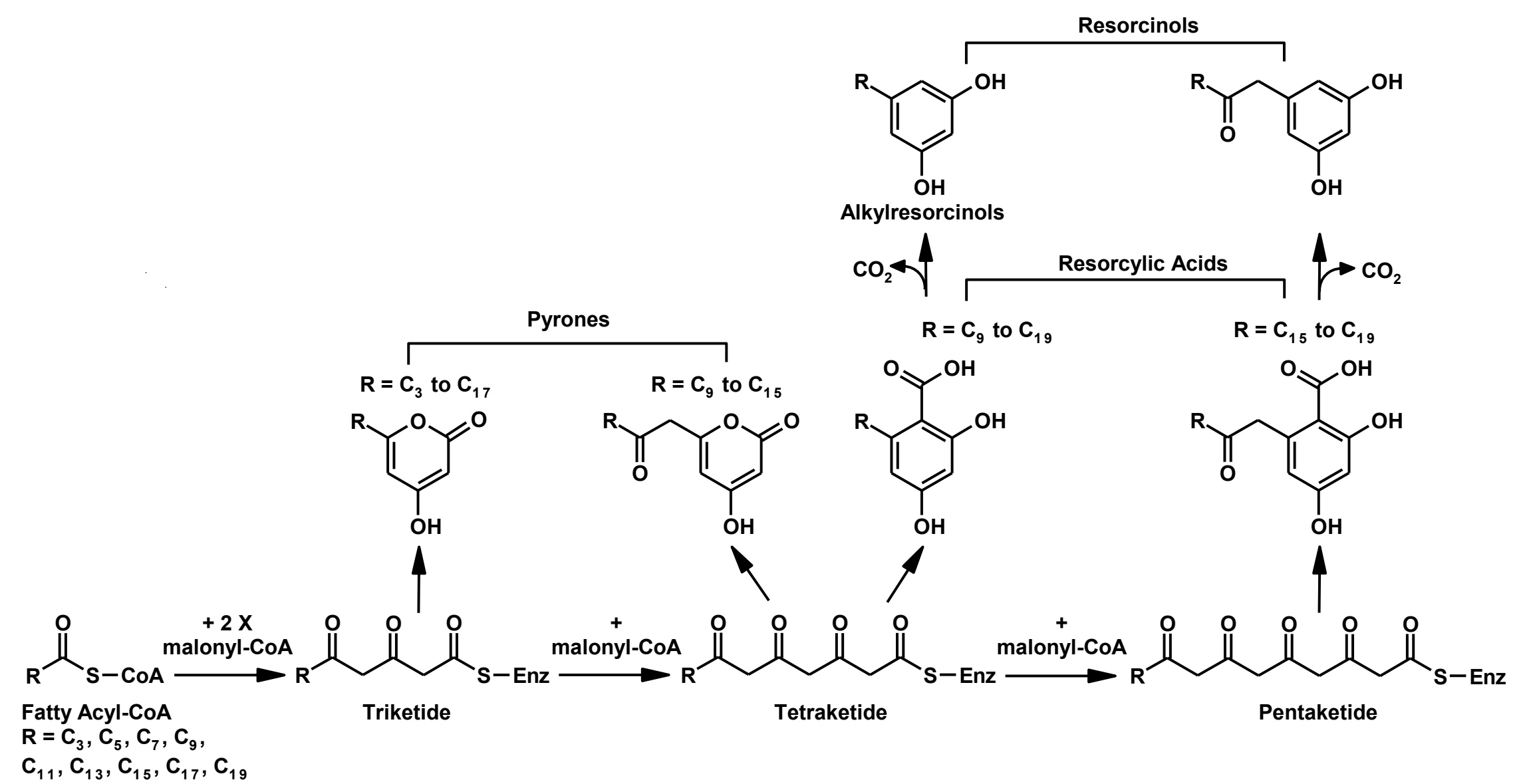

Figure 1-2: Biosynthesis of alkylresorcinols and various triketide and tetraketide pyrones and pentaketide resorcylic acids, modified from Yu et al. ${ }^{14}$. 


\subsection{Intake, absorption and metabolism of ARs}

Humans consume ARs in their regular diet in the form of wheat and rye products such as bread and baked goods. Intake of ARs has been determined to be highest in Northern and Eastern Europe due to higher intake of rye bread, with Finns consuming the most rye $(39.8 \mathrm{mg} / \mathrm{d})$. Food supply data is used frequently to determine per capita intake of ARs, where the amounts of milled rye is converted to per capita amounts and then multiplied by the average AR content in rye ${ }^{20}$.

A human ileostomy study has shown that ARs are approximately absorbed by $60 \%$, where short chain AR homologues were absorbed more easily than long chain AR homologues. The study suggested AR absorption in the upper intestine via the lymphatic system $^{21}$. Furthermore, a study with rats showed that ARs are absorbed and metabolized. An oral dose of ${ }^{14} \mathrm{C}$-labelled ARs $(\mathrm{C} 21: 0)$ was administered to rats and ${ }^{14} \mathrm{C}$ recovery in the feces, urine and plasma was determined. Results showed that $31 \%$ of radioactivity was recovered in the urine and $61 \%$ of radioactivity was recovered in the feces for an overall recovery of $92 \%{ }^{10}$. Both studies suggest that ARs are absorbed in the small intestine and excreted in the metabolized form in the urine.

It has been suggested that ARs are metabolized similarly to tocopherol, where $\omega$ hydroxylation of the alkyl side chain first formed a carboxylic acid followed by several steps of $\beta$-oxidation to shorten the side chain. The resulting products are $3-(3,5-$ dihydroxyphenyl)-propanoic acid (DHPPA) and 3,5-dihydroxybenzoic acid (DHBA), which are water soluble and found in both urine $\mathrm{e}^{22,23}$ and plasma ${ }^{24}$. Glucuronides and sulfates are conjugated forms of the AR metabolites and are observed in the urine and plasma as well. About $50 \%$ of AR metabolites are in conjugated forms ${ }^{23}$. 
A diet rich in wholegrain cereals has been linked to a lower risk of cardiovascular disease, diabetes, obesity and certain cancers. ARs present in wholegrain products are thus suggested to act as biomarkers and might help determine a connection between modern diseases and wholegrain intake ${ }^{20}$.

\subsection{Health benefits of ARs}

ARs have been determined to have health benefits to humans. Among others are the ability to reduce adipocyte lipolysis in vivo and therefore the potential to protect against diabetes ${ }^{25}$ and increase $\gamma$-tocopherol levels which could prevent cardiovascular disease $^{26}$. ARs have also shown to prevent triglyceride accumulation and inhibit glycerol3-phosphate dehydrogenase, which plays a major role in triglyceride synthesis in adipocytes. This finding suggests that ARs could regulate excessive fat accumulation and hence have antiobesity properties ${ }^{27}$.

\subsubsection{Anticancer}

A number of in vitro and in vivo studies have linked ARs to prevention of different types of cancer. In vitro experiment with human colon cancer cells showed that ARs from wheat bran are able to inhibit proliferation of cancer cells ${ }^{28}$ and in vivo experiments showed that colon cancer growth was inhibited by $35.7 \%$ in a mouse model $^{29}$. In vitro cytotoxic effects of ARs on human prostate adenocarcinoma cells have also been determined ${ }^{30}$. ARs from rye bran were able to drastically reduce the growth and size of prostate cancer cell that have been transplanted into mice ${ }^{31}$. 


\subsubsection{Antioxidant activity}

\subsubsection{Free radicals and oxidative stress}

Reactive oxygen species (ROS) are produced in the body through normal aerobic metabolic processes, mainly by mitochondria. They are oxygen species that contain unpaired electrons, making them highly unstable and reactive. Free radicals that are derived from oxygen are called ROS and are of most concern in biological systems. ROS can be hydroxyl radicals, superoxide anion radical, and hydrogen peroxide. These damage DNA, carbohydrates, proteins and lipids and can cause cell damage and homeostatic disruption ${ }^{32}$. An abundance of ROS in the body can cause diseases such as cancer, atherosclerosis ${ }^{33}$, neurodegenerative disorders, ageing and age-related diseases ${ }^{34}$. Antioxidants are molecules that have the ability to scavenge free radicals by donating an electron to the free radical and neutralize it. When the balance between ROS production and antioxidant defense in the body is disrupted, oxidative stress arises.

Total antioxidant capacity of cells and tissues is mainly provided by antioxidants synthesized by the body, and can include non-enzymatic antioxidants such as glutathione (GSH), or enzymatic antioxidants such as superoxide dismutase (SOD). These antioxidants play more important roles in free radical defense than those obtained from the diet $^{35}$. An increase in these endogenous antioxidants by components obtained from the diet would increase total antioxidant activity in the body and decrease oxidative stress. 


\subsubsection{ARs as antioxidants}

Early studies have suggested that ARs have antioxidant properties due to their hydroxyl groups on the aromatic ring being able to donate hydrogen atoms and scavenge free radicals. An early study by Winata and Lorenz ${ }^{36}$ compared antioxidant activity of ARs and butylatedhydroxyanisole (BHA) in different oils, incubated over time, at temperatures ranging from 10 to $40{ }^{\circ} \mathrm{C}$. Results showed that ARs were able to reduce lipid peroxidation over time at higher concentrations but are not as strong antioxidants as BHA.

Antioxidant activity of ARs has been assessed in vitro by Parikka et al. ${ }^{37}$ and Koryzińska et al. ${ }^{2}$ using the 2,2-diphenyl-1-picrylhydrazyl (DPPH) and ferric reducing antioxidant power (FRAP) assay. Parikka et al. ${ }^{37}$ showed that ARs possessed antioxidant activity that was only about $10 \%$ of the activity of ferulic acid (FA), a known antioxidant in cereals. Koryzińska et al. $^{2}$ used the DPPH assay and the luminal chemiluminescent method to determine antioxidant activity of AR homologues as well as bread and cereal products. AR homologues demonstrated antioxidant activity that was much lower than that of the antioxidant tocopherol. At a concentration of $50 \mu \mathrm{M}$, tocopherols were able to reduce DPPH radicals by $70-90 \%$, whereas ARs only reduced radical formation by 20 $30 \%$ at the same concentration. Similarly, at $5 \mu \mathrm{M}$ tocopherols reduced luminescence by $80-90 \%$ and thus protected against oxidative stress, whereas ARs only elicited a reduction of $30-60 \%$. In addition, antioxidant studies on wholegrain cereal products showed no correlation between AR content and radical scavenging activity.

A study by Kamal-Eldin et al. ${ }^{38}$ specifically illustrated that ARs are weak antioxidants due to their structure. Hydroxyl groups in the para and ortho position 
enhance antioxidant activity of phenols, whereas meta-substituted phenols, as is the case with ARs, normally show almost no antioxidant activity. In their study, 5-npentadecylresorcinol was compared to tocopherol and results showed that higher concentrations of ARs (256 fold), compared to tocopherol, were needed to react with DPPH radicals. Additionally, ARs reacted much slower than tocopherol and needed a longer time to complete the reaction. Tocopherols were able to complete the reaction in less than 5 minutes, whereas it took 60 minutes for ARs.

These previous studies illustrate that ARs are capable of scavenging free radicals but are not nearly as powerful as other antioxidants already present in our diets.

\subsubsection{ARs in membranes}

Observing only slight antioxidant activity of ARs in vitro has led to questions about antioxidant activity in vivo. Specifically, studies on ARs and their interactions with membranes have shown that most of the bioactivity of ARs stems from their effect on membranes. ARs can incorporate into membranes in vitro ${ }^{39}$ and in vivo ${ }^{40}$, as well as form monolayers themselves. By incorporating themselves into membranes, they have shown to increase membrane permeability ${ }^{41}$.

ARs have demonstrated to protect erythrocyte membranes from lipid oxidation caused by hydrogen peroxide in vitro when incorporated into the membranes. The chain length of ARs seems to play a crucial role in antioxidant activity. The C15:0 AR homologue had the greatest effect in reducing the products of lipid peroxidation, at both low and high concentrations, but as the alkyl chain length increased, the antioxidant activity decreased. The short chain AR, C5:0 showed the lowest antioxidant activity and 
is said to be practically inactive. It is assumed that short chains would not efficiently penetrate the membrane while very long chains have antioxidant molecules too far away from the membrane interface ${ }^{42}$. The importance of alkyl chain length in incorporation into membranes was also confirmed by Linko and Adlerkreuz ${ }^{40}$.

\subsection{Antioxidant assays}

Antioxidant activity can be measured in a variety of ways. Common in vitro assays include Oxygen Radical Absorbance Capacity (ORAC) and beta-carotene bleaching. Determination of GSH and reduced glutathione (GSSG) as well as SOD activity are commonly used in in vitro antioxidant assays.

\subsubsection{Oxygen Radical Absorbance Capacity (ORAC) and B-carotene bleaching assays}

In vitro antioxidant activity is commonly assessed using the ORAC assay. The assay measures antioxidant activity of a sample by its ability to inhibit fluorescent decay of the fluorescent probe fluorescein. Fluorescein is subjected to attack by free radicals generated by 2,2`azobis (2-methylpropionamidine) dihydrochloride (AAPH). As a result, fluorescent decay commences. The stronger the antioxidant, the longer the delay in fluorescence decay. The area under the fluorescence decay curve of the sample is compared to that of a Trolox standard (a vitamin E analogue) ${ }^{43}$.

The antioxidant assay based on bleaching of $\beta$-carotene is used frequently in the food industry. Linoleic acid, which forms free radicals, is added to ß-carotene and oxidizes it. The result is rapid discolouration (bleaching) of $\beta$-carotene due to a loss of its 
chromophore $^{44}$. In the presence of a strong hydrogen donating radical scavenger, Bcarotene bleaching is inhibited. The bleaching of $\beta$-carotene in the presence of an antioxidant is compared to that of a control, which consists of everything except the sample, to determine percent inhibition of bleaching.

\subsubsection{Glutathione and superoxide dismutase assays}

Glutathione is an antioxidant molecule that is naturally synthesized in the body. It is a tripeptide of L-glutamic acid, L-cysteine and glycine. Reduced glutathione (GSH) serves as a reductant for ROS by the oxidation of the thiol group of its cysteine residue ${ }^{45}$. Two GSH are oxidized to form GSSG in the presence of ROS. Glutathione reductase (GR) restores GSH by immediately reducing GSSG and keeping a reasonable GSSG/GSH ratio ${ }^{46}$. However, large amounts of ROS can lead to an increased ratio of GSSG/GSH. The ratio of GSSG/GSH is often used as an indicator of oxidative stress.

The assay for glutathione is based on the reaction between GSH and 5-5'dithiobis-(2-nitrobenzoic acid) (DTNB). DTNB will react with GSH forming 5thionitrobenzoic acid (TNB), which is the visible chromophore at $412 \mathrm{~nm}$. GS-TNB is formed as well,which is reduced by GR and converted back to GSH, amplifying the signal. GR added to the reaction will reduce GSSG, allowing for total glutathione (GSH+GSSG) measurement. GSSG is measured by derivatizing GSH first using 2vinylpyridine and then adding GR to reduce the amount of GSSG present. The amount of total glutathione of a tissue sample is then compared to the amount of GSSG in the same tissue, to determine the amount of GSH and degree of oxidative stress occurring in the tissue $^{47}$. 
The superoxide dismutase activity assay is an antioxidant activity assay that measures the amount of the SOD activity in a sample. SOD is a potent antioxidant in the body, catalyzing the breakdown of superoxide to form hydrogen peroxide and oxygen in cellular compartments. Therefore, a higher amount of SOD activity in tissue samples indicates a high overall antioxidant activity. In this assay, EDTA, manganese(II) chloride $\left(\mathrm{MnCl}_{2}\right)$, 2-mercaptoethanol (MeSH) and atmospheric oxygen form superoxide which will lead to the oxidation of nicotinamide adenine dinucleotide (NADH). In the presence of SOD, oxidation is decreased ${ }^{48}$.

\subsection{Inflammation}

Inflammation is the response of an organism to harmful stimuli and cell damage. It is a protective mechanism against cellular injury ${ }^{49}$. Acute inflammation has the purpose of removing harmful stimuli toinitiate the healing process of the affected tissue by increasing blood flow and flow of leukocytes to the site of injury. Chronic inflammation however can lead to diseases such as cancer ${ }^{50}$, diabetes, and cardiovascular disease ${ }^{51}$ and thus needs to be prevented.

Proinflammatory mediators such as nitric oxide (NO), and prostaglandins (PGs), and various cytokines are mainly responsible for inflammation. Large amounts of these mediators are produced by the inducible nitric oxide synthase (iNOS or NOS2), and cyclooxygenase-2 (COX-2) systems ${ }^{52,53}$. Nitric oxide is a major mediator in inflammatory processes. High amounts of NO have shown to contribute to a number of diseases such as osteoarthritis ${ }^{54}$ and diabetes ${ }^{55}$. iNOS synthesizes NO from L-arginine ${ }^{56}$, which in turn is activated and expressed during inflammation in response to cytokines or 
microbial products (but not in resting cells) ${ }^{57}$. In the presence of an anti-inflammatory agent, expression of both the protein and mRNA of iNOS is reduced.

Prostaglandins are normally produced by the body in low amounts. However, during acute inflammation, production increases immediately. COX-2 is responsible for the synthesis of prostaglandins from arachidonic acid during acute inflammation ${ }^{58}$. Nonsteroidal anti-inflammatory drugs are designed to target COX-2 and therefore, any compound that is able to reduce COX-2 protein and mRNA expression could be a potential anti-inflammatory agent ${ }^{59}$.

Macrophages also play an important role in the organization and release of inflammatory mediators. When stimulated with lipopolysaccharides (LPS), an endotoxin found in the cell walls of Gram-negative bacteria, macrophages are activated and release NO, PGs and cytokines. The murine macrophage cell line RAW 264.7, which was derived from the ascites of an Abelson murine leukemia virus-induced tumor in BALB/c mice $^{60}$, is frequently used for anti-inflammatory studies, due to their reproducible response to LPS ${ }^{61}$.

Oxidative stress and inflammation are caused by ROS and are both involved in the development of diseases such as cancer and cardiovascular disease. Antioxidants are able to reduce both oxidative stress and inflammation and are thus important components of the diet. This study is concerned with the identification of alkylresorcinols as both antioxidant and anti-inflammatory agents. 


\section{Chapter 2 - Extraction and characterization of alkylresorcinols and their antioxidant and anti-inflammatory activity in vitro}

\subsection{Abstract}

Alkylresorcinols were extracted from Hazlet rye bran and characterized by high performance liquid chromatography (HPLC). It was determined that the extract was comprised of primarily saturated AR homologues and trace amounts of unsaturated and keto or hydroxyl AR homologues. Rye bran ARs showed high antioxidant activity over other cereals, such as wheat and oat bran, with $2,461,1,576$, and 1,020 $\mu \mathrm{mol} \mathrm{TE} / \mathrm{g}$ of ARs, respectively, using the ORAC assay and 78.53, 70.31, and 35.95\% inhibition of $ß-$ carotene bleaching, respectively, using the $\beta$-carotene bleaching assay. Furthermore, rye bran ARs have exhibited anti-inflammatory activity in RAW 264.7 macrophages, by inhibiting NO production upon LPS stimulation by $46 \%$, as well as iNOS and COX-2 protein and mRNA expression.

\subsection{Introduction}

ARs from cereals have previously been identified as weak antioxidants in vitro ${ }^{38}$, but possibly strong antioxidants in vivo due to their interaction with membranes ${ }^{42}$. Several studies have linked oxidative stress to inflammation, which is the protective mechanism against cellular stimuli. Inflammation is caused by the release of excessive ROS from the mitochondria. ROS alters the intracellular redox state, which in turn is responsible for proper signaling and transcription processes. It has been shown that

antioxidants suppress upstream signaling systems and downstream transcription factors ${ }^{62}$, 
which are proteins that alter gene transcription by binding to enhancers or silencers in the 5' upstream region of target genes. More specifically, ROS triggerthe transcription factor nuclear factor-kappa B (NF-kB), which upregulates the production of inflammatory mediators, such as iNOS, COX-2, and cytokines like TNF- $\alpha$ and IL- $1 \beta^{63,64}$. NF- $\mathrm{kB}$ is activated when oxidative and inflammatory stimuli, such as cytokines and ultraviolet radiation, activate I- $\mathrm{\kappa B} \alpha$ kinase, which in turnphosphorylates and degrade the cellular

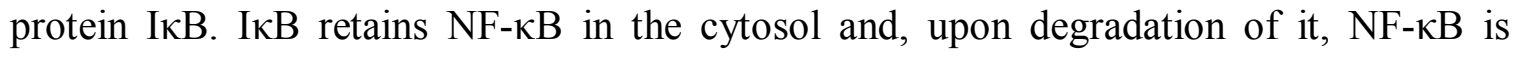
released to travel to the nucleus and activate gene expression in response to inflammation, which has been shown to be prevented by phenolic antioxidants ${ }^{65}$. Previous studies have shown that phenolic antioxidants do not inhibit the degradation of I $\kappa \mathrm{B}$ as well as the translocation of NF- $\kappa \mathrm{B}$ into the nucleus, suggesting that inhibition of this transcription factor occurs in the nucleus. In the nucleus, phenolic antioxidants inhibit the binding of NF- $\mathrm{kB}$ to DNA. However, resorcinoldid not exhibit the same effect. The binding of NF- $\mathrm{kB}$ to DNA is inhibited by redox reactions of the antioxidant molecule, possibly due to the interference with redox-sensitive proteins involved in the binding ${ }^{65}$.

Phenolic antioxidants have been shown to activate transcription factor nuclear factor (erythroid-derived 2)-like 2 (Nrf2), which in turn upregulates enzymes such as SOD, hemeoxygenase-1 (HO-1), and $\gamma$-glutamyl cysteine ligase (GCL), which are endogenous antioxidant defense enzymes ${ }^{66}$, as well as inhibit the expression of cytokines such as TNF- $\alpha$, by inducing detoxifying enzymes such as HO-1. When Nrf2 is exposed to phenolic antioxidants, it dissociates from the Kelch-like ECH-associated protein 1 (Keap1) and translocates into the nucleus and dimerizes with another transcription factor 
and eventually binds to the antioxidant-response element (ARE) for gene expression ${ }^{65}$. Activation of transcription factors may involve kinases such as mitogen-activated protein kinases (MAPK) and ligands such as Vitamin A and D, which in turn can be activated by cytokines $^{64}$. Activation of transcription factors may also involve oxidative and proinflammatory factors other than those listed above.

However, increased production of cytokines also produces more ROS, by binding to receptors responsible for the induction of ROS. To break this viscous cycle, the demand for natural antioxidants that would also act as anti-inflammatory agents is rising $^{67}$.

Antioxidant phytochemicals are able to prevent inflammation either by activating Nrf2, which will then enhance endogenous antioxidants or suppress NF- $\mathrm{BB}$ and thus proinflammatory gene expression ${ }^{66}$.

It is therefore of interest to determine whether rye bran ARs can reduce transcription of iNOS and COX-2 mRNA and translation into the corresponding protein, in order to confirm anti-inflammatory activity of ARs.

The objectives of this study were to a) extract ARs from Hazlet rye bran and characterize the components in the extract, b) determine antioxidant activity of ARs from Hazlet rye bran as compared to that of wheat and oat bran in vitro, and c) determine antiinflammatory activity of ARs by examining the inhibition of iNOS and COX-2 expressions. 


\subsection{Materials and Methods}

\subsubsection{Hazlet rye samples}

Hazlet rye, which is a cultivar of winter rye (Secale cereal L.), was developed and grown by Dr. Grant McLeod at Agriculture and Agri-Food Canada (AAFC) in Swift Current, Saskatchewan. Only the bran layer of Hazlet rye was used in all experiments. Bran was separated from the kernel by Dr. Nancy Ames at AAFC in Winnipeg, Manitoba, using a Satake TM 05 laboratory-scale pearler (Satake Co, Japan).

\subsubsection{Extraction of ARs from Hazlet bran}

ARs from Hazlet rye bran were extracted using acetone in a 1:40 w/v ratio according to the methods of Gliwa et al. ${ }^{68}$. After 24 hours of constant stirring at room temperature, the samples were filtered using Whatman double filter paper. The precipitate was discarded, and the acetone was completely evaporated from the supernatant under nitrogen flush. The dried product was weighed and stored at $-20^{\circ} \mathrm{C}$ for further use.

\subsubsection{High Performance Liquid Chromatography (HPLC)}

AR extracts were analyzed via reverse-phase HPLC on the Alliance ${ }^{\circledR}$ HPLC system e2695 Separation Module with the 2998 Photodiode Array Detector from Waters (Milford, Massachusetts). The software used was Empower 3. AR standards (mixture of $\mathrm{C} 15: 0, \mathrm{C} 17: 0, \mathrm{C} 19: 0, \mathrm{C} 21: 0, \mathrm{C} 23: 0$, and C25:0) (ReseaChem GmbH, Burgdorf, Switzerland) were prepared in methanol at concentrations of $2,1,0.5,0.25$, and 0.125 $\mathrm{mg} / \mathrm{mL}$. AR extracts were prepared in methanol as well. A gradient program was used to 
separate the different homologues at a flow rate of $1 \mathrm{~mL} / \mathrm{min}$ and $U V$ detection at $280 \mathrm{~nm}$ with a C18 column $(4.6 \times 150 \mathrm{~mm}$, inner diameter $5 \mu \mathrm{m})$. Solvent A was $4 \%$ acetic acid in water and solvent $\mathrm{B}$ was $1 \%$ acetic acid in methanol. The gradient started as $10 \% \mathrm{~A}$ and $90 \% \mathrm{~B}, 0 \% \mathrm{~A}$ and $100 \% \mathrm{~B}$ at 10 minutes, $10 \% \mathrm{~A}$ and $90 \% \mathrm{~B}$ at 40 minutes until the end of the run at 50 minutes. The area under the curve was used to determine the amount of each AR homologue compared to the standards.

\subsubsection{ORAC}

The antioxidant activity of tissue samples was determined using the ORAC assay according to Gliwa et al. ${ }^{68}$. Samples were analyzed on the FLx $800^{\mathrm{TM}}$ Multi-Detection Microplate Reader with Gen5 $5^{\mathrm{TM}}$ software by BioTek Instruments at excitation and emission wavelengths of $485 \mathrm{~nm} 525 \mathrm{~nm}$ respectively. Peroxyl radicals were generated by 2,2`azobis (2-methylpropionamidine) dihydrochloride (AAPH) (Acros Organics, New Jersey, USA). Fluorescein (J. T. Baker, Phillipsburg, New Jersey) served as the fluorescence probe. The vitamin E analog 6-hydroxy-2,5,7,8-tetramethylchromane-2carboxylic acid (Trolox) (Sigma-Aldrich, St. Louise, Missouri) was used as a control standard and Rutin (Sigma, St. Louise, Missouri) was used as a positive control. All reagents were prepared using $75 \mathrm{mM}$ potassium phosphate buffer (Mallinckrodt, Paris, Kentucky) at pH 7.4. Hazlet rye, red hard wheat, and commercial oat bran were assayed at a concentration of $0.063 \mathrm{mg} \mathrm{AR}$ extract $/ \mathrm{mL}$ solvent. Potassium phosphate buffer served as a blank. A 96-well microplate was loaded to contain $20 \mu \mathrm{L}$ of buffer, standard, control, or sample and $120 \mu \mathrm{L}$ fluorescein solution $(0.068 \mu \mathrm{M})$. After 20 minutes of incubation at $37^{\circ} \mathrm{C}, 60 \mu \mathrm{L}$ of $47.29 \mu \mathrm{M}$ AAPH was added to a total volume of $200 \mu \mathrm{L}$ 
and absorbance was read for 60 minutes at 1 minute intervals. Final ORAC values of cereal samples were determined using the AUC (Area Under the Curve) of the fluorescein decay curve. The AUC is calculated as follows:

$$
\mathrm{AUC}=1+f_{1} / f_{0}+f_{2} / f_{0}+f_{3} / f_{0}+\ldots+f_{89} / f_{0}+f_{90} / f_{0}
$$

Where $f_{0}$ is the initial fluorescence reading at 0 minutes and $f_{i}$ is the fluorescence reading at time i.

The regression equation from the Trolox standard curve was used to determine the concentration of Trolox equivalent (TE) of samples in $\mu \mathrm{M}$. Results were reported as $\mu \mathrm{mol} \mathrm{TE} / \mathrm{g}$ of ARs.

\subsubsection{B-Carotene bleaching assay}

Antioxidant activity of Hazlet rye, wheat, and oat bran samples was assessed using the B-carotene bleaching method. The assay by Prieto et al. ${ }^{69}$ and Çam et al. ${ }^{70}$ was slightly modified. Two milligrams of ß-carotene (Sigma, St. Louise, Missouri), $0.25 \mathrm{~mL}$ of linoleic acid (Acros Organics, Waltham, Massachusetts), and $2 \mathrm{~g}$ of Tween-80 (Fisher Scientific, Waltham, Massachusetts) were mixed and added to $10 \mathrm{~mL}$ of chloroform. The mixture was evaporated under nitrogen and $1 \mathrm{~mL}$ of the oily residue was dissolved in 30 $\mathrm{mL}$ of Milli-Q water. The $\beta$-carotene mixture $(250 \mu \mathrm{L})$ was added to $50 \mu \mathrm{L}$ of control, standard, or sample in a 96-well microplate. Samples were dissolved in ethanol to concentrations of $0.03125,0.0625,0.125,0.25$, and $0.5 \mathrm{mg} / \mathrm{mL}$ and ferulic acid (FA) (Sigma, St. Louis, Missouri) to $0.17 \mathrm{mg} / \mathrm{mL}$. The control consisted of everything except the sample and the blank consisted of everything but the sample and $\beta$-carotene. Absorbance was read at $470 \mathrm{~nm}$ every 20 minutes for 2 hours on the SpectraMax 
340PC ${ }^{384}$ microplate reader (Molecular Devices, Sunnyvale, California). Samples were incubated at $50{ }^{\circ} \mathrm{C}$ in between reads. Percent inhibition of bleaching was calculated as follows:

$$
\% \text { Inhibition }=\frac{\left(A_{t}-C_{t}\right)}{\left(C_{0}-C_{t}\right)} \times 100
$$

Where $A_{t}$ is the absorbance of test sample at $120 \mathrm{~min}, C_{t}$ is the absorbance of the control at $120 \mathrm{~min}$, and $\mathrm{C}_{0}$ is the absorbance of the control at $0 \mathrm{~min}$.

\subsubsection{Cyclooxygenase (COX) assay}

Anti-inflammatory activity of ARs was determined using the COX Fluorescent Inhibitor Screening Assay Kit (Cayman Chemicals, Ann Arbor, Michigan). The experiment was performed as per the kit instructions. A 96-well microplate was set up to contain $150 \mu \mathrm{L}$ Assay Buffer (1M Tris-HCl, $\mathrm{pH} 8.0$ ), $10 \mu \mathrm{L}$ heme, $10 \mu \mathrm{L}$ fluorometric substrate (lyophilized powder of 10-acetyl-3,7-dihydroxyphenoxazine (ADHP)), $10 \mu \mathrm{L}$ COX-2 (human recombinant) enzyme, $10 \mu \mathrm{L}$ either solvent (DMSO), sample or DuP-697 (COX-2 inhibitor), and $10 \mu \mathrm{L}$ arachidonic acid. The plate was incubated for 2 minutes after which absorbance was read at an excitation wavelength of $544 \mathrm{~nm}$ and an emission wavelength of $590 \mathrm{~nm}$ on the FLUOstar Optima from BMG LABTECH. DuP-697 was supplied by Cayman Chemicals as a positive control for COX-2 inhibition. A concentration of $25 \mathrm{nM}$ of DuP-697 was assayed to yield a 50\% inhibition. AR extracts were added to the final well at concentrations of $0.24,0.49,0.97$, and $1.94 \mathrm{mg} \mathrm{AR}$ extract $/ \mathrm{mL}$ solvent.

Percent inhibition of COX-2 activity was calculated as follows: 


$$
\% \text { Inhibition }=\frac{(\text { Initial Activity }- \text { Sample Activity })}{\text { Initial Activity }} \times 100
$$

\subsubsection{Cell culture}

RAW 264.7 murine macrophage cells were obtained from the American Type Culture Collection (ATCC). Cells were cultured in Dulbecco's Modified Eagle's Medium (DMEM) (Life Technologies, Grand Island, New York), supplemented with 10\% fetal bovine serum (Life Technologies, Grand Island, New York) and maintained at $37^{\circ} \mathrm{C}$ and $5 \% \mathrm{CO}_{2}$.

\subsubsection{Cell viability assay}

Cell viability, in the presence of AR extract, was determined using the MTT (3(4,5-dimethylthiazol-2-yl)-2,5-diphenyltetrazolium bromide) assay. Cells were plated out in the inner 60 wells of a $96-$ well microplate at a density of $2 \times 10^{5}$ cells $/ \mathrm{mL}$ and incubated at $37{ }^{\circ} \mathrm{C}$ and $5 \% \mathrm{CO}_{2}$. After 24 hour incubation, old medium was discarded and fresh medium was added to the cells. AR extracts were dissolved and diluted in 95\% ethanol. Two microliters of serially diluted extract $(10.85,21.70,43.39,86.79,173.58,433.9$, 867.8, and $1735.6 \mu \mathrm{g}$ extract $/ \mathrm{mL})$ were added to the wells $(\mathrm{n}=6)$. After 24 hour incubation, the medium was removed completely and $10 \mu \mathrm{L}$ of $5 \mathrm{mg} / \mathrm{mL}$ MTT (SigmaAldrich, St. Louis, Missouri) was added to the cells. After incubation for 1 hour at $37{ }^{\circ} \mathrm{C}$ and $5 \% \mathrm{CO}_{2}$, medium was removed and $50 \mu \mathrm{L}$ of DMSO (BioShop, Burlington, Ontario) was added to lyse the cells and solubilize the product. Absorbance was read at $570 \mathrm{~nm}$

with a background subtraction at $630 \mathrm{~nm}$ on the SpectraMax $340 \mathrm{PC}^{384}$ microplate reader (Molecular Devices, Sunnyvale, California). 


\subsubsection{Nitrite assay}

RAW 264.7 cells were plated out in the inner 60 wells of a 96 -well microplate at a density of $2 \times 10^{5}$ cells $/ \mathrm{mL}$. After a 24 hour incubation period, cells were pretreated with $2 \mu \mathrm{L}$ of diluted extract $(10.85,21.70,43.39$, and $86.79 \mu \mathrm{g} \mathrm{AR}$ extract $/ \mathrm{mL})$ in ethanol and incubated for 2 hours before being stimulated with $10 \mu \mathrm{L}$ of $1 \mu \mathrm{g} / \mathrm{mL}$ LPS from Escherichia coli (Sigma-Aldrich, St. Louis, Missouri). After a further 24 hour incubation period, $50 \mu \mathrm{L}$ of Griess reagent (1 part $0.1 \%$ naphthylenediaminedihydrochloride (Sigma-Aldrich, St. Louis, Missouri) in water and 1 part 1\% sulfanilamide (SigmaAldrich, St. Louis, USA) in 5\% concentrated phosphoric acid (Fisher Scientific, New Jersey) was added to $50 \mu \mathrm{L}$ of cell supernatant. After 10 minutes of incubation in the dark, absorbance was read at $540 \mathrm{~nm}$ on the SpectraMax $340 \mathrm{PC}^{384}$ microplate reader (Molecular Devices, Sunnyvale, California). A standard curve of sodium nitrite standards (Anachemia Chemicals LTD, Montreal, Quebec) in DMEM was run for each assay to determine the concentration of nitrite in the cell supernatant for each treatment. Percent nitrite concentration is reported with concentrations adjusted to cell treatment with LPS only as $100 \%$.

\subsubsection{Western blot analysis}

RAW 264.7 cells were plated out at a density of $1.375 \times 10^{6}$ cells $/ \mathrm{mL}$ in a 6 -well microplate to a confluency of nearly $100 \%$ after 48 hours. Cells were incubated for 24 hours and then pretreated with $5 \mu \mathrm{L}$ of diluted extract $(10.85,21.70,43.39$, and $86.79 \mu \mathrm{g}$ AR extract $/ \mathrm{mL}$ ) in ethanol. After a 2 hour incubation period, cells were treated with 10

$\mu \mathrm{L}$ LPS $(1 \mu \mathrm{g} / \mathrm{mL})$ and incubated for 24 hours. Cells were harvested in ice cold 
phosphate buffered saline (PBS) (Sigma-Aldrich, St. Louis, Missouri) and centrifuged at $4^{\circ} \mathrm{C}$ and 1,000 $\mathrm{g}$ for 5 minutes. The supernatant was discarded and the pellet frozen at $80^{\circ} \mathrm{C}$ until further use.

The cell pellet was resuspended in FLAG lysis buffer (50 mM Tris-HCL, pH 7.4, $150 \mathrm{mM}$ NaCL, $1 \mathrm{mM}$ EDTA, 1\% Triton $^{\mathrm{TM}} \mathrm{X}-100$ ) and incubated on ice for 20 minutes before centrifugation at $4^{\circ} \mathrm{C}$ and top speed for 15 minutes. Protein determination on the supernatant was performed using the Pierce ${ }^{\circledR}$ BCA Protein AssayKit (Thermo Scientific, Rockford, Illinois) according to the manufacturer's instructions. Cellular proteinswere separated on a $10 \%$ sodium dodecyl sulfate polyacrylamide gel electrophoresis (SDSPAGE) for 1 hour at 150 Volts and then electrically transferred to a polyvinylidene fluoride (PVDF) membrane (Millipore, Billerica, Massachusetts) overnight at $4^{\circ} \mathrm{C}$ and $180 \mathrm{~mA}$. For COX-2, $10 \mu \mathrm{g}$ of protein was loaded for cells treated with LPS, and $35 \mu \mathrm{g}$ of protein were loaded for cells not treated with LPS. Proteins for iNOS were loaded at a concentration of $50 \mu \mathrm{g}$.After blocking the membrane with 5\% non-fat dried milk in Trisbuffered saline-Tween (TBST) for 1 hour, membranes were incubated for 1 hour with specific primary antibodies (anti-COX-2 mouse IgG, 1:2,000, and anti-NOS2 rabbit IgG, 1:1,000) (Santa Cruz Biotechnology Inc, Dallas, Texas) followed by a 1 hour incubation with appropriate secondary antibody at a 1:5,000 dilution (polyclonal goat anti-mouse IgG/HRP (Dako, Burlington, Ontario), or polyclonal goat anti-rabbit IgG/HRP (Santa Cruz Biotechnology Inc, Dallas, Texas) respectively. COX-2 and iNOS Western blots were visualized with the FluorChem ${ }^{\circledR}$ Q system from Alpha Innotech and analyzed with the AlphaView ${ }^{\circledR}$ Q software. Membranes were stripped of primary and secondary antibodies using a mild stripping buffer (200 mM glycine, $3.5 \mathrm{mM} \mathrm{SDS,} \mathrm{1 \%} \mathrm{Tween} \mathrm{20,}$ 
$\mathrm{pH}$ 2.2) and reprobed with the primary mouse antibody $ß$-tubulin $(1: 1,000)$ (Iowa Hybridoma Bank, Iowa City, Iowa) for 1 hour followed by 1 hour incubation with polyclonal goat anti-mouse IgG/HRP (1:5,000).

\subsubsection{RNA isolation and RT-PCR}

Cell pellets were obtained as described for Western blot analysis. RNA was extracted from pellets with the RNeasy RNA Extraction Kit (QIAGEN, Mississauga, Ontario) as described by the manufacturer. cDNA was synthesized from $1 \mu \mathrm{g}$ RNA using the $\mathrm{RT}^{2}$ Easy First Strand Kit (QIAGEN, Mississauga, Ontario). Two microliters of COX-2 or iNOS cDNA was added to $23 \mu \mathrm{L}$ of $\mathrm{iQ}^{\mathrm{TM}} \mathrm{SYBR}^{\circledR}$ Green Supermix (Bio-Rad Laboratories, Hercules, California) and primers. Primers for iNOS were 5'-

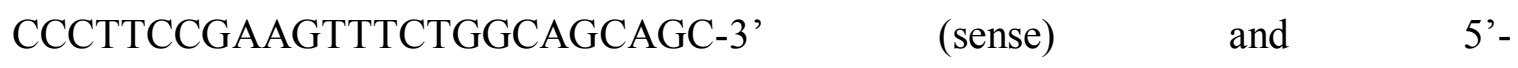
GGCTGTCAGAGCCTCGTGGCTTTGG-3' (antisense) and for COX-2 were 5'CACTACATCCTGACCCACTT-3' (sense) and 5'-ATGCTCCTGCTTGAGTATGT-3' (antisense) (Integrated DNA Technologies, Coralville, Iowa). PCR amplification was performed with the following cycles: initial melting temperature of $95^{\circ} \mathrm{C}$ for 3 minutes, 45 cycles of $95{ }^{\circ} \mathrm{C}$ for 10 seconds (melting), $56^{\circ} \mathrm{C}$ for 10 seconds (annealing), and $72{ }^{\circ} \mathrm{C}$ for 30 seconds (extension). The data was normalized to $18 \mathrm{~S}$ rRNA.

\subsubsection{Statistical analysis}

HPLC, ORAC, ß-carotene, nitrite assay, Western blots and RT-PCR results were obtained from three individually performed experiments. Results are expressed as mean values \pm SEM. Statistical significance was determined with one-way ANOVA followed 
by the Tukey's test. P values less than 0.05 and 0.01 were considered significantly different.

\subsection{Results}

\subsubsection{Characterization of $A R$ homologues from Hazlet rye bran}

Alkylresorcinols were extracted from Hazlet rye bran and analyzed using HPLC. Figure 2-1a shows the composition of AR homologues in a mixture of AR standards and Figure 2-1b shows AR homologues in the extract. Large peaks confirm the presence of saturated AR homologues C15:0 (7.39 minutes), C17:0 (9.44 minutes), C19:0 (11.52 minutes), C21:0 (13.44 minutes), C23:0 (15.57 minutes), and C25:0 (18.29 minutes), whereas smaller peaks indicate the presence of unsaturated or keto or hydroxyl AR homologues. Known ARs made up $78.49 \%$ of all components present in the extract. The amount of AR homologues in Hazlet rye bran differed as seen in Figure 2-1c. Homologue C19:0 was the most prominent with $55.84 \mathrm{mg}$ ARs/100g of bran and C25:0 the least common homologue with $9.33 \mathrm{mg}$ ARs/100g of bran. The total amount of ARs in the extract was $187.40 \mathrm{mg} \mathrm{ARs} / 100 \mathrm{~g}$ bran. 
A

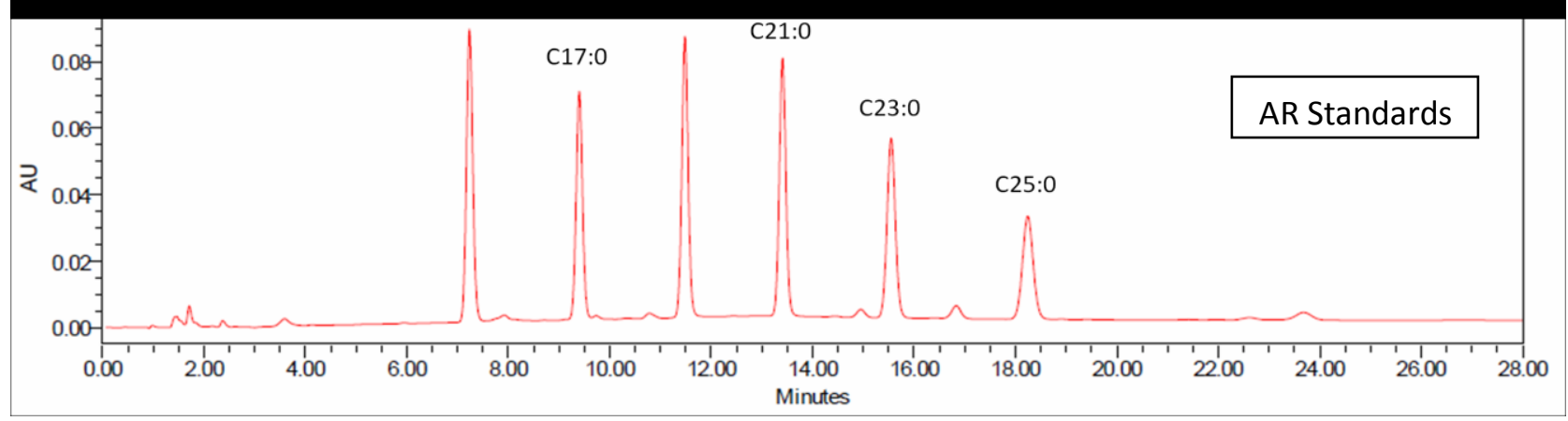

B

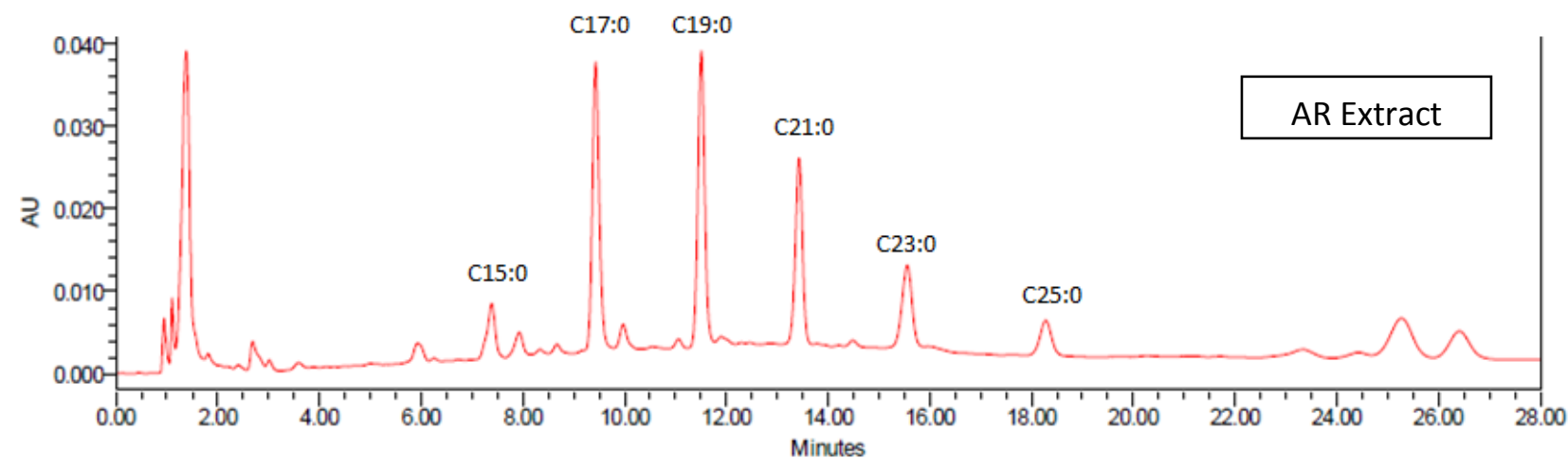


C

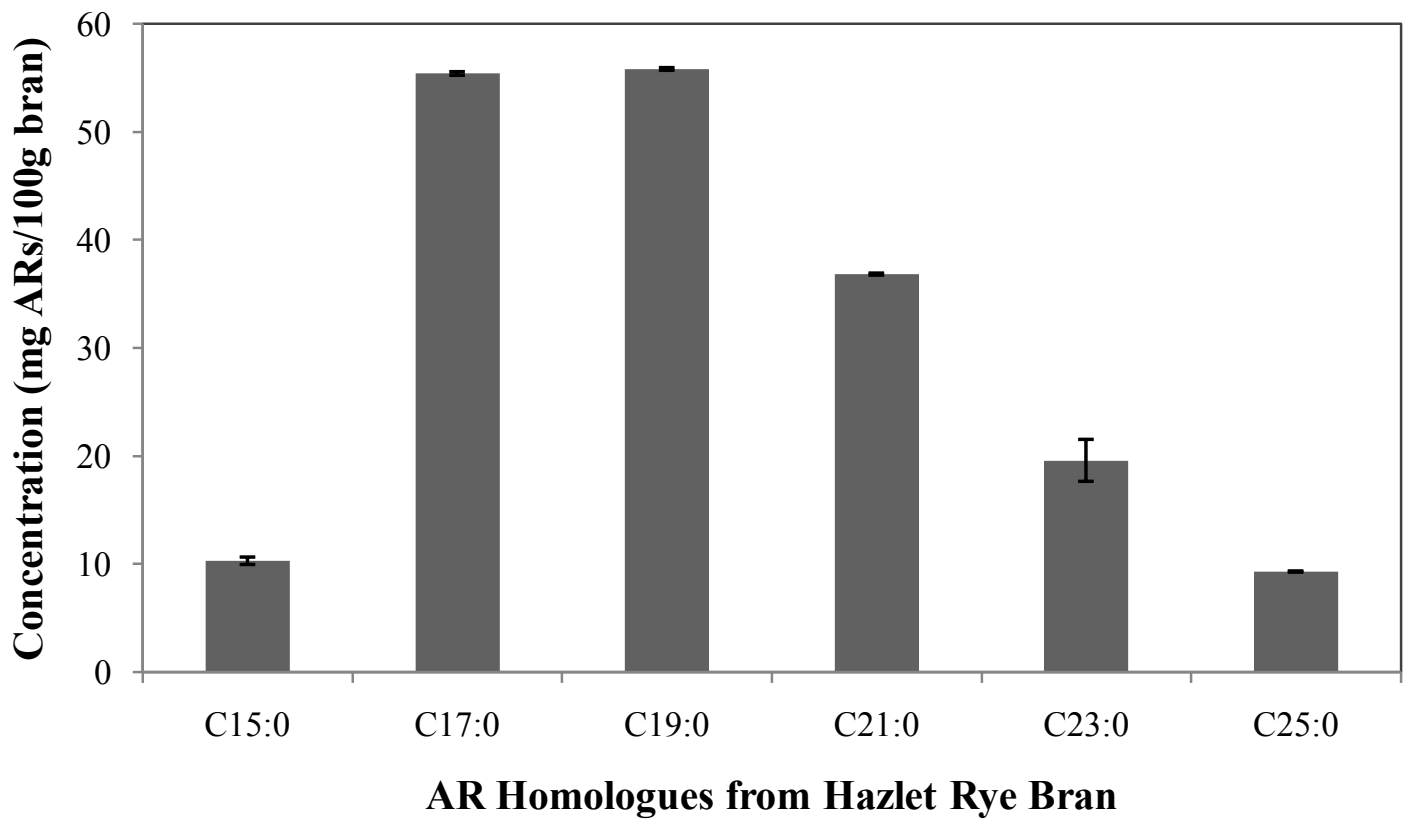

Figure 2-1: (A) HPLC chromatogram of AR homologues from a mixture of AR standards and (B) from Hazlet rye bran obtained with ultraviolet detection. (C) Total amount of AR homologues in Hazlet rye bran as determined with HPLC analysis. Results are expressed as mean values \pm SEM. 


\subsubsection{In vitro antioxidant activity of ARs from Hazlet rye bran}

Antioxidant activity of AR extract from Hazlet rye bran was determined in vitro using the ORAC and $B$-carotene bleaching assay. Activity was compared to that of ARs from wheat and oat bran, with wheat being a positive control for high amounts of ARs and thus high antioxidant activity and oat being a negative control for low antioxidant activity due to a lack of $\mathrm{ARs}^{4}$. In both assays, Hazlet showed the highest antioxidant activity amongst the cereals $(2,461 \mu \mathrm{mol} \mathrm{TE} / \mathrm{g}$ of ARs and $78.53 \%$ inhibition of bleaching). Wheat bran had high antioxidant activity overall, but showed significantly lower $(\mathrm{P}<0.01)$ antioxidant activity than Hazlet rye bran using ORAC with $1,576 \mu \mathrm{mol}$ $\mathrm{TE} / \mathrm{g}$ of ARs (Figure 2-2a), and slightly lower activity using the $\beta$-carotene bleaching assay with $70.31 \%$ inhibition of bleaching (Figure 2-2b). Oat had much lower antioxidant activity than Hazlet rye bran, as determined by both ORAC and $\beta$-carotene bleaching $(1,020 \mu \mathrm{mol} \mathrm{TE} / \mathrm{g}$ of ARs and 35.94\% inhibition of bleaching) $(\mathrm{P}<0.01)$. Antioxidant activity of cereals, as determined by $\beta$-carotene bleaching, was also compared to that of FA, a known antioxidant. FA inhibited bleaching by $81.84 \%$, which was similar to Hazlet, however, the concentration of Hazlet ARs required to reach this level of inhibition was larger than that ofFA. 
A

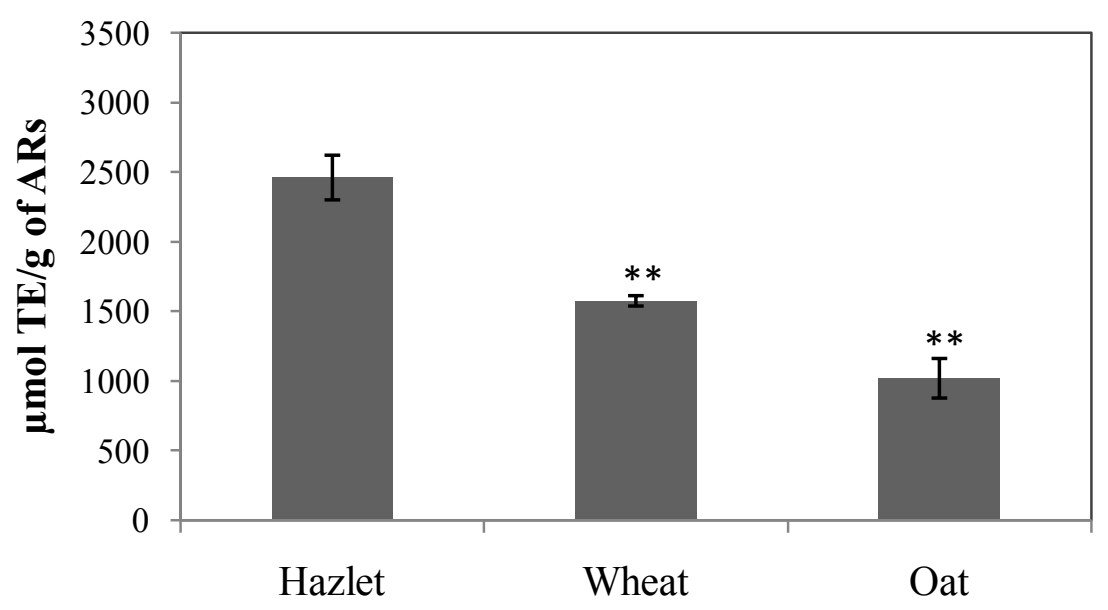

Cereal Bran

B

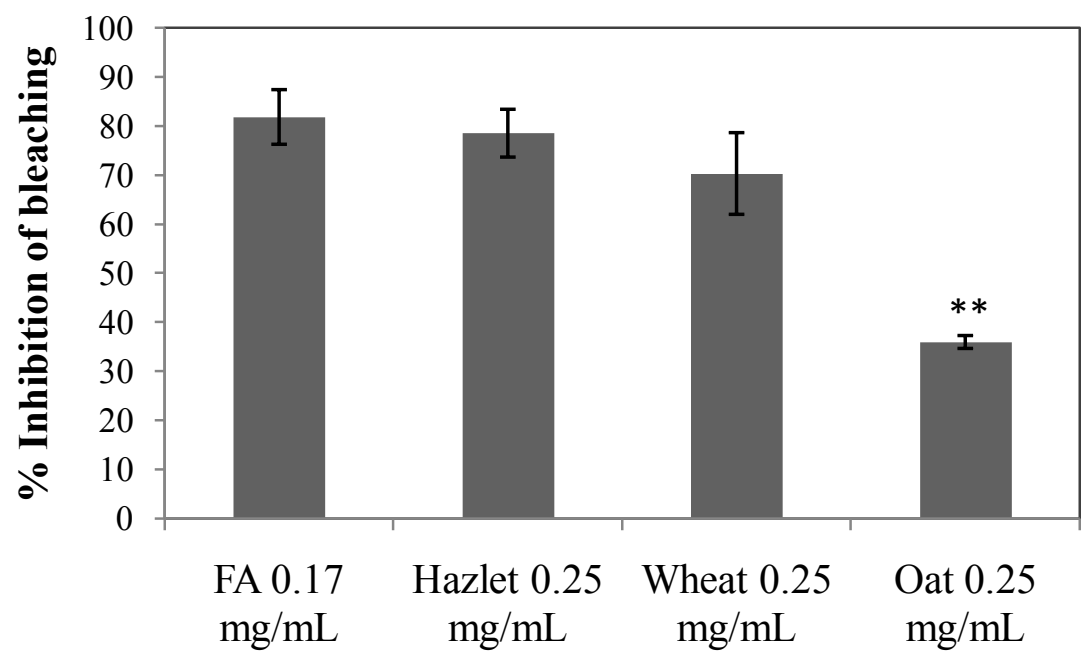

Figure 2-2: Antioxidant activity of AR extracts from Hazlet rye, wheat, and oat bran, determined by (A) ORAC in $\mu \mathrm{mol} \mathrm{TE} / \mathrm{g}$ of ARs and (B) B-carotene bleaching as \% Inhibition of $B$-carotene bleaching. Results are expressed as mean values \pm SEM. Significantly different from Hazlet, $* \mathbf{P}<0.05, * * \mathbf{P}<0.01$. 


\subsubsection{In vitro effect of rye bran ARs on COX-2 inhibition}

Anti-inflammatory activity of AR extracts from Hazlet rye was determined in vitro using the $\mathrm{COX}$ inhibitor screening assay. Figure $2-3$ illustrates the $\%$ inhibition of COX-2 by increasing concentrations of Hazlet. As the concentration of Hazlet increased, the $\%$ inhibition of COX-2 did as well. At $0.24 \mathrm{mg}$ AR extract $/ \mathrm{mL}, \mathrm{COX}-2$ is inhibited by only $27.58 \%$, whereas a concentration of $1.94 \mathrm{mg}$ AR extract $/ \mathrm{mL}$ yielded an inhibition of 77.48\%. The known inhibitor DuP-697 was assayed as a control. At 25 nM, DuP-697 inhibits COX-2 by 50\%. The assay yielded an inhibition of $52.87 \%$.

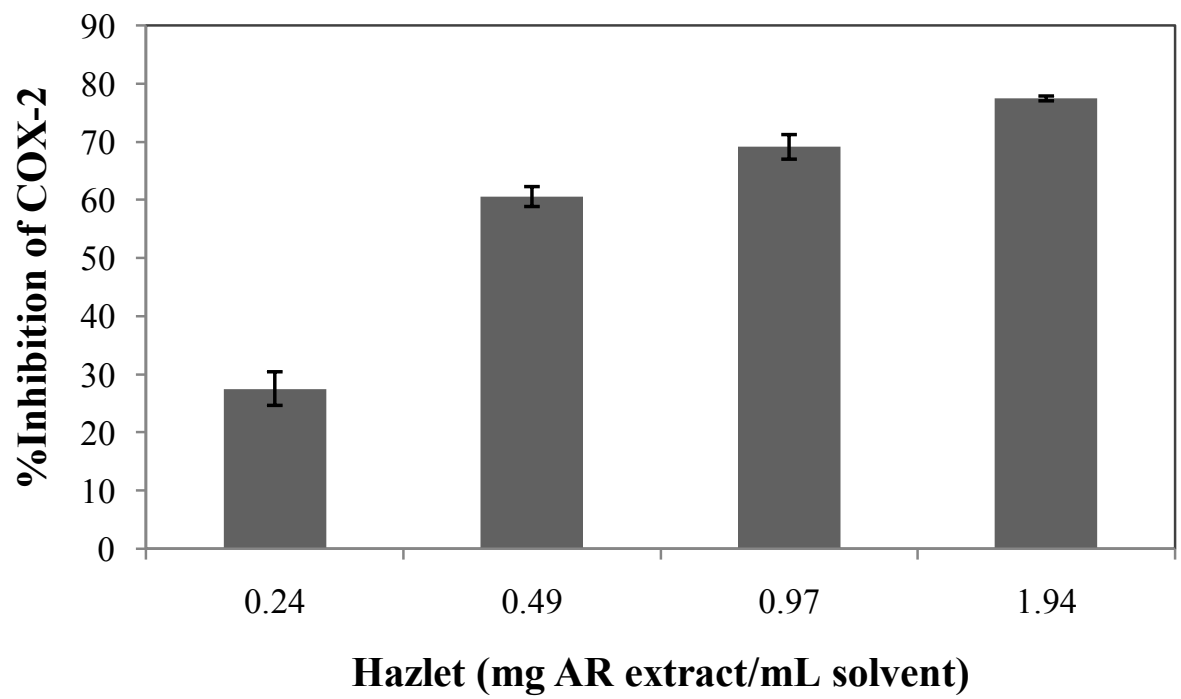

Figure 2-3: Inhibition of human recombinant COX-2 by AR extract from Hazlet rye bran. Results are expressed as mean values \pm SEM. 


\subsubsection{Effect of rye bran ARs on cytotoxicity on RAW 264.7 macrophages}

Using the murine macrophage RAW 264.7 cell line, which produces NO upon stimulation with LPS, the anti-inflammatory activity of AR extracts from Hazlet rye was determined. Prior to anti-inflammatory assays, ARs had to be tested for cytotoxicity, to determine if ARs are harmful and cause cell death of the macrophages. Cytotoxicity of ARs in ethanol was determined using the MTT assay. A range of concentrations was tested and as seen in Figure 2-4, cell viability did not change up to an AR concentration of $86.79 \mu \mathrm{g}$ AR extract/mL. Beyond this concentration, ARs were cytotoxic to the cells, indicated by a low absorbance. Based on these findings, only concentrations up to 86.79 $\mu \mathrm{g}$ AR extract/mL were chosen for all subsequent experiments.

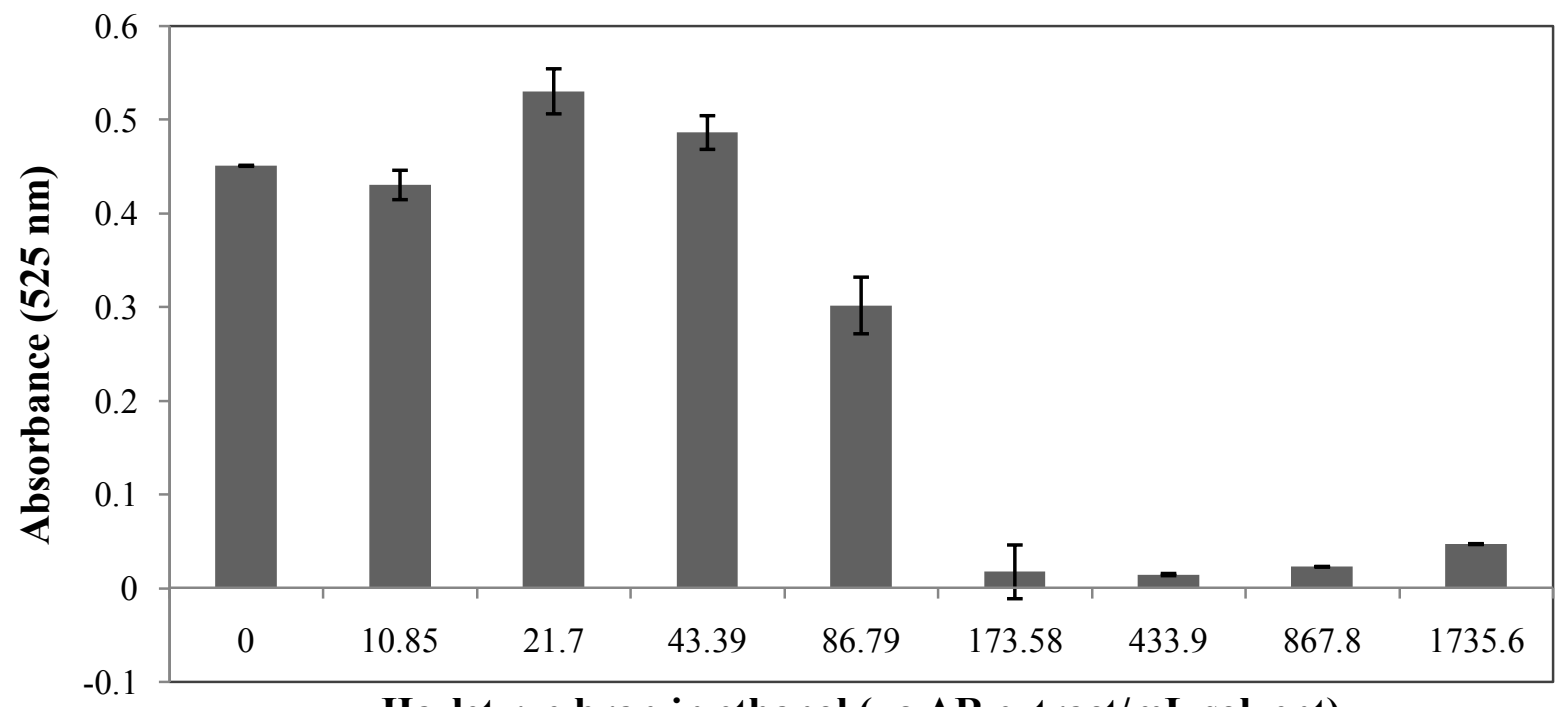

Hazlet rye bran in ethanol ( $\mu \mathrm{g}$ AR extract/mL solvent)

Figure 2-4: Reduction of cellular metabolic activity of RAW 264.7 cells at increasing concentrations of AR extracts from Hazlet rye bran using the MTT assay. Results are expressed as mean values \pm SEM. 


\subsubsection{Effect of rye bran ARs on LPS-induced NO production in RAW 264.7 macrophages}

RAW 264.7 macrophages were pretreated with AR extract from either Hazlet rye bran or oat bran and then stimulated with LPS. Subsequent production of NO was determined by measuring the accumulation of the NO metabolite nitrite in the culture medium. Cells treated with LPS alone were considered a control with $100 \%$ nitrite accumulation, with all other treatments relative to this. Untreated cells (no LPS, no AR extract) showed no accumulation of nitrite (Figure 2-5). At increasing concentrations of both Hazlet and Oat ARs, the \% nitrite accumulation decreased in LPS-stimulated RAW 264.7 cells. Hazlet caused a much greater reduction in nitrite than oat. All four concentrations of Hazlet tested significantly reduced nitrite concentration with $\mathrm{P}<0.01$. At a concentration of $86.79 \mu \mathrm{g} \mathrm{AR}$ extract/mL, Hazlet inhibited nitrite accumulation by $46 \%$. As for oat, only concentrations of 43.39 and $86.79 \mu \mathrm{g}$ AR extract $/ \mathrm{mL}$ significantly reduced nitrite with $\mathrm{P}<0.01$. At $21.7 \mu \mathrm{g}$ AR extract $/ \mathrm{mL}$ oat significantly reduced nitrite with $\mathrm{P}<0.05$ and no significant change was observed at the lowest concentration tested (10.85 $\mu \mathrm{g}$ AR extract $/ \mathrm{mL})$. At $86.79 \mu \mathrm{g}$ AR extract $/ \mathrm{mL}$, oat was only able to reduce nitrite accumulation by $70 \%$. 


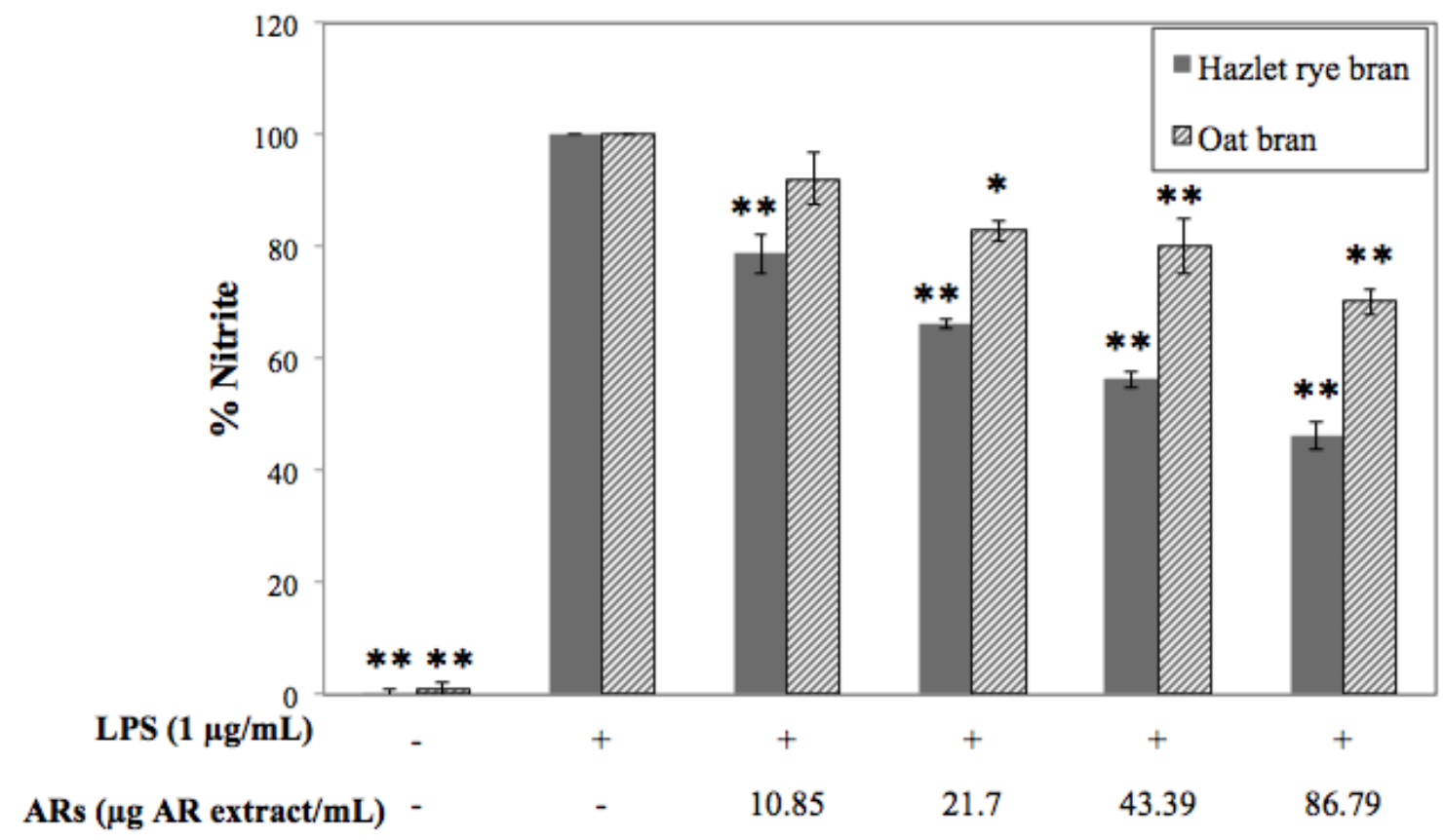

Figure 2-5: Inhibition on NO production in LPS-stimulated RAW 264.7 cells by AR extracts from Hazlet rye bran and oat bran. Results are expressed as mean values \pm SEM. Significantly different from the corresponding control (LPS, no treatment), $* \mathbf{P}<\mathbf{0 . 0 5}, * * \mathbf{P}<0.01$ 


\subsubsection{Effect of rye bran ARs on the protein expression of iNOS and COX-2}

ARs from Hazlet rye were analyzed by Western blot analysis for their ability to influence the protein expression of iNOS and COX-2. Figure 2-6a shows the effect of ARs on iNOS protein expression. In the absence of LPS and AR extract, iNOS was not expressed. LPS stimulated RAW 264.7 macrophages greatly expressed iNOS in the absence of ARs. In the presence of ARs, iNOS expression was significantly reduced $(\mathrm{P}<0.01)$. Reduction of expression was not in a concentration dependent manner, all four concentrations of ARs showed a similar effect on iNOS protein expression.

Western blot analysis of COX-2 can be seen in Figure 2-6b. COX-2 was not expressed in the absence of LPS and AR extract. Similarly to iNOS, ARs were able to significantly reduce COX-2 expression $(\mathrm{P}<0.01)$ but not in a concentration dependent

manner. All four concentrations of ARs reduced COX-2 protein expression to approximately the same degree. 
A
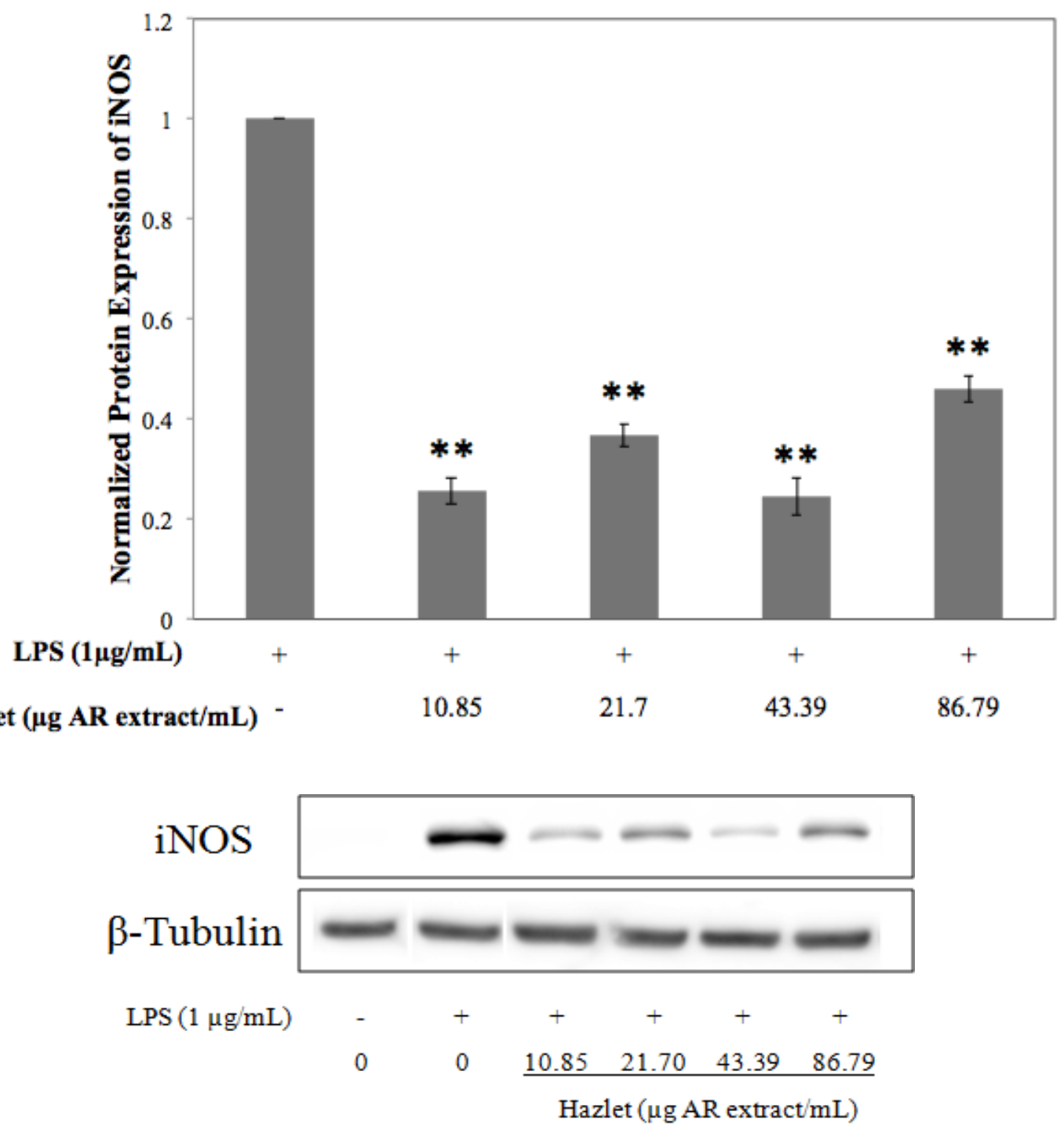
B

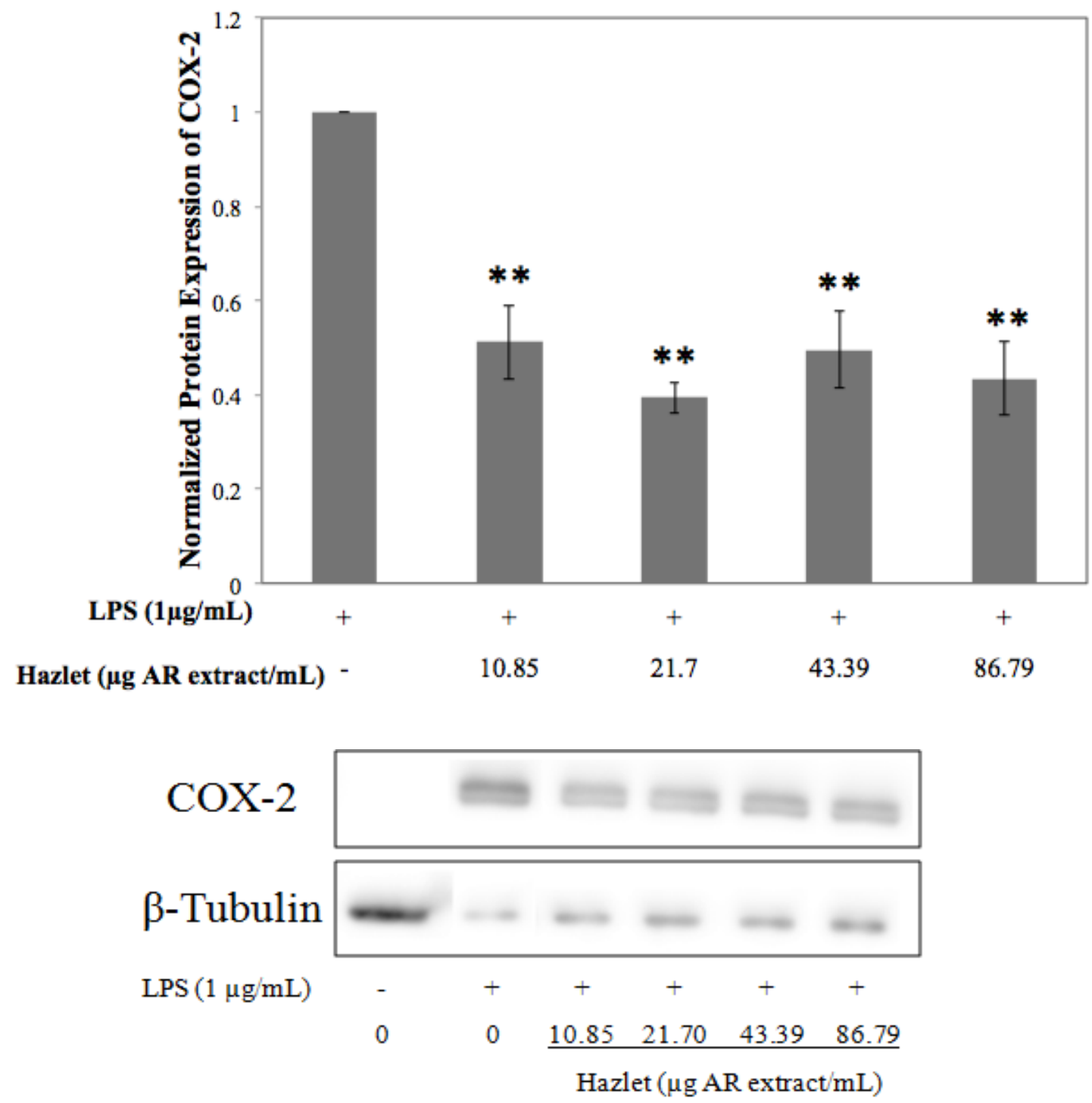

Figure 2-6: Inhibition of (a) iNOS and (b) COX-2 protein expression by AR extracts from Hazlet rye bran in LPS-stimulated RAW 264.7 cells. Results are expressed as mean values \pm SEM. Significantly different from the control (LPS, no treatment), $* \mathbf{P}<0.05, * * \mathbf{P}<0.01$ 


\subsubsection{Effect of rye bran ARs on the mRNA expression of iNOS and COX-2}

The effect of ARs on mRNA expression of iNOS and COX-2 was evaluated using RT-PCR. As seen in Figure 2-7a, AR concentrations of 10.85 and $21.7 \mu \mathrm{g}$ AR extract $/ \mathrm{mL}$ were not able to significantly reduce mRNA expression of iNOS, whereas concentrations of 43.39 and $86.79 \mu \mathrm{g}$ AR extract $/ \mathrm{mL} \operatorname{did}(\mathrm{P}<0.05)$.

All four concentrations of Hazlet rye bran ARs significantly reduced mRNA expression of COX-2 $(\mathrm{P}<0.01)$ to approximately the same degree. 
A

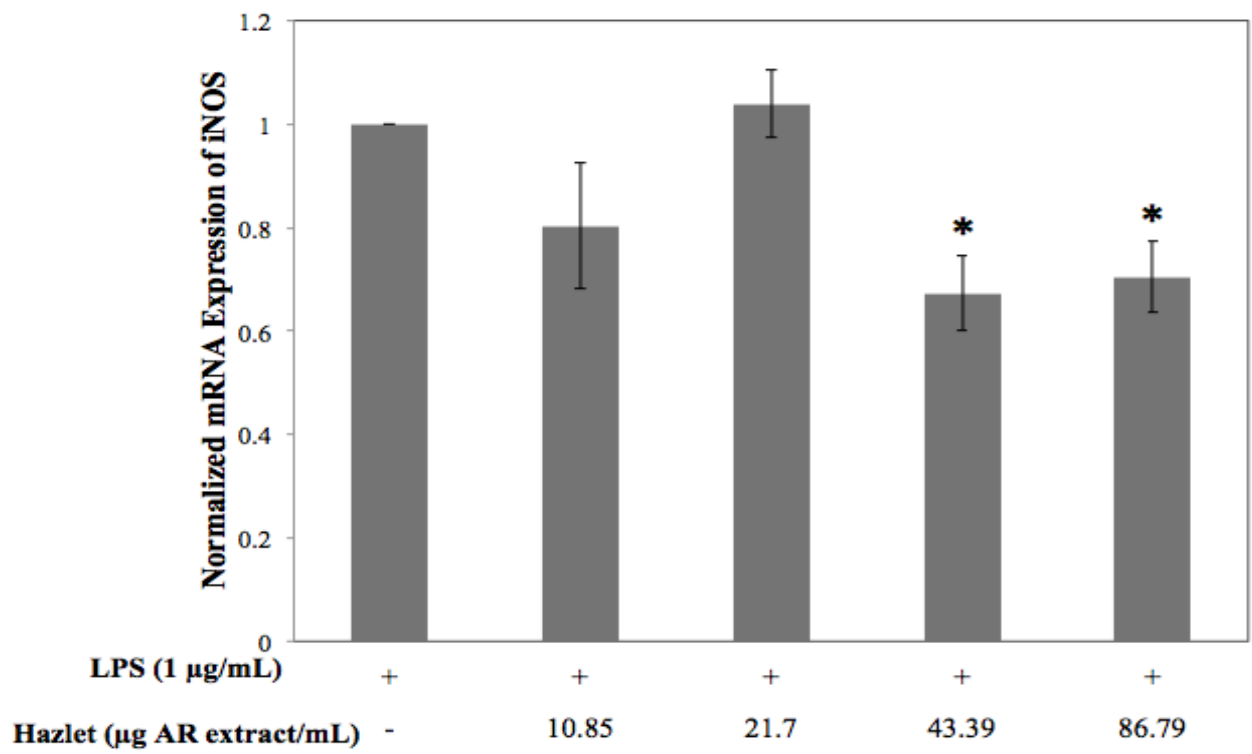

B

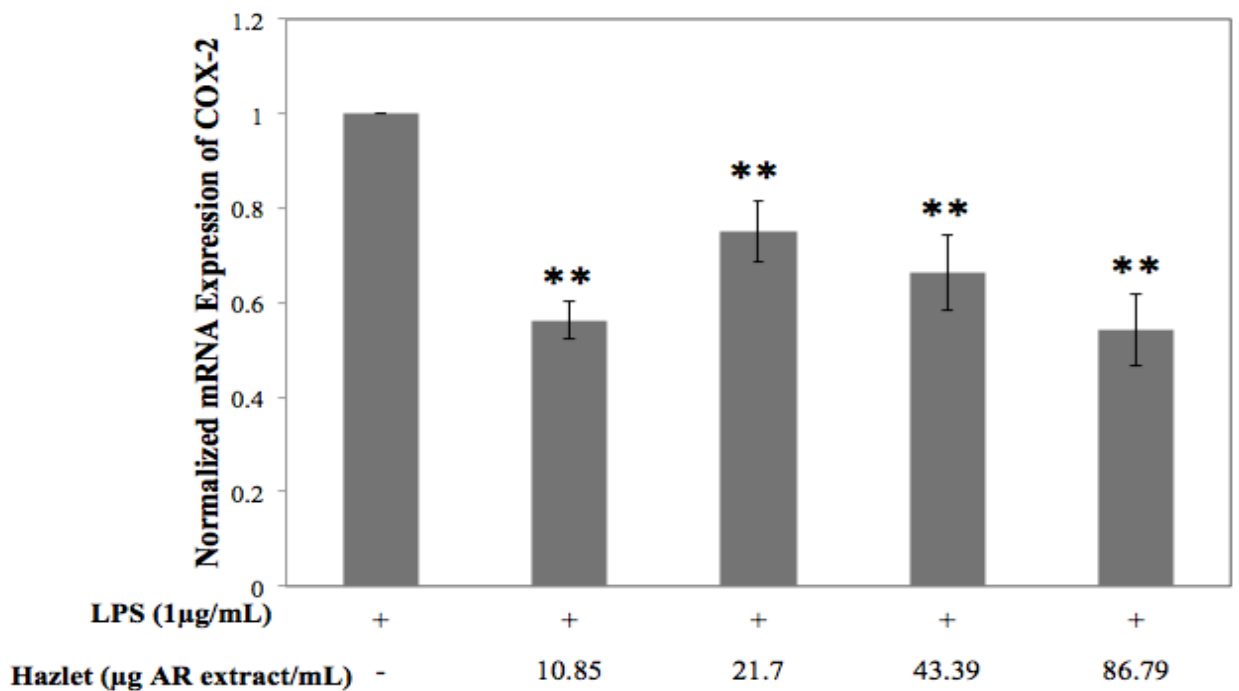

Figure 2-7: Inhibition of (A) iNOS and (B) COX-2 mRNA expression by AR extracts from Hazlet rye bran in LPS-stimulated RAW 264.7 cells. Results are expressed as mean values \pm SEM. Significantly different from the control (LPS, no treatment), $* \mathbf{P}<0.05, * *<\mathbf{P}<0.01$ 


\subsection{Discussion}

ARs are found in cereals such as rye, wheat and triticale, and to a lesser extent in barley. In this study, ARs were extracted from Hazlet rye bran with acetone, which is selective for ARs. Therefore, peaks for saturated AR homologues C15:0, C17:0, C19:0, C21:0, C23:0, and C25:0 should be predominant ${ }^{3}$. As seen in Figure 2-1b, the HPLC chromatogram of isolated ARs shows six large peaks, identifying correctly the six different homologues found in rye when compared to a mixture of AR standards (Figure 2-1b). Smaller peaks were due to mono- and diunsaturated ARs, keto and hydroxyl AR homologues, as well as less defined or unknown $\mathrm{ARs}^{11}$, and possibly other phenolic compounds from the bran.

The distribution of AR homologues differs between cereals. C19:0 is most common in rye, whereas $\mathrm{C} 21: 0$ is most common in wheat, triticale, and barley ${ }^{4}$. Figure 21c shows a predominance of homologue C19:0 and it can therefore be assumed that extracted ARs were from pure rye bran. The total amount of ARs in the extract was 1,874 $\mu \mathrm{g} / \mathrm{g}$ of bran, which was slightly less than the expected $2,034-2,573 \mu \mathrm{g} / \mathrm{g}^{5,6}$. It is possible that during the milling process, bran was contaminated with the endosperm, lowering the overall AR content.

Studies have shown that ARs have low antioxidant capacity in vitro, compared to other natural antioxidants, such as FA and tocopherol ${ }^{38}$. Nevertheless, ARs from Hazlet rye bran still showed high antioxidant activity compared to wheat and oat bran as determined using the ORAC and $\beta$-carotene bleaching assay. Among the cereals, rye has

the highest content of ARs, followed by triticale, wheat, and barley ${ }^{4}$ and should therefore show higher antioxidant activity than wheat, which was chosen as a positive control. Oat, 
due to its lack of AR content ${ }^{4}$, should show almost no antioxidant activity, which is why it was chosen as a negative control. Figure $2-2 \mathrm{a}$ and $2-2 \mathrm{~b}$ show the results of in vitro antioxidant activity as determined with ORAC and $ß$-carotene bleaching assay, which confirm the expected outcome. Rye had the highest antioxidant activity among the cereals, followed by wheat and then oat. Oat showed more antioxidant activity than expected, possibly due to other phenolic componentspresent in oat that were extracted along with it, giving it antioxidant activity.

FA is a strong antioxidant, that has previously shown much higher antioxidant activity than $\mathrm{ARs}^{37}$, which is confirmed in this study by showing that ARs have approximately the same antioxidant activity in vitro as FA, but at $1.5 \mathrm{x}$ the concentration.

Our previous study has investigated the antioxidant activity of Hazlet rye bran ARs using ORAC, and determined ORAC values of $136.05 \mu \mathrm{mol} \mathrm{TE} / \mathrm{g}$ for the outermost fraction of $\mathrm{ARs}^{68}$. This value is much lower than the one determined during this study $(2,461 \mu \mathrm{mol} \mathrm{TE} / \mathrm{g}$ of ARs). Discrepancies in results might be due to different cultivation years and external factors such as weather conditions, affecting the crop. Additionally, acetone was previously evaporated using the rotary evaporator, which uses high temperatures to separate the ARs from the solvent. Large amounts of ARs were extracted and stored at $4^{\circ} \mathrm{C}$ until further use. In this study, acetone was evaporated under nitrogen flush, just prior to use for each experiment. The shorter storage times and lack of heat might increase antioxidant activity, by preventing the breakdown of ARs.

This study focused mainly on determining whether ARs are able to reduce NO production and thus inflammation and if this activity was due to the down-regulation of inflammatory enzymes iNOS and COX-2 and the protein and mRNA levels. 
Figure 2-3 illustrates the effect of ARs extracted from Hazlet rye bran on the inhibition of COX-2. ARs inhibited COX-2 in a concentration dependent manner in the in vitro assay. However, when the influence of ARs on COX-2 protein (Figure 2-6b) and mRNA (Figure 2-7b) expression was determined in RAW 264.7 macrophages, the same trend was not visible. ARs were able to significantly reduce both protein and mRNA expression in LPS-stimulated RAW 264.7 cells, however, all four concentrations seem to reduce COX-2 protein and mRNA expression to approximately the same degree. A threshold might have been reached by ARs at a concentration of $10.85 \mu \mathrm{g} / \mathrm{mL}$, making it unable for ARs to further reduce COX-2 expression. A trend, simulating a concentration dependent relationship, could be obtained by testing much lower concentrations of ARs. Nevertheless, the results confirm that ARs are able to inhibit COX-2 expression at the transcriptional and post-transcriptional level.

ARs also showed the ability to inhibit NO production, resulting from stimulating RAW 264.7 cells with LPS, in a concentration dependent manner (Figure 2-5). Inhibition was much greater than that of oat bran, which was expected, because of the lack of ARs in this cereal. This indicates that ARs are the driving force in inhibiting inflammation related NO accumulation. Inhibition of NO was attributed to the ability to downregulated protein and mRNA expression of iNOS as seen in Figure 2-6a and 2-7a. Just as with COX-2, protein and mRNA expression were not reduced in a concentration dependent manner, due to a threshold being reached and $10.85 \mu \mathrm{g} / \mathrm{mL}$. As seen in Figure 2-7a, only at concentrations of 43.39 and $86.79 \mu \mathrm{g} / \mathrm{mL}$ were ARs able to down-regulate iNOS mRNA expression. The effect of ARs on the inhibition of NO production due to the reduction of iNOS expression might be mostly due to inhibition at the post- 
transcriptional level. Low concentrations of ARs might not be able to modify transcription but can inhibit translation to reduce iNOS protein. ARs ability to inhibit NO and iNOS and COX-2 were not due to cytotoxicity on RAW 264.7 macrophages as determined by the MTT assay (Figure 2-4). Results show that rye bran ARs were able to reduce protein and mRNA expression of iNOS and COX-2 and thus have antiinflammatory activity.

Phenolic antioxidants have previously shown to inhibit the expression of cytokines by inhibition of NF- $\mathrm{kB}$ binding to DNA through redox cycling. However, resorcinol, which is structurally similar to ARs, did not exhibit inhibition of NF-kB binding to DNA ${ }^{65}$. ARs have a long odd-numbered alkyl chain that has previously been shown to incorporate into membranes ${ }^{39,40}$. This feature would explain differences in the function compared to resorcinol, which lacks an alkyl chain. Vitamin E derivatives such as alpha and gamma tocopherol are similar in structure to ARs. They have shown antiinflammatory activity, but are also not able to inhibit $\mathrm{NF}-\mathrm{\kappa B}^{71}$, suggesting a different route of inhibiting inflammation. Vitamin E, as well as ARs might inhibit inflammation indirectly by interacting with the membrane and thus influencing membrane bound proteins that play a role in inflammation. Studies on anti-inflammatory activity of ARs have never been performed, so it is uncertain how ARs inhibit inflammation. Therefore, inhibition of iNOS and COX-2 expression could be due to a number of reasons. ARs might be able to directly inhibit transcription factors, such as NF- $\mathrm{kB}$, responsible for proinflammatory gene expression of COX-2 and iNOS, or its inhibiting protein IкB, or ARs could induce endogenous antioxidants by activating Nrf2.It is also possible that ARs could increase binding of $\mathrm{Nrf2}$ to its antioxidant response element on the gene to increase 
antioxidant and phase 2 detoxification enzyme gene expression. The long alkyl side chain of ARs might interact with proteins in the cell membrane to inhibit binding of LPS to the LPS-binding protein, or with proteins in the nuclear membrane to inhibit the translocation of transcription factors into the nucleus.

Additionally, ARs might also show anti-inflammatory activity by scavenging ROS, which would lead to the activation of cytokines, which activate NF-kB. However this mechanism seems less likely, due to the low radical scavenging activity of ARs.

The results of this study show that ARs could be used as potential antiinflammatory agents to prevent diseases such as cancer $^{67}$, diabetes, and cardiovascular disease $^{51}$.

\subsection{Conclusion}

ARs from cereal grains have been studied widely for their antioxidant activity in vitro and their use as a biomarker. In this study, ARs from Hazlet rye bran were shown to have high antioxidant activity over other cereals such as wheat and oat. Furthermore, this study is novel in that it looked at anti-inflammatory activity of ARs in RAW 264.7 cells, which has never been studied before. Rye bran ARs show promising anti-inflammatory activity by inhibiting the accumulation of NO in LPS-stimulated macrophages and by down-regulating inflammatory enzymes iNOS and COX-2, which are responsible for the release of inflammatory mediators. This inhibition could be caused by a number of scenarios, including the activation of Nrf2 and inhibition of NF- $\mathrm{KB}$, or the interaction with membrane bound proteins to inhibit translocation of LPS or NF-kB. It can be 
concluded that ARs, although weak antioxidants in vitro, could serve as potent antiinflammatory agents and be used for therapeutic uses. 


\section{Chapter 3 - Effect of alkylresorcinols from Hazlet rye bran on antiobesity and antioxidant activity in mouse tissues}

\subsection{Abstract}

Alkylresorcinols from Hazlet rye bran did not significantly reduce weight gain in CF-1 mice fed a high fat (HF) diet compared to a HF diet treatment without supplementation, indicating that ARs do not have anti-obesity activity. Furthermore, ARs did not show a protective effect against diabetes as they were not able to clear glucose from the blood efficiently. ARs were able to significantly increase antioxidant activity in a high fat diet in liver tissue, when compared to a HF diet alone using the ORAC assay, suggesting a protective effect against liver disease. Although ARs showed the highest antioxidant activity in liver and heart tissues, results were not significant from the HF diet control.

\subsection{Introduction}

A diet rich in whole grains has been associated with reduced weight gain. A study by Liu et al. ${ }^{72}$ followed middle-aged women over a period of 12 years and evaluated their weight gain as an effect of either a whole grain, or refined grain diet. Generally, women with higher whole grain intake gained $1.52 \mathrm{~kg}$ less weight than those with lower whole grain intake. On the other hand, women who consumed more refined grain products, compared to those consuming less refined grain products, gained more weight. Similarly, an increased consumption of whole grains is also inversely related with a risk of type 2 
diabetes, where bran shows a stronger effect on the reduction of cases of diabetes than $\operatorname{germ}^{73}$.

ARs, found in the bran of cereals such as rye, wheat and triticale, have mostly been studied for their antioxidant activity. In vitro studies show conflicting results but lean towards low antioxidant activity compared to known antioxidants such as tocopherol and ferulic acid ${ }^{2,38}$. Studies showed that ARs are able to incorporate into membranes in vitro ${ }^{39}$ and in vivo ${ }^{40}$. This activity is said to be the major driving force behind ARs bioactivity and possibly antioxidant activity. However, in vivo studies on antioxidant activity are absent.

ARs have other health benefits for humans, such as anti-cancer activity ${ }^{28-31}$, and they have shown a possible protection against diabetes ${ }^{25}$ and cardiovascular disease ${ }^{26}$. It was also speculated that ARs have anti-obesity activity, due to their ability to inhibit triglyceride accumulation and glycerol-3-phosphate dehydrogenase ${ }^{27}$, but studies have not been conducted to confirm anti-obesity activity of ARs.

Endogenous antioxidants, such as SOD and GSH, are far more important regulators of oxidative stress in the body than dietary antioxidants. The regulation of these antioxidants can be influenced by exogenous antioxidants, which is of interest in this study.

Glutathione is a tripeptide, consisting of L-glutamic acid, L-cysteine and glycine. It is found in all mammals, predominately in the liver ${ }^{74}$. Its role in the body is as an endogenous antioxidant, but GSH also detoxifies xenobiotics and maintains the intracellular redox balance due to its thiol group. GSH is synthesized in 2 steps. The first step is catalyzed by $\gamma$-glutamyl-cysteine ligase (GCL), which forms $\gamma$-glutamyl-L- 
cysteine from glutamate and cysteine. The second step is catalyzed by GSH synthase and forms GSH by catalyzing the reaction between L-glutamyl-L-cysteine and glycine. Synthesis of GSH is regulated by different factors. Most important factors include the availability of cysteine and the activity of $\mathrm{GCL}^{74}$. Changes in the synthesis of GCL have shown to be the result of transcriptional and post-transcriptional regulation. The transcription factor nuclear factor (erythroid-derived 2)-like 2 (Nrf2) stimulates GCL synthesis in response to oxidative stress. Nrf2 then binds to the antioxidant response element (ARE) on the DNA in the nucleus. Additionally, the transcription factor NF- $\kappa \mathrm{B}$ plays a crucial role in the regulation of GCL, inducing its expression when activated ${ }^{74}$. The role of these two transcription factors on the synthesis of GSH suggests a possible mechanism for the regulation of GSH by ARs.

Superoxide dismutase is an endogenous antioxidant that is responsible for the elimination of superoxide anion radicals ${ }^{48}$. There are three isoforms of SOD in mammals; copper-zinc SOD ( $\mathrm{Cu} / \mathrm{ZnSOD})$ which is encoded by the sodl gene and is cytosolic, manganese SOD (MnSOD) which is encoded by the sod2 gene and is mitochondrial, and extracellular SOD (ECSOD), also containing copper and zinc metal ions, which is encoded by the sod3 gene. Although all three isoforms differ in structure and gene distribution, they have similar functions in the body. The transcription of endogenous SOD genes is controlled by a number of transcription factors, including NF- $\kappa \mathrm{B}, \mathrm{Sp} 1$, AP1, AP-2, and C/EBP, which can induce or repress the gene expression of $\mathrm{SOD}^{75}$.

In this study, anti-obesity and antioxidant activity of ARs was assessed in a mouse model in vivo. The objectives of this study were a) to determine if ARs can reduce weight gain in mice fed a HF diet, and thus have anti-obesity activity and b) to determine the 
effects of AR treatment on the antioxidant activity in mouse liver and heart tissuesusing the ORAC, SOD, and GSH assays.

\subsection{Materials and Methods}

\subsubsection{Hazlet rye samples}

Hazlet rye, which is a cultivar of winter rye (Secale cereal L.), was developed and grown by Dr. Grant McLeod at Agriculture and Agri-Food Canada (AAFC) in Swift Current, SK. Only the bran layer of Hazlet rye was used in all experiments. Bran was separated from the kernel by Dr. Nancy Ames at AAFC in Winnipeg, MB, using a Satake TM 05 laboratory-scale pearler (Satake Co, Japan).

\subsubsection{Extraction of ARs from Hazlet bran}

Alkylresorcinols from Hazlet rye bran were extracted using acetone as previously described. Acetone was completely evaporated from the supernatant using a BüchiRotavapor R-215 (New Castle, Delaware). The dried product was weighed and stored at $-20^{\circ} \mathrm{C}$ for further use.

\subsubsection{Animals}

Male CF-1 mice (Charles River Farms, Quebec) with a mean body weight of $32.32 \mathrm{~g}$ on day 0 were used in this study. Mice were housed individually in standard plastic mouse cages at $22^{\circ} \mathrm{C}$ and $45-55 \%$ humidity. The animals were kept on a 12 hour light-dark cycle with light on at 08:00 hours. 
The procedures of this study were approved by the Carleton University Animal Care Committee and followed the guidelines of the Canadian Council on Animal Care.

\subsubsection{Animal study design}

All mice were fed a standard laboratory chow diet for two weeks. After the baseline period, mice were randomized into treatment and control groups of 8 mice each, with similar mean body weights. Control groups included: standard chow (Chow), and high-fat (HF). The treatment groups included: high fat and $5 \mathrm{~g}$ rye AR/kg feed (HF+ARs), high fat and $10 \%$ rye bran $(\mathrm{HF}+\mathrm{Bran})$, and high fat and Vitamin $\mathrm{E}(\mathrm{HF}+\mathrm{Vit} \mathrm{E})$. At the end of the treatment period 4 mice had died leaving 8 mice in groups HF+ARs and $\mathrm{HF}+\mathrm{Vit} \mathrm{E}, 7$ mice in Chow and HF+Bran, and 6 mice in HF. Body weights and food intake for each mouse were measured at the same time each day. Water was provided ad libitum.

The standard chow diet used was the 2014 Teklad Global 14\% Protein Rodent Maintenance Diet from Harlan Laboratories (Mississauga, Ontario), with an energy density of $2.9 \mathrm{kcal} / \mathrm{g}$. It contained $14.3 \%$ crude protein, $4.0 \%$ fat, and $4.1 \%$ crude fiber and was designed to promote longevity and normal body weight.

The $60 \%$ HF diet used was the TD.06414 from Harlan Laboratories (Mississauga, Ontario) with an energy density of $5.1 \mathrm{kcal} / \mathrm{g}$. It consisted of $18.4 \%$ protein, $21.3 \%$ carbohydrates, and $60.3 \%$ fat. The HF diet pellets were soft pellets and treatments were added to yield a homogenous mixture using a standard household coffee grinder. Vitamin E was added to the HF diet as $5 \mathrm{~g}$ Vitamin $\mathrm{E} / \mathrm{kg}$ feed ( $0.5 \%$ of the diet). ARs were 
extracted from Hazlet bran as described above and added to the HF diet as $5 \mathrm{~g} \mathrm{AR} / \mathrm{kg}$ feed $(0.5 \%$ of the diet). Hazlet bran was added to the high-fat diet as $10 \%$ of the diet.

At the end of the 10 week treatment period, mice were deprived of feed for 12 hours before being sacrificed by decapitation without anesthesia. Blood glucose levels were determined at time of death. Organs were excised, weighed, and frozen at $-80^{\circ} \mathrm{C}$ immediately.

\subsubsection{Body fat analysis}

Headless carcasses were analyzed for $\%$ fat mass, $\%$ water, and $\%$ lean tissue mass using the EchoMRI4in1 ${ }^{\mathrm{TM}}$ mouse composition analyzer from EchoMRI(Houston, Texas).

\subsubsection{Intraperitoneal Glucose Tolerance Test (GTT)}

Mice were fasted overnight for 12 hours. Each mouse was nicked at the base of the tail to draw blood. Blood glucose levels at time 0 minutes were determined using the Contour ${ }^{\circledR}$ next EZ Blood Glucose Monitoring System from Bayer Inc. (Toronto, Ontario). A $20 \%$ D-glucose solution was injected into the peritoneal cavity of each mouse. The amount of solution added was determined based on body weight, where $0.5 \%$ of the total body weight was injected. Blood glucose levels were determined at 15,30 , 60, and 120 minutes. 


\subsubsection{Tissue homogenization and protein determination}

Frozen mouse liver and heart tissues were homogenized in $100 \mathrm{mM}$ potassium phosphate buffer ( $\mathrm{pH}$ 7.5) (Mallinckrodt, Paris, Kentucky), containing $1 \mathrm{mM}$ ethylenediaminetetraacetic acid (EDTA) (BioShop, Burlington, Ontario). Tissue was homogenized at 1:5 w/v in phosphate buffer using the Fisher Scientific Tissuemiser Homogenizer (Ottawa, Ontario) and centrifuged at $4^{\circ} \mathrm{C}$ and $12,000 \mathrm{~g}$ for 15 minutes. The supernatant was removed and stored at $-80^{\circ} \mathrm{C}$ until further use.

Protein determination was carried out by the Bradford method. A standard curve was prepared from $1 \mathrm{mg} / \mathrm{mL}$ bovine serum albumin (BSA) (BioShop, Burlington, Ontario). Liver samples were diluted to $0.5 \mathrm{mg} / \mathrm{mL}$ and heart samples were diluted to $0.25 \mathrm{mg} / \mathrm{mL}$. Absorbance was read at $595 \mathrm{~nm}$ on the SpectraMax $340 \mathrm{PC}^{384}$ microplate reader (Molecular Devices, Sunnyvale, California).

\subsubsection{ORAC}

The antioxidant activity of tissue samples was determined using the ORAC assay according to Gliwa et al. ${ }^{68}$ and as previously described in Chapter 2. All reagents were prepared using $100 \mathrm{mM}$ potassium phosphate buffer at $\mathrm{pH}$ 7.5. Liver samples were prepared at $1 \mathrm{mg} / \mathrm{mL}$, whereas heart samples were prepared at $1.5 \mathrm{mg} / \mathrm{mL}$ from the original homogenate $(200 \mathrm{mg} / \mathrm{mL})$ for a final concentration in the assay of 0.1 and 0.15 $\mathrm{mg} / \mathrm{mL}$, respectively. Absorbance was read for 90 minutes at 1 minute intervals after addition of AAPH. The regression equation from the Trolox standard curve was used to determine the concentration of Trolox equivalent (TE) of tissue samples in $\mu \mathrm{M}$. Protein concentrations of each tissue samples were used to report final ORAC values in $\mu$ mol 
$\mathrm{TE} / \mathrm{mg}$ protein. Additionally, ORAC values were represented as $\mu \mathrm{mol} \mathrm{TE} / \mathrm{mg}$ wet weight of tissue.

\subsubsection{SOD activity assay}

Tissue samples were prepared as previously described, by homogenizing in 100 $\mathrm{mM}$ phosphate buffer ( $\mathrm{pH}$ 7.5) containing $1 \mathrm{mM}$ EDTA and centrifuging for 15 minutes at $12,000 \mathrm{~g}$ at $4{ }^{\circ} \mathrm{C}$. A series of dilutions was prepared for each sample ranging from 0.052 to $0.5 \mathrm{mg} / \mathrm{mL}$ for liver samples and 0.025 to $4 \mathrm{mg} / \mathrm{mL}$ for heart. Phosphate buffer served as the blank and $1 \mu \mathrm{g} / \mathrm{mL}$ SOD (Sigma, St. Louis, Missouri) was used as a positive control. A 96-well microplate was loaded with $50 \mu \mathrm{L}$ blank, sample or standard, $10 \mu \mathrm{L}$ buffer, $10 \mu \mathrm{L}$ of $5 \mathrm{mM}$ EDTA, $10 \mu \mathrm{L}$ of $2.5 \mathrm{mM} \mathrm{MnCl}_{2}$ (Sigma-Aldrich, St. Louis, Missouri), $10 \mu \mathrm{L}$ of $0.27 \mathrm{mM}$ nicotinamide adenine dinucleotide (NADH) (BioShop, Burlington, Ontario), and $10 \mu \mathrm{L}$ of $3.9 \mathrm{mM} \mathrm{MeSH}$ (BioShop, Burlington, Ontario). Once MeSH was added, absorbance was read at $340 \mathrm{~nm}$ for 10 minutes at 30 second intervals on the SpectraMax $340 \mathrm{PC}^{384}$ microplate reader (Molecular Devices, Sunnyvale, California). The slope for each curve was determined and \% inhibition of each sample was calculated as follows:

$$
\% \text { Inhibition }=\frac{\text { rate of blank }- \text { rate of sample }}{\text { rate of blank }} \times 100
$$

The amount of sample required to inhibit $50 \%$ of NADH oxidation (I50) was determined by plotting a curve of slope vs. concentration for each tissue sample. Using the protein concentration determined for each sample, final SOD results were reported in Units $\mathrm{SOD} / \mathrm{mg}$ protein. 


\subsubsection{Determination of glutathione and glutathione disulfide}

The antioxidant activity of tissue samples was determined using glutathione

measurements according to Hermes-Lima et al. ${ }^{76}$. Tissue samples were homogenized 1:5 $(\mathrm{w} / \mathrm{v})$ in ice cold 5\% (w/v) sulfosalicylic acid (BioShop, Burlington, Ontario) that has previously been bubbled with $\mathrm{N}_{2}$ gas for 10 minutes. Homogenates were then centrifuged at $12,000 \mathrm{~g}$ for 5 minutes at $4^{\circ} \mathrm{C}$. Part of the supernatant was used directly to determine the concentration of total Glutathione (total $\mathrm{GSH}=\mathrm{GSH}+2 \mathrm{GSSG}$ ). Liver supernatants were diluted to a concentration of $0.09 \mathrm{mg} / \mathrm{mL}$, whereas heart supernatants were diluted to a concentration of $0.18 \mathrm{mg} / \mathrm{mL}$ for glutathione measurement. A glutathione (BioShop, Burlington, Ontario) standard curve was prepared fresh every day. Sulfosalicylic acid served as the blank. A 96-well microplate was loaded with $10 \mu \mathrm{L}$ of blank, sample, or standard, $200 \mu \mathrm{L}$ of a 5,5'-dithiobis-(2-nitrobenzoic acid) (DTNB) (Sigma, St. Louis, Missouri) and nicotinamide adenine dinucleotide phosphate (NADPH) (BioShop, Burlington, Ontario) solution, and $10 \mu \mathrm{L}$ of glutathione reductase (GR) (Sigma, St. Louise, Missouri). The concentrations in the well were $0.6 \mathrm{mM}$ for DTNB, $0.25 \mathrm{mM}$ for NADPH and 0.5 units of GR/mL. Absorbance was read at $412 \mathrm{~nm}$ for 20 minutes at 30 second intervals on the SpectraMax $340 \mathrm{PC}^{384}$ microplate reader (Molecular Devices, Sunnyvale, California). Using the GSH standard curve, with concentrations of $1.25,2.5$, 5,10 , and $20 \mu \mathrm{M}$, the concentration of total GSH for each tissue sample was determined.

Fifty microliters of the remaining supernatant were treated with $10 \mu \mathrm{L}$ of 2 vinylpyridine (Sigma, St. Louis, Missouri) and $50 \mu \mathrm{L}$ of $500 \mathrm{mM}$ potassium phosphate buffer ( $\mathrm{pH} 7$ ) to adjust the $\mathrm{pH}$ between 5.5 and 7.5. Samples were incubated at room temperature for 1 hour to derivatize GSH. A GSSG stock solution was treated with 44.7 
$\mathrm{mM}$ 2-vinylpyridine and buffer as well and incubated for 1 hour before preparing a standard curve, with concentrations of $0.1,0.2,0.4,0.7,1,1.5$, and $2 \mu \mathrm{M}$. After the incubation, tissue samples were diluted as before and GSSG (oxidized GSH) (Santa Cruz Biotechnology, Dallas, Texas) standards were prepared. A 96-well microplate was prepared as before, with $10 \mu \mathrm{L}$ of blank, standard, or sample, $200 \mu \mathrm{L}$ of a DTNB and NADPH solution, and $10 \mu \mathrm{L}$ of GR. Absorbance was read at $412 \mathrm{~nm}$ for 20 minutes at 30 second intervals. Using the GSSG standard curve, the concentration of the total GSH for each tissue sample was determined.

\subsubsection{Statistical analysis}

Results are expressed as mean values \pm SEM. Statistical significance was determined with one-way ANOVA followed by either Tukey's test (for multiple comparisons) or Dunn's method when the normality test failed. P values less than 0.05 and 0.01 were considered significantly different.

\subsection{Results}

\subsubsection{Changes in body weight and caloric intake of control and treatment mice}

At the beginning of the study, mice were grouped into control and treatment groups so that the average body weight of each group was nearly the same (approximately $32 \mathrm{~g}$ ). All groups were given the standard Chow diet for the first two weeks (baseline). The average body weight, average daily weight gain, and average daily caloric intake during the baseline period were similar between the five groups and not significantly different. During the treatment period mice consuming the Chow diet had 
gained the least amount of weight, with an average of $9.35 \mathrm{~g}$ and mice fed the HF+Bran diet gained the most $(22.45 \mathrm{~g})$. HF+ARs treated mice gained $17.99 \mathrm{~g}$, HF+Vit E treated mice gained $18.24 \mathrm{~g}$, and HF control mice gained $18.33 \mathrm{~g}$. At the end of the treatment period, mice fed the Chow diet weighted significantly less (44.39 g) than HF (53.16 g) $(\mathrm{P}<0.05), \mathrm{HF}+\mathrm{ARs}(53.42 \mathrm{~g})(\mathrm{P}<0.05)$, and HF+Bran $(57.51 \mathrm{~g})(\mathrm{P}<0.01)$, but not than $\mathrm{HF}+\mathrm{Vit} \mathrm{E}(52.12 \mathrm{~g}) . \mathrm{HF}+\mathrm{ARs}, \mathrm{HF}+\mathrm{Bran}$, and $\mathrm{HF}+\mathrm{Vit} \mathrm{E}$ did not show significantly lower body weight than HF fed mice.

The average daily body weight gain during the treatment period was lowest for the Chow group $(0.13 \mathrm{~g})$. This was about half of the daily weight gain for HF or treatment groups. The Chow group had significantly lower average daily body weight gains than $\mathrm{HF}, \mathrm{HF}+\mathrm{ARs}$, and $\mathrm{HF}+\mathrm{Bran}(\mathrm{P}<0.05)$, but not $\mathrm{HF}+\mathrm{Vit} \mathrm{E}$. There was no significant difference between HF and treatment groups.

During the treatment period, Chow fed mice consumed significantly less calories on a daily basis $(16.68 \mathrm{kcal})$ than HF or treatment groups $(19.75-23.43 \mathrm{kcal})(\mathrm{P}<0.01)$. There was also a significant difference in daily caloric intake between Chow and $\mathrm{HF}+\mathrm{Bran}(\mathrm{P}<0.01)$, Chow and $\mathrm{HF}+\mathrm{ARs}(\mathrm{P}<0.05)$, and Chow and HF+Vit $\mathrm{E}(\mathrm{P}<0.05)$. $\mathrm{HF}+\mathrm{Bran}$ treated mice consumed significantly more calories than $\mathrm{HF}+\mathrm{ARs}$ and $\mathrm{HF}+\mathrm{Vit} \mathrm{E}$ $(\mathrm{P}<0.05)$. There was no significant difference between HF and treatment groups. 
A

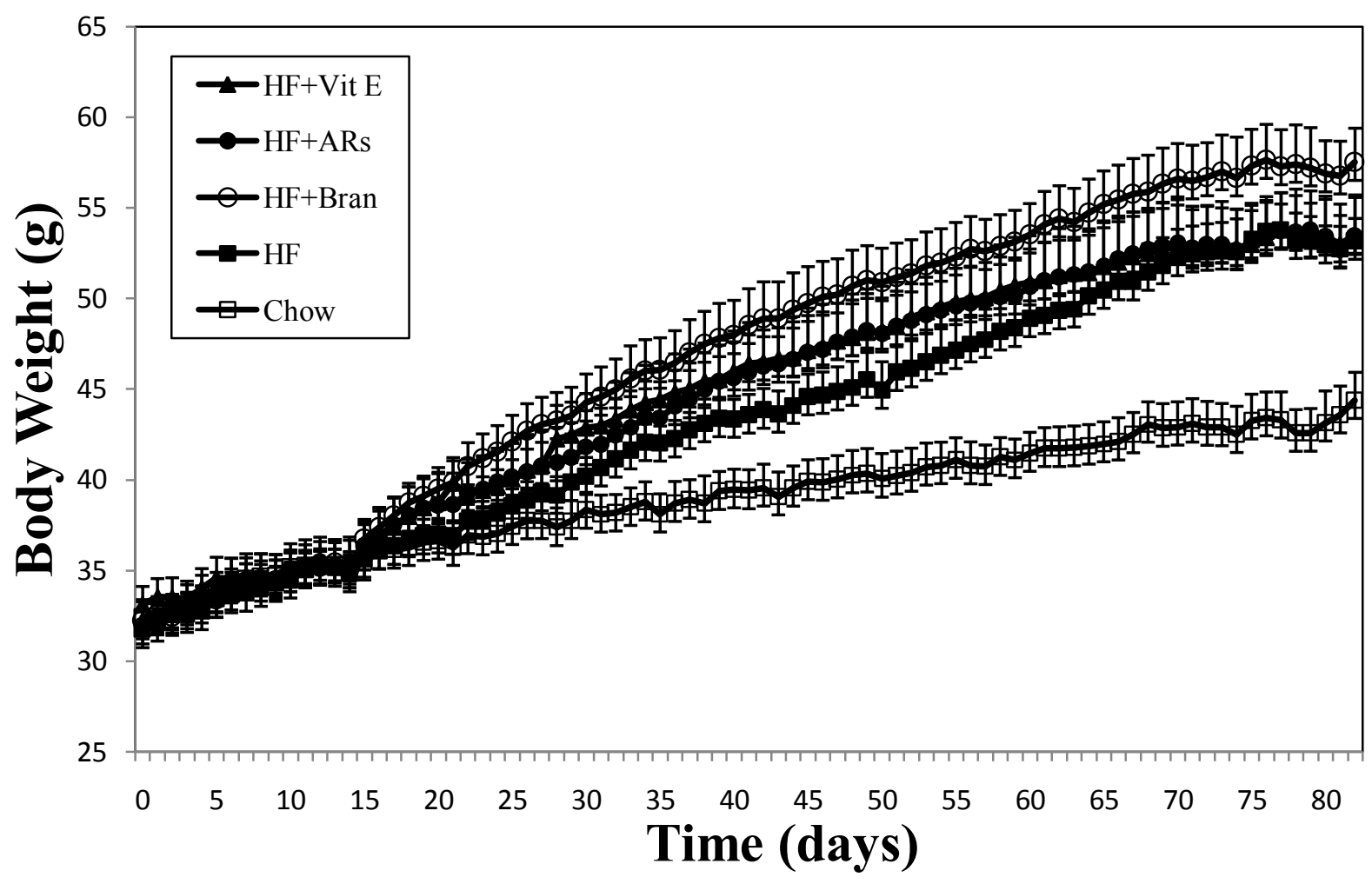

B

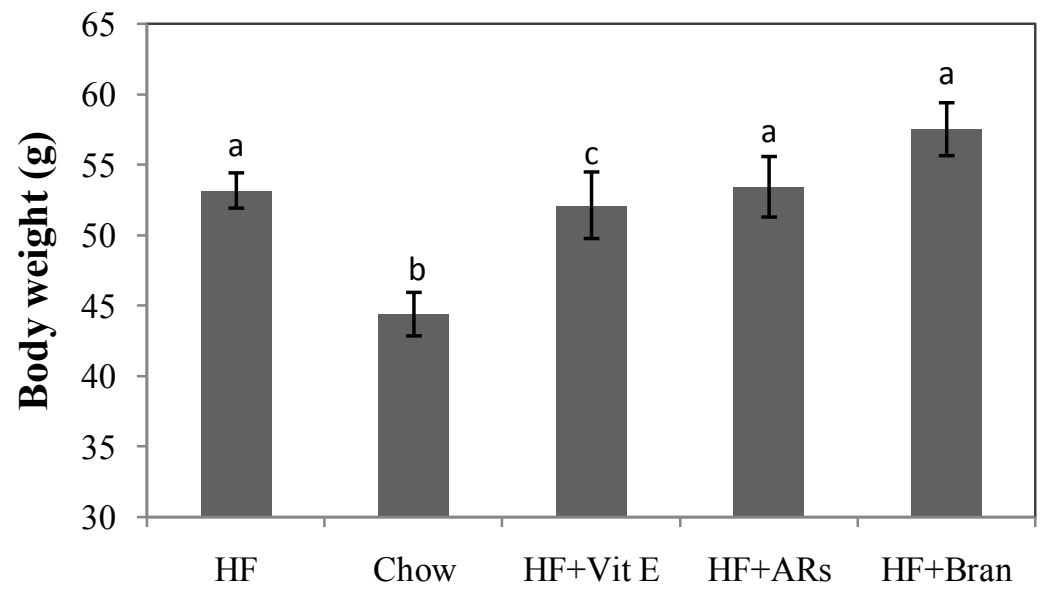


C

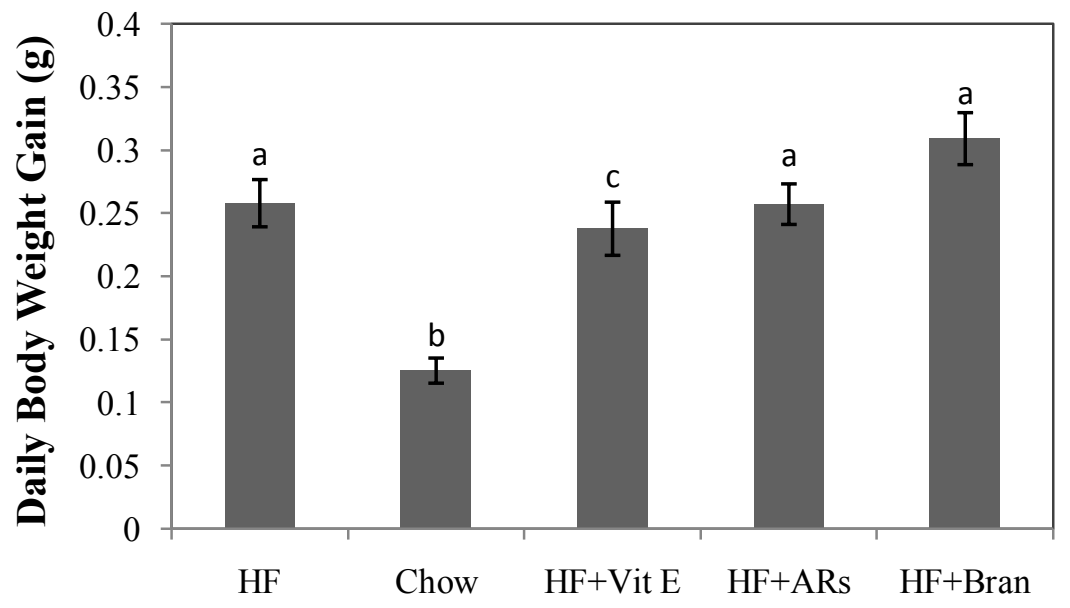

D

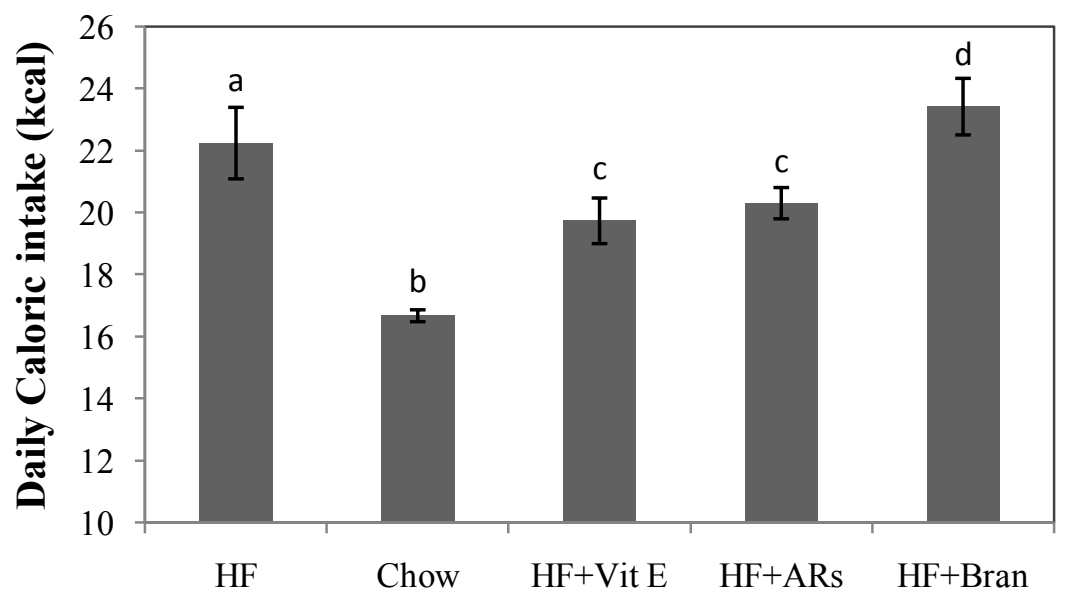

Figure 3-1: (A) Body weight of control and treatment mice over 82 days. (B) Average body weight at the end of the treatment period $(c=a+b) .(C)$ Average body weight gain $(c=a+b)$ and (D) caloric intake per day of control and treatment miceover the course of the treatment period $(a=c, a=d, c \neq d)$. Mice were fed and weighted daily. Results are expressed as mean values \pm SEM. 


\subsubsection{Blood glucose clearance incontrol and treatment mice after overnight fasting}

The effect of a HF diet and that of a high fat diet supplemented with ARs, rye bran, or Vitamin E on diseases related to obesity, such as hyperglycemia and diabetes, was determined using the intraperitoneal glucose tolerance test. All mice were fasted overnight and injected with a glucose solution. Clearance of glucose from the body was determined in the blood after 15, 30, 60, and 120 minutes (Figure 3-2). Blood glucose levels were similar and not significantly different for all groups $(8-10 \mathrm{mM})$ before the administration of glucose. Glucose levels increased for all groups from the time of injection for 30 minutes showing no significant difference, after which glucose levels decreased for the Chow group. Levels for HF and HF+Vit E stabilized from 30-60 minutes and started to decrease after 60 minutes, whereas glucose levels for HF+ARs and HF+Bran increased until 60 minutes after injection and started to decrease after that. Blood glucose levels were significantly lower for Chow fed mice at 60 minutes than for $\mathrm{HF}+\mathrm{Bran}, \mathrm{HF}$ and HF+ARs. After 120 minutes, glucose levels for mice fed the Chow diet were $10.43 \mathrm{mM}$. Mice fed the HF diet and mice fed the HF diet supplemented with ARs, rye bran, or Vitamin E all showed very similar results for glucose levels at 120 minutes, ranging from 13.5 to $15.56 \mathrm{mM}$. However, only the $\mathrm{HF}+\mathrm{ARs}$ diet showed significantly higher blood glucose levels than Chowafter 120 minutes $(\mathrm{P}<0.05)$. $\mathrm{HF}+\mathrm{Bran}, \mathrm{HF}+\mathrm{Vit} \mathrm{E}$, and $\mathrm{HF}$ were not significantly different from Chow. There is no significant difference between mice consuming a HF diet and those consuming a HF diet supplemented with ARs, rye bran, and Vitamin E from injection of glucose until the end of the intervention (120 minutes). 
At time of death, mice were tested for blood glucose levels. There was no difference in blood glucose levels between treatment and control groups (Figure 3-3).

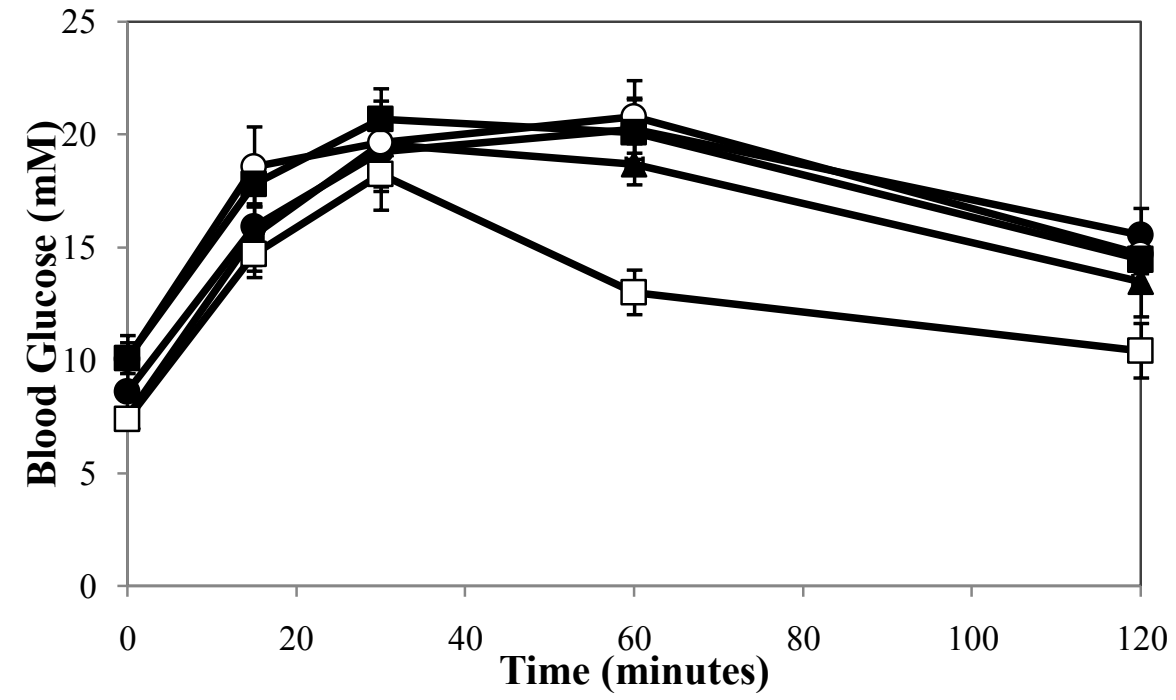

Figure 3-2: Blood glucose levels of control and treatment mice obtained with the intraperitoneal glucose tolerance test after overnight fasting. Values were obtained after 10 weeks of treatment. HF+Vit E ( $\Delta), \mathrm{HF}+\mathrm{ARs}(\bullet), \mathrm{HF}+\mathrm{Bran}(\circ), \mathrm{HF}(\mathbf{\square})$, and Chow ( $\square$ ). Results are expressed as mean values \pm SEM.

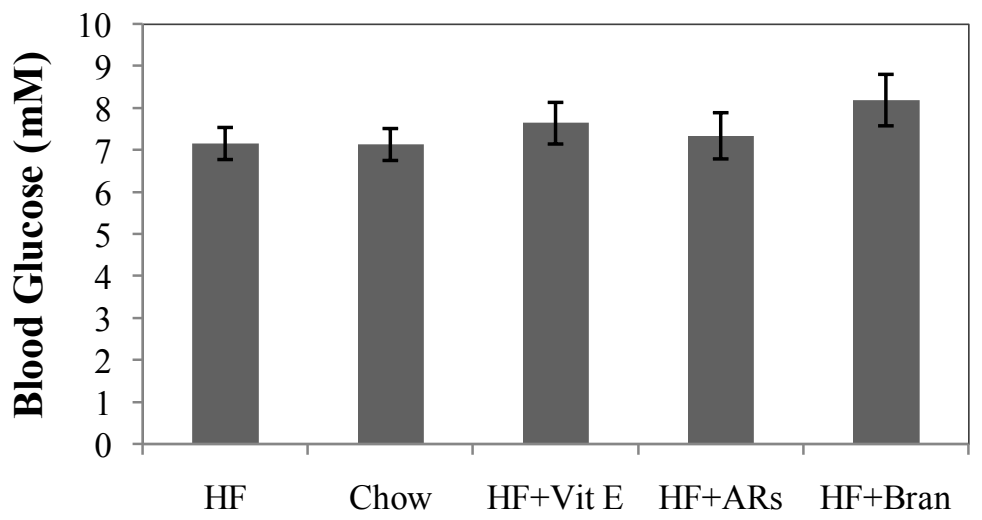

Figure 3-3: Blood glucose levels of control and treatment mice at time of death after overnight fasting. Values were obtained after 11 weeks of treatment. Results are expressed as mean values \pm SEM. 


\subsubsection{Mouse carcass composition of control and treatment mice after a 3-month intervention period}

Mice carcasses were analyzed for $\%$ fat mass, $\%$ lean mass, and $\%$ water. Mice fed the standard Chow diet had significantly less fat (18.02\%) than those fed a HF diet and those that were treated with ARs, rye bran, or Vitamin E (24.83-27.00\%), with $\mathrm{P}<0.01$ (Figure 3-4a). There was no statistical difference between mice fed a HF diet and those fed a HF diet supplemented with ARs, rye bran, and Vitamin E.

Mice fed the Chow diet had the highest \% lean mass $(72.27 \%)$ compared to that of HF and treatment groups (67.26-69.90\%) (Figure 3-4b). Mice fed the Chow diet had significantly higher \% lean mass than $\mathrm{HF}$ and $\mathrm{HF}+\mathrm{Bran}$ fed mice $(\mathrm{P}<0.05)$, but not than $\mathrm{HF}+\mathrm{ARs}$, and $\mathrm{HF}+\mathrm{Vit} \mathrm{E}$. There was no significant difference between the HF group and treatment groups.

There was no significant difference between the five groups and their water content (Figure 3-4c). 
A

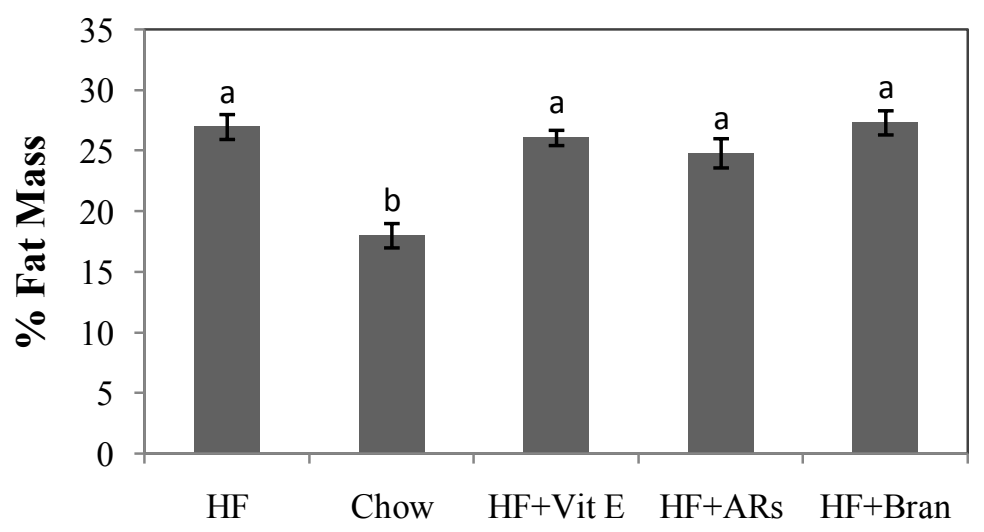

B

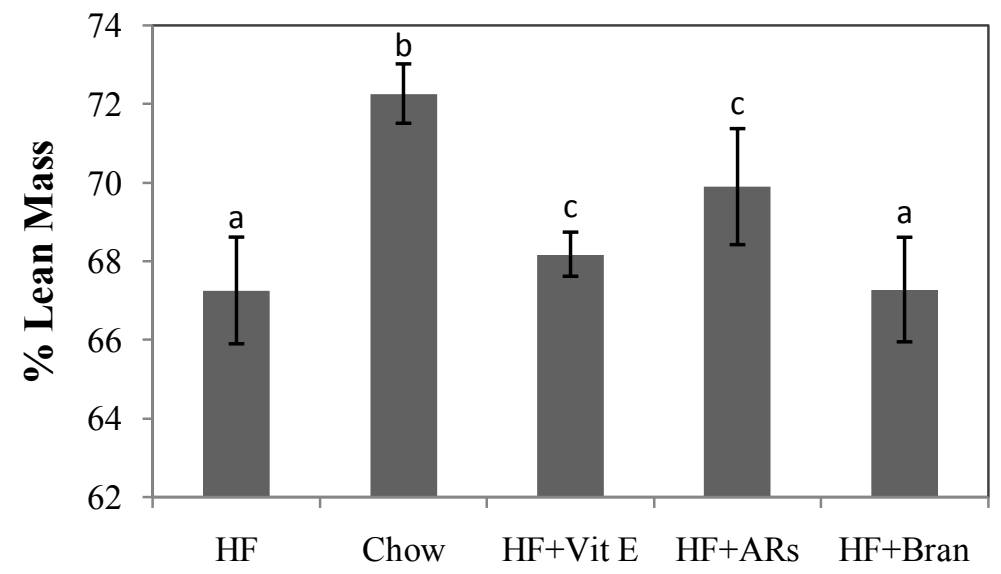

C

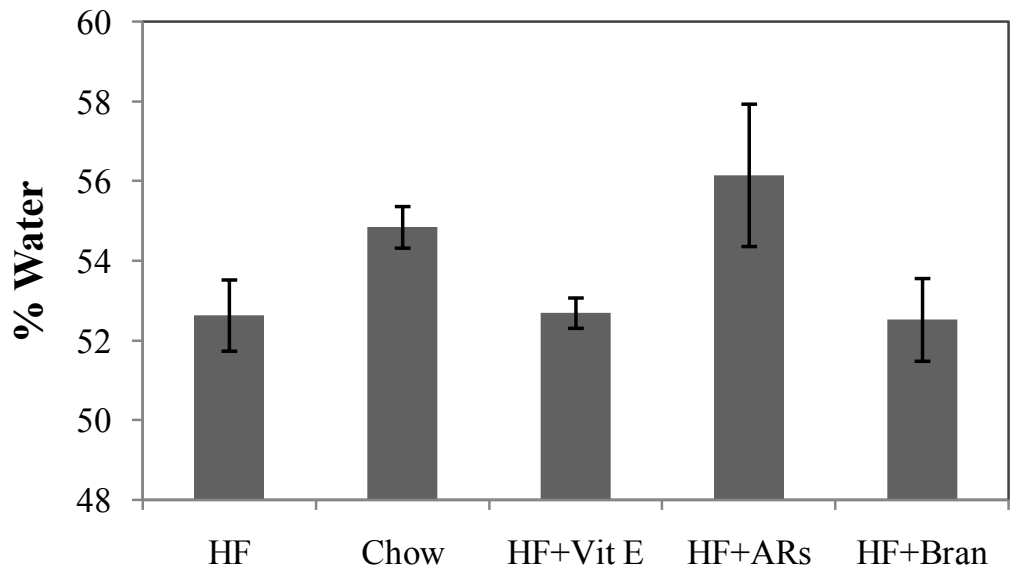

Figure 3-4: Mice carcass composition of control and treatment groups, obtain with the EchoMRI4in $1^{\mathrm{TM}}$ mouse composition analyzer. (A)\% Fat Mass, (B) \% Lean mass $(c=a+b),(C) \%$ Water. Results are expressed as mean values \pm SEM. 


\subsubsection{Antioxidant activity in liver and heart tissue of control and treatment mice}

Antioxidant activities in liver and heart tissues were analyzed using three different

methods. The HF diet was used as the control for all other treatments, and significantly different results from this group indicate a change in antioxidant activity. Figure 3-5a illustrates ORAC results for liver and heart in both control and treatment groups represented as $\mu \mathrm{mol} \mathrm{TE} / \mathrm{mg}$ protein. ORAC values are lowest for mice fed a HF diet in both liver and heart, with 0.31 and $0.33 \mu \mathrm{mol} \mathrm{TE} / \mathrm{mg}$ protein, respectively. In liver tissues, HF+ARs showed the greatest ORAC value $(0.50 \mu \mathrm{mol} \mathrm{TE} / \mathrm{mg}$ protein $)$, which was statistically significant from that of the HF diet $(\mathrm{P}<0.01)$. Mice fed the HF diet did not show a difference in ORAC values to those fed the Chow, HF+Bran, or HF+Vit E diet and were thus not statistically significant. Chow, HF+ARs, HF+Vit E, and HF+Bran exhibit higher ORAC values (0.43-0.50 $\mu \mathrm{mol} \mathrm{TE} / \mathrm{mg}$ protein) in liver tissues than HF but values were not significant. There is no significant difference between any of the groups.

Figure 3-5b illustrated ORAC results for liver and heart tissue represented as $\mu \mathrm{mol} \mathrm{TE} / \mathrm{mg}$ wet weight. ORAC values were lower than those in Figure 3-5a and significant differences were only seen between $\mathrm{HF}$ and $\mathrm{HF}+\mathrm{Vit} \mathrm{E}$ in the heart, where $\mathrm{HF}+\mathrm{Vit} \mathrm{E}$ showed higher ORAC values than $\mathrm{HF}(\mathrm{P}<0.01)$. Generally, ORAC values represented as $\mu \mathrm{mol} \mathrm{TE} / \mathrm{mg}$ wet weight follow those represented as $\mu \mathrm{mol} \mathrm{TE} / \mathrm{mg}$ protein.

As seen in Figure 3-6a, mice that consumed the HF diet showed the lowest SOD activity in liver tissues, with 484 Units SOD/mg protein. SOD activity was highest for HF+ARs with 679.68 Units SOD/mg protein, followed by HF+Bran with 640.59 Units $\mathrm{SOD} / \mathrm{mg}$ protein. The Chow and $\mathrm{HF}+\mathrm{Vit} \mathrm{E}$ diets had similar SOD activity to that of the HF diet. There was no significant difference between the groups. Heart tissue was also 
analyzed for the amount of SOD, however, there was no change in \% inhibition of NADH oxidation between the different concentrations of liver tissue. Hence, SOD values could not be determined.

In both liver and heart tissue samples, the ratio of GSSG/GSH was highest in mice consuming the HF diet alone, with 0.41 and 0.51, respectively (Figure 3-6b). Treatment with ARs reduced the ratio the most, with 0.23 for liver and 0.27 for heart. Diets comprised of Chow, $\mathrm{HF}+\mathrm{Bran}$, and $\mathrm{HF}+\mathrm{Vit} \mathrm{E}$ reduced the ratio of $\mathrm{GSSG} / \mathrm{GSH}$ as well in both liver and heart, similar to HF+ARs. However, neither the Chow nor treatment groups were significantly different from the HF diet. 
A

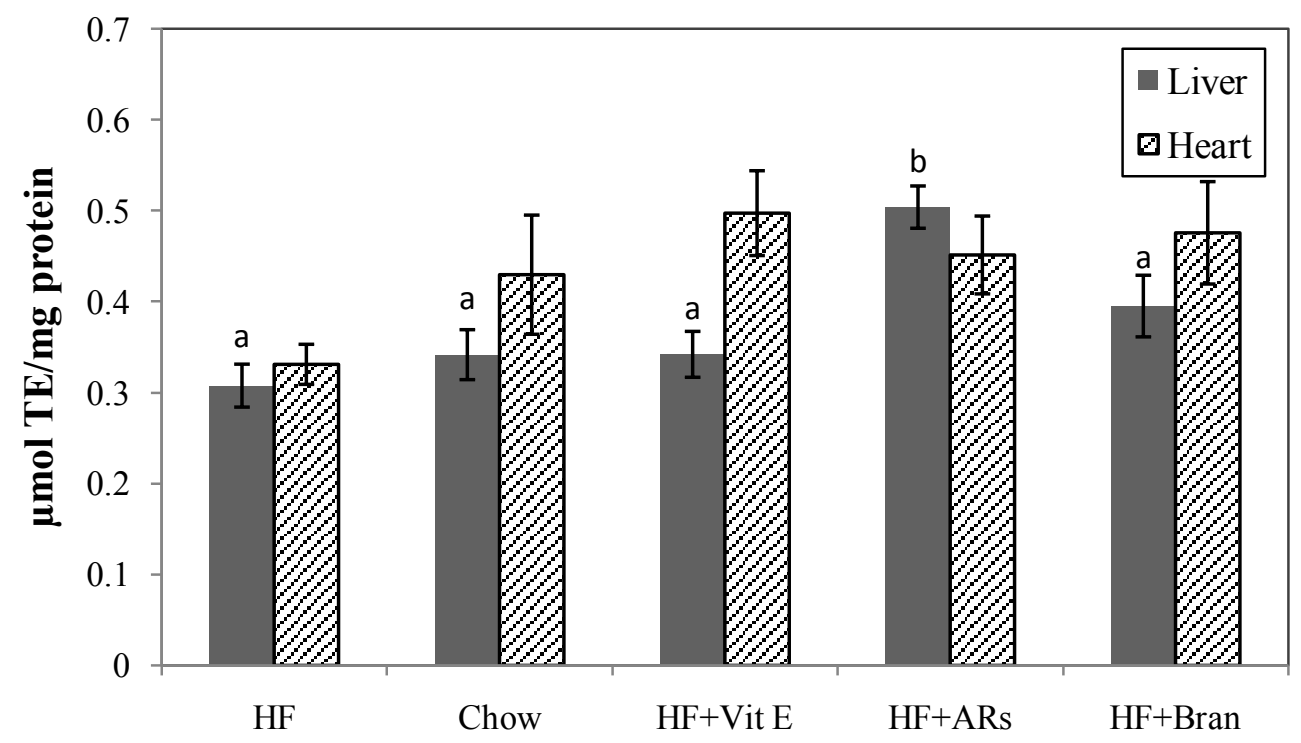

B

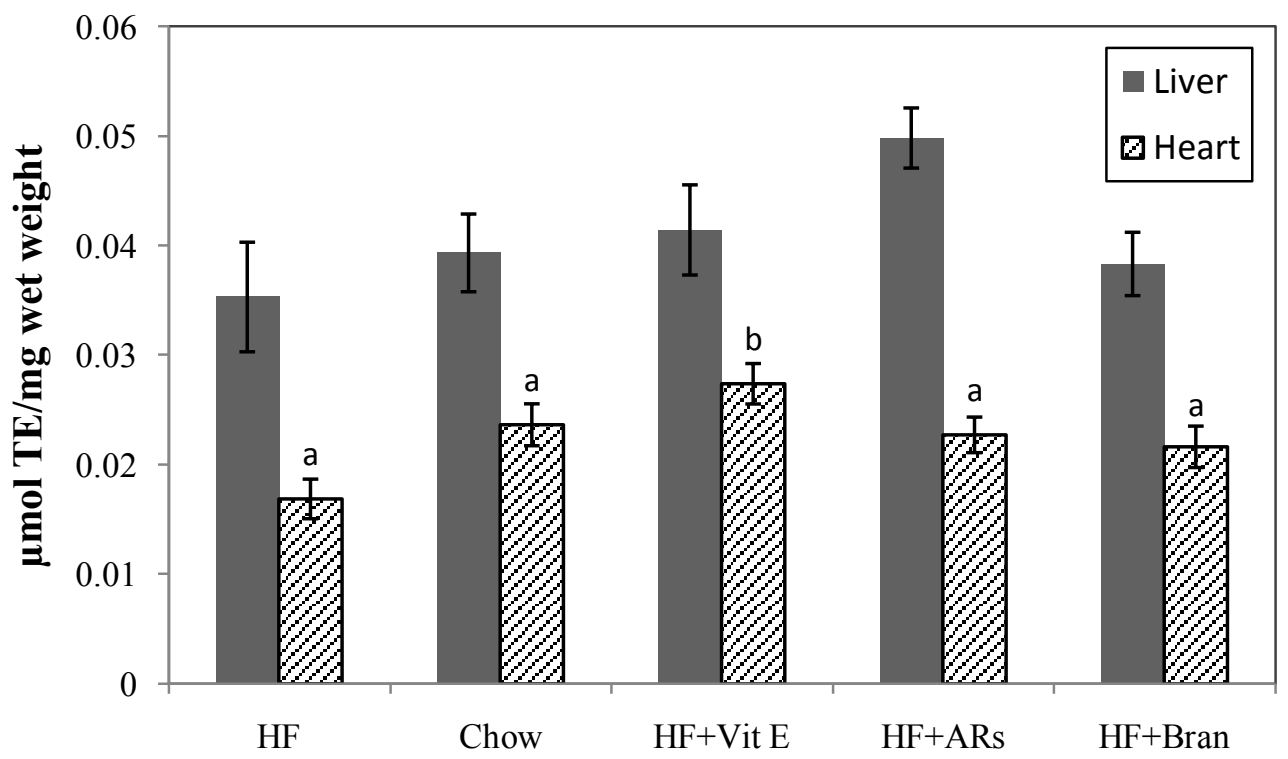

Figure 3-5: Antioxidant activity of liver and heart tissue from control and treatment mice determined by the ORAC assay, expressed as (A) $\mu \mathrm{mol} \mathrm{TE} / \mathrm{mg}$ protein and (B) $\mu$ mol TE/mg wet weight. Results are expressed as mean values \pm SEM. 
A

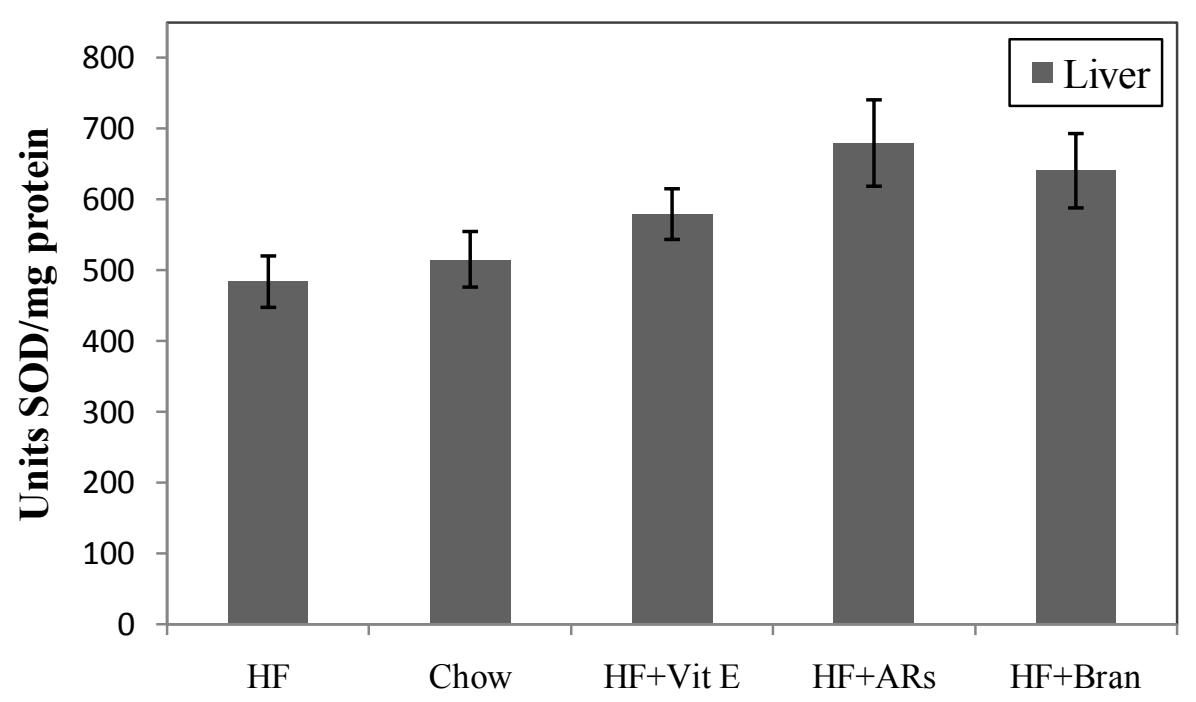

B

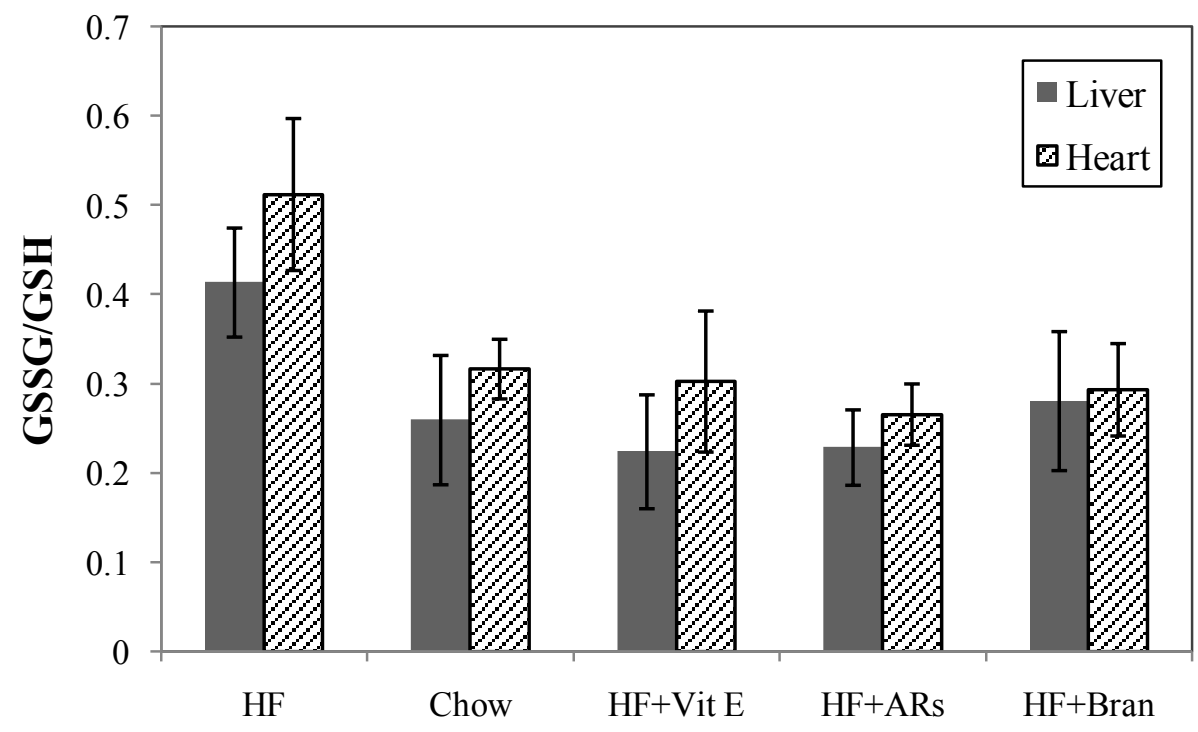

Figure 3-6: Antioxidant activity of liver tissue from control and treatment mice determined by the (A) SOD activity assay (Units SOD/mg protein), and of liver and heart tissue from control and treatment mice determined by $(B)$ the ratio of oxidized to reduced glutathione (GSSG/GSH). Results are expressed as mean values \pm SEM. 


\subsubsection{Glutathione levels in liver and heart tissue of control and treatment mice}

In both liver and heart tissue, mice fed the HF diet had the lowest levels of GSH, with 2264.50 and $554.26 \mu \mathrm{mol} / \mathrm{mg}$ protein, respectively. In the liver, $\mathrm{HF}+\mathrm{Vit} \mathrm{E}$ and HF+ARs showed similar levels of GSH as HF. HF+Bran fed mice had the largest levels of GSH $(4,318 \mu \mathrm{mol} / \mathrm{mg}$ protein), followed by Chow $(3,565 \mu \mathrm{mol} / \mathrm{mg}$ protein). There was no significant difference between any of the groups.

In the heart tissue, HF+ARsfedmice showed the highest levels of GSH, with 1,522 $\mu \mathrm{mol} / \mathrm{mg}$ protein. Chow, $\mathrm{HF}+\mathrm{Bran}$, and $\mathrm{HF}+\mathrm{Vit} \mathrm{E}$ all had similar GSH levels, which were about twice as high as HF. There was no significant difference between any of the groups.

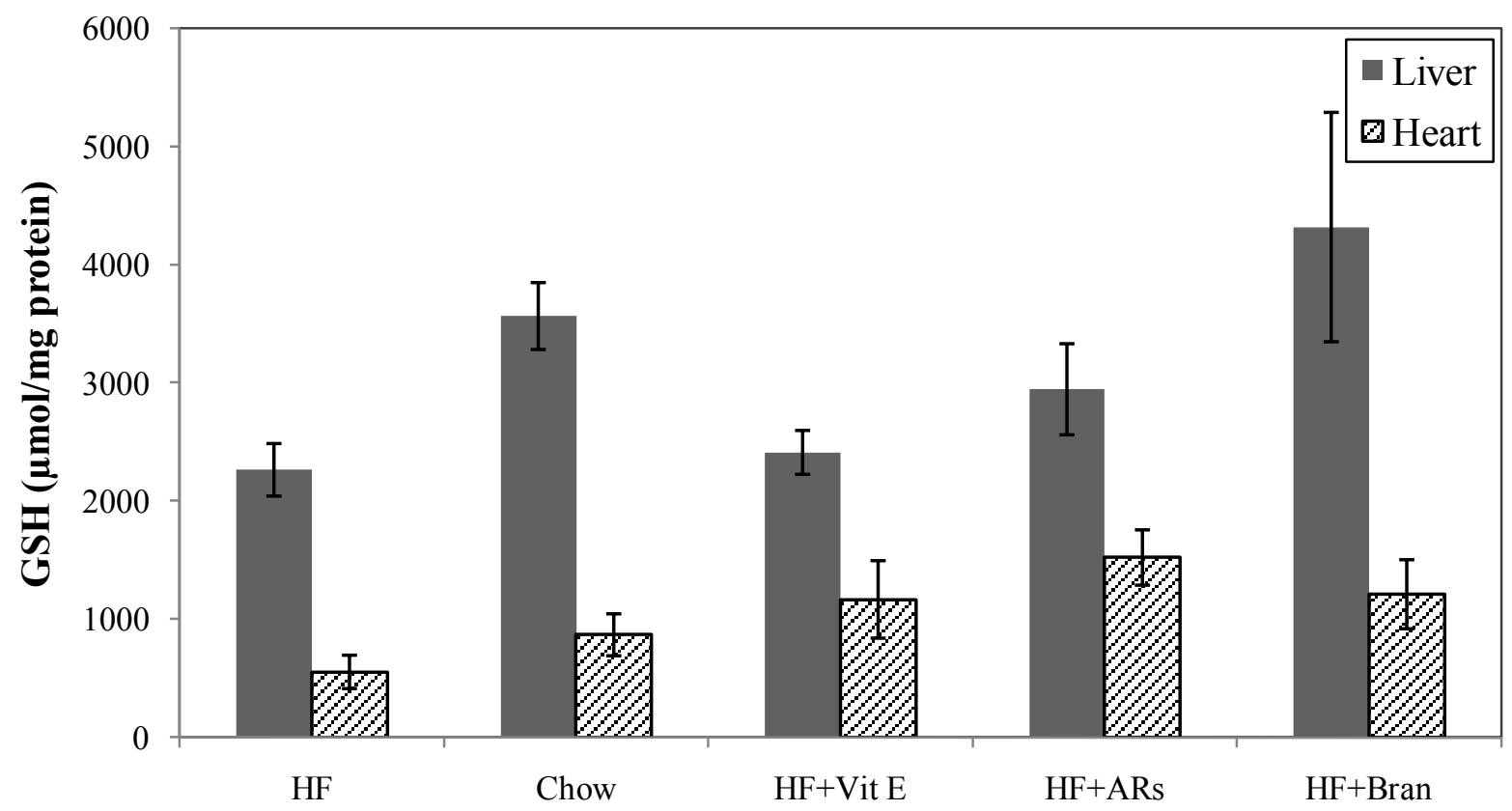

Figure 3-7: Reduced glutathione levels in liver and heart tissue of control and treatment mice. Results are expressed as mean values \pm SEM. 


\subsection{Discussion}

The objective of the first part of this study was to investigate the ability of ARs to reduce excessive weight gain when added to a $60 \%$ HF diet, compared to a HF diet control. Changes would suggest an effect of ARs on obesity-related diseases such as hyperglycemia and diabetes. As expected, mice from all five groups gained weight over the course of the study due to being in a confined space with a lack of exercise, stimulation and interaction with other mice. During the baseline period, all mice gained approximately the same amount of weight and had the same caloric intake. Over the course of the treatment period, mice consuming the Chow diet gained the least amount of weight (Figure 3-1a and b) due to their lower caloric intake through their diet (Figure 31c). It was hypothesized that mice fed the HF diet would gain the most weight and that supplementation with ARs, rye bran,or Vitamin E would reduce weight gain in the HF diet. Results for weight gain and average body weight gain of $\mathrm{HF}, \mathrm{HF}+\mathrm{ARs}, \mathrm{HF}+\mathrm{Bran}$, and $\mathrm{HF}+\mathrm{Vit} \mathrm{E}$ were similar, showing no statistical differences. Treatment with HF, $\mathrm{HF}+\mathrm{ARs}$, and $\mathrm{HF}+\mathrm{Bran}$ diets showed significantly higher body weight and daily weight gain than Chow, whereas $\mathrm{HF}+\mathrm{Vit} \mathrm{E}$ did not. This indicates that Vitamin $\mathrm{E}$ has the potential to reduce weight gain in a high fat diet. Supplementation with ARs and rye bran did not reduce weight gain. A diet rich in whole grains and bran has previously shown to reduce weight gain in humans ${ }^{72}$, hence it was expected that mice fed the $\mathrm{HF}+\mathrm{Bran}$ diet would show similar results to Chow and reduce weight gain in the HF diet. Our results show that mice consuming the HF+Bran diet gained the most weight of all groups (although not significantly different from other treatment groups). As seen in Figure 3-1c, this excessive weight gain was due to a higher caloric intake than the observed in the 
other groups. Mice might have consumed more of their diet because of a better taste due to the addition of bran, which made up $10 \%$ of their diet. These results show that a diet rich in bran alone does not reduce weight gain but that other factors are involved, such as exercise and moderate fat consumption.

Carcass analysis was performed on all groups to determine whether excessive body weight was entirely due to high amounts of fat or possible water retention. As seen in Figure 3-2a, mice consuming the Chow diet had the least amount of fat, which was significantly lower than HF or treatment groups. The body weight of Chow treated mice is mainly composed of lean mass, whereas HF and treatment groups have less lean mass than Chow (Figure 3-2b), meaning that fat contributes more to their overall weight than in Chow fed mice. The amount of total water is highest for the HF+ARs treatment group suggesting that body weight of this treatment group was not due to fat alone, but possibly water retention. The results are not significantly different from the HF diet group to confirm this, but the general trend suggests that this could be the case. Similarly, the total water content of Chow fed diet is higher than that of HF, HF+Bran, and HF+Vit E fed mice, but was not significant to suggest that water retention increased the overall average weight of this group.

At a concentration of $5 \mathrm{~g} \mathrm{ARs} / \mathrm{kg}$ feed there was no significant change in body weight between the HF diet and HF+ARs. ARs were not able to decrease weight gain. The concentration of ARs used is the highest concentration at which intake is safe for mice without having a toxic effect ${ }^{77}$. The current results suggest that a diet consisting of $60 \%$ fat, as was the case with the HF diet, has a detrimental effect on weight gain that cannot be reversed by supplementing the diet with ARs, rye bran, or Vitamin E. For 
future studies, a diet lower in fat should be considered for a more realistic representation of the human diet, that does not consist primarily of fat. Overall, ARs did not show antiobesity activity in mice fed a $60 \% \mathrm{HF}$ diet.

The effect of supplementation of a HF diet with ARs, rye bran, and Vitamin E on hyperglycemia and diabetes was determined using the GTT. The GTT is used to determine if individuals have normal or impaired glucose tolerance, where impaired glucose tolerance is generally associated with hyperglycemia and diabetes ${ }^{78}$. As seen in Figure 3-3, ARs, rye bran, and Vitamin E showed a similar trend of glucose clearance to the HF diet that indicates poor glucose clearing ability. Mice fed the Chow diet were able to clear glucose more effectively from the blood after 30 minutes of injection. The results agree with literature, where mice fed a standard diet start clearing glucose after 30 minutes, whereas a high fat diet treatment results in delayed glucose clearance that starts around 60 minutes $^{79}$, indicating impaired glucose tolerance. Supplementation of Vitamin E shows potential in reducing the risks of a HF diet on hyperglycemia and diabetes because it brought glucose levels closer to those of the Chow diet. Although there was no significant difference between Chow and $\mathrm{HF}+\mathrm{Vit} \mathrm{E}$ after 120 minutes, there also was also no significant difference between $\mathrm{HF}$ and $\mathrm{HF}+\mathrm{Vit} \mathrm{E}$. A higher dose of Vitamin $\mathrm{E}$ in the diet might increase its health benefits on obesity related diseases. Supplementation of a HF diet with ARs was not able to normalize glucose tolerance in mice and thus shows that ARs cannot protect against hyperglycemia or diabetes, as has previously been suggested $^{25}$. Additionally, the results obtained with Vitamin E as a supplement indicate that the effect of a diet consisting mostly of fat on obesity and obesity related diseases cannot be canceled out by supplementation with an antioxidant. 
Similarly, blood glucose levels at time of death showed no significant difference among the control and treatment groups (Figure 3-4), but fall within the normal range ${ }^{78}$.

Findings from body weight, carcass analysis, GTT, and blood glucose at time of death did not indicate that ARs could be potential anti-obesity agents, nor are they able to reduce obesity related diseases when added to a $60 \% \mathrm{HF}$ diet. Lower fat diets should be considered for future studies for a more representative model.

In the second part of this study, the main objective was to determine antioxidant activity in liver and heart tissue of mice, when treated with ARs from Hazlet rye bran in a $60 \% \mathrm{HF}$ diet compared to a control of $60 \% \mathrm{HF}$ diet alone. Additionally, groups of mice consuming either a standard diet (Chow), 60\% HF diet supplemented with rye bran or Vitamin E were considered in this study. Antioxidant activities in liver and heart were determined using the ORAC, SOD, and glutathione assays.

In liver and heart tissues, mice from the HF control group showed lowest antioxidant activity of all groups (low ORAC and SOD, and high GSSG/GSH). These results were expected because a high fat diet induces oxidative stress ${ }^{80}$. It was expected that mice fed the Chow diet would not have shown signs of oxidative stress, due to the makeup of the diet that includes proteins, fiber, vitamins, amino acids, fatty acids, and minerals and was designed to promote health. Supplementation of the HF diet with ARs, rye bran, or Vitamin E was expected increase antioxidant activity and cancel out the effects of the HF diet on oxidative stress, to show results similar to those for Chow. In the three tests performed, Chow did not show significantly higher antioxidant activity than $\mathrm{HF}$, indicating that the HF diet might not have increased oxidative stress as expected or that oxidative stress was high in mice fed the Chow diet. Generally, treatment with ARs, 
rye bran, or Vitamin E seemed to have increased antioxidant activity in liver and heart tissue more than the Chow diet, although not significantly. ARs did show significantly higher antioxidant activity in the liver using the ORAC assay, but not with SOD or levels of glutathione in heart tissue. HF+Bran and $\mathrm{HF}+\mathrm{Vit} \mathrm{E}$ did not show significantly higher antioxidant activity using any of the three assays as well. The ORAC assay is a measure of total antioxidant activity. Uric acid, ascorbic acid, $\alpha$-tocopherol, $\beta$-carotene, bilirubin, and glutathione contribute most to ORAC values in plasma ${ }^{81}$, but any compound that scavenges the free radicals generated by AAPH contributes as well. It was therefore expected that the ratio of GSSG/GSH would be decreased and GSH levels would increase in the liver when treated with ARs. Although the ratio of GSSG/GSH was in fact lowest for HF+ARs in the liver, results were not significantly different from HF. Also, levels of GSH in the liver were not affected by ARs and were similar to those of HF. This suggests that glutathione might only contribute to a lesser extent the ORAC values and that uric acid, ascorbic acid and tocopherol might play a bigger role. Nevertheless, ORAC results represented as $\mu \mathrm{mol} \mathrm{TE} / \mathrm{mg}$ wet weight (Figure $3-5 \mathrm{~b}$ ) follow the same trend as those represented as $\mu \mathrm{mol} \mathrm{TE} / \mathrm{mg}$ protein (Figure 3-5a), indicating that other proteins in the tissues, such as SOD, contributed largely to antioxidant activity.

Even though the results for ORAC, SOD and glutathione assay did not show significant differences between the groups, a general trend was observed that suggested that ARs, and sometimes rye bran and Vitamin E, have the potential to reduce oxidative stress.

ARs seem to increase antioxidant activityto the highest extend in the liver over a HF diet alone (Figure 3-5a and Figure 3-6a,b), whereas supplementation with rye bran or 
Vitamin E showed lower GSSG/GSH levels than HF but similar ORAC (Figure 3-5a) and SOD (Figure 3-6a) activity values. In the heart, supplementation of HF with rye bran or Vitamin E showed similar high antioxidant activities than with supplementation with ARs (Figure 3-5a and Figure 3-6b).

Rye bran contains many phenolic compounds in addition to fiber, vitamins and minerals ${ }^{82}$. Phenolics and vitamins generally show high antioxidant activity, due to radical scavenging activity, and it was therefore expected that supplementation of the HF diet with bran would show increased levels of antioxidant activity. An increase in antioxidant activity in the heart tissue would suggest a protective effect against cardiovascular disease. Bran is said to have a protective effect against cardiovascular disease $^{83}$, however, our study illustrates that an intake of bran cannot cancel out the harmful effects to the heart of a HF diet, when consumed daily. Similarly, Vitamin E, which is a potent radical scavenger, was expected to increase antioxidant activity and reduce oxidative stress induced by a HF diet, which only occurred in the heart tissue, although results were not significant.

As seen in Figure 3-6a, ARs were able to increase SOD activity when compared to the HF diet alone, although not significantly. Increased activity was most likely due to an increase in SOD protein. It is possible that ARs could increase endogenous SOD, and thus antioxidant activity, by either inducing the transcription factor $\mathrm{Nrf} 2$, which is responsible for the upregulation of $\mathrm{SOD}$, or a kinase responsible for its activation. Transcription factors, such as NF- $\mathrm{B}, \mathrm{Sp} 1, \mathrm{AP}-1$ and AP-2, which are responsible for gene expression of all three SOD genes, could be the target of ARs as well. Additionally, ARs could also affect SOD expression at the posttranscriptional level, by interfering with 
translation or posttranscriptional modifications due to the interaction with proteins. Translation of proteins occurs in the cytoplasm, whereas transcription occurs in the nucleus of cells. ARs might be able to affect enzymes in the nuclear membrane, involved in the transfer of mRNA and thus alter SOD expression.

Units of SOD/mg protein could not be determined for heart tissue. Even at high concentrations tested, heart tissues were not able to inhibit NADH oxidation caused by ROS and no change in inhibition from the blank was observed. Hence, a standard curve of $\%$ inhibition of oxidation could not be obtained, to calculate the amount of SOD activity. The levels of SOD were overall highest in the liver, due to its high metabolic activity and role as a detoxification organ. Heart has been shown to have about a tenth of extracellular SOD than that of liver ${ }^{84}$. The low amount of SOD in heart tissue is a possible reason for the inability to determine $\%$ inhibition of NADH oxidation and thus SOD activity. It is possible that a straight tissue homogenate would reduce inhibition of oxidation, in order to see a difference from the blank.

In the liver, ARs were able to decrease the ratio of GSSG/GSH (Figure 3-6b), although not significantly. A decrease in this ratio indicates increased radical scavenging activity, that would otherwise oxidize GSH to form GSSG at a higher rate, or an increased amount of GSH compared to that of GSSG. ARs most likely decreased the ratio of GSSG/GSH through radical scavenging and not by increasing the amount of GSH. As seen in Figure 3-7, endogenous levels of GSH were similar to those in mice fed the HF diet, indicating that ARs did not increase antioxidant activity in the liver by increasing synthesis of GSH. 
The higher antioxidant activity of HF+ARs over HF in the heart tissue (Figure 36b) was most likely due to an increase in the endogenous antioxidant GSH (Figure 3-7). ARs might have increased levels of GSH by regulating ARE, and thus GSH synthesis. This enhancer sequence is responsible for the regulation of transcription of a number of antioxidant genes, such as $\gamma$-glutamyl-cysteine ligase (GCL) and GSH synthase. These enzymes are responsible for the synthesis of GSH and ultimately increased antioxidant activity. ARs might also be able to regulate the binding of Nrf2 to ARE, by interacting with Nrf2 proteins, and thus increase antioxidant gene expression and synthesis of GSH.

Levels of GSSG/GSH ranged from 0.25 to just above 0.5 for all groups. A healthy ratio of these proteins is greater than $1: 100^{46}$, thus indicating that oxidative stress occurred in all mice, possibly due to the lack of exercise and variety in food. However, supplementation of a HF diet with ARs still showed a decrease in this ratio, indicating that ARs could potentially still reduce oxidative stress for increased health.

Overall, it appears that the antioxidant activity of ARs in tissues is mainly due to its ability to increase levels of endogenous antioxidants GSH and SOD and not due to radical scavenging activity. This activity seems to be predominant in the liver, where levels of SOD and GSH are higher than the heart. Additionally, ARs have previously shown to increase endogenous $\gamma$-tocopherol levels ${ }^{26}$, which would further increase overall antioxidant activity. The results also suggest that supplementation with rye bran and Vitamin E would have a positive effect on the heart but not necessarily the liver. This effect might be primarily due to radical scavenging activity, rather than the stimulation of SOD and GSH. 


\subsection{Conclusion}

The results of this study show that supplementation of a high fat diet with ARs from Hazlet rye bran, as well as rye bran itself or Vitamin E could not reduce weight gain over a 3-month period, when compared to a diet of high fat alone. Similarly, supplementation also did not reduce the risk of obesity related disease, such as hyperglycemia and diabetes.

Our antioxidant studies in vivo have shown that ARs have significantly higher antioxidant activity in the liver compared to a HF diet treatment. However, other assays revealed that ARs increase SOD activity and decrease the ratio of GSSG/GSH but not significantly over a high fat diet. The results suggest that ARs have a potential in protecting against oxidative stress but not at the low concentrations tested. In humans, who can tolerate higher doses of ARs, supplementation with ARs at high concentrations could potentially reduce oxidative stress as an effect of a high fat diet, but only when the fat content of such diets is lower than $60 \%$. 


\section{Chapter 4- Conclusion and Future Directions}

Alkylresorcinols have been studied widely for their roles as biomarkers and antioxidant activity. In vitro studies are plentiful $1^{2,36-38,42}$, attributing ARs low antioxidant activity compared to antioxidants such as tocopherol and ferulic acid ${ }^{38}$. ARs incorporate into membranes, which provides most of their bioactivity and are said to contribute to high antioxidant activity in vivo ${ }^{39,40,42}$, although these studies have not been performed. Our study was novel in that it determined both the in vitro anti-inflammatory and in vivo antioxidant activities of ARs from Hazlet rye bran.

Both oxidative stress and inflammation are caused by the release of excessive amounts of ROS. Proper signaling and transcription processes are altered during oxidative stress $^{62}$. Antioxidants, such as phenolic compounds, have previously shown to suppress upstream signaling systems and downstream transcription factors which regulate inflammatory processes ${ }^{65}$. Inflammatory mediators such as iNOS and COX-2 play a crucial role in inflammation and the inhibition of their gene expression is the target of non-steroidal anti-inflammatory drugs.

In this study, ARs extracted from Hazlet rye bran exhibited higher antioxidant activity over those found in wheat and oat bran in vitro. In this study, ARs were shown to have anti-inflammatory activity by reducing inflammation-induced NO accumulation in LPS stimulated RAW 264.7 macrophages. The inhibition of NO accumulation was most like due to the down-regulation of the inflammatory enzyme iNOS. ARs were also able to inhibit the expression of COX-2 protein and mRNA, further illustrating their antiinflammatory activities. 
Our in vivo antioxidant studies have shown that oxidative stress, caused by a HF diet, is significantly reduced by rye bran ARs. ARs also exhibited reduced oxidative stress in the heart, although these changes were not significant. Increased antioxidant activity is most likely due to an increase in endogenous antioxidants, such as SOD and GSH. These antioxidants regulate the cellular redox system, and contribute to a reduction in inflammation by regulating signaling and transcription factors responsible for inflammation.

The results indicate that ARs are potent antioxidant and anti-inflammatory agents, not due to their radical scavenging activity, but possibly from their ability to increase endogenous levels of antioxidants. However, an increase in SOD and GSH might not be the only mechanism by which ARs reduce inflammation.

To obtain a better understanding of the mechanism of the anti-inflammatory activity of ARs, they should be analyzed in terms of their ability to inhibit cytokines, such as TNF- $\alpha$, IL-6, and IL-1ß. Additionally, it would be of interest to determine at what level inhibition of iNOS and COX-2 occurs. Therefore, it should be determined whether

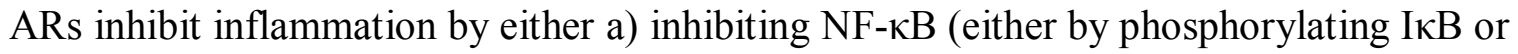
by inhibiting its translocation into the nucleus), b) increasing the binding ofNrf2 to the ARE (through the activation of Nrf2), c) by regulating kinases involved in the activation of transcription factors, or d) by influencing other proteins involved in inflammation, such as membrane proteins.

It should also be determined whether ARs increase detectable SOD activity by increasing SOD protein or if they affect other non-protein factors, present in the tissues, that contribute to detectable SOD activity. The mechanism by which ARs increase 
endogenous levels of glutathione should be determined as well. This includes the regulation of glutathione synthesis enzymes, as well as the regulation of cysteine availability. For both SOD activity and glutathione levels, possible activation and regulation of transcription factors NF- $\mathrm{kB}$ and Nrf2 by ARs should also be determined.

Lastly, this study should be carried out with a lower fat diet, to represent a normal adult diet. It would be interesting to see the effects of rye bran ARs on antioxidant activity in mice placed on minimal HF diets to determine whether there is a point at which the amount of fat taken in with the diet negates any beneficial effects that dietary antioxidants could have on weight gain and caloric intake. These studies would provide evidence of the efficacy of antioxidant supplementation on North American diets that are currently high in fat leading to the high levels of obesity found within the population today. 


\section{References}

1. Kozubek, A. \& Tyman, J. H. P. Resorcinolic lipids, the natural non-isoprenoid phenolic amphiphiles and their biological activity. Chem. Rev.99, 1-26 (1999).

2. Korycińska, M., Czelna, K., Jaromin, A. \& Kozubek, A. Antioxidant activity of rye bran alkylresorcinols and extracts from whole-grain cereal products. Food Chem.116, 1013-1018 (2009).

3. Ross, A. B., Kamal-Eldin, A., Jung, C., Shepherd, M. J. \& Åman, P. Gas chromatographic analysis of alkylresorcinols in rye (Secale cereale L) grains. $J$. Sci. Food Agr.81, 1405-1411 (2001).

4. Ross, A. B. et al. Alkylresorcinols in cereals and cereal products. J. Agric. Food Chem.51, 4111-4118 (2003).

5. Kulawinek, M., Jaromin, A., Kozubek, A. \& Zarnowski, R. Alkylresorcinols in selected Polish rye and wheat cereals and whole-grain cereal products. J. Agric. Food Chem.56, 7236-7242 (2008).

6. Andersson, A. A. M., Åman, P., Wandel, M. \& Frølich, W. Alkylresorcinols in wheat and rye flour and bread. J. Food Comp. Anal.23, 794-801 (2010).

7. Landberg, R., Kamal-Eldin, A., Salmenkallio-Marttila, M., Rouau, X. \& Åman, P. Localization of alkylresorcinols in wheat, rye and barley kernels. J. Cereal Sci.48, 401-406 (2008).

8. Landberg, R., Kamal-Eldin, A., Andersson, R. \& Åman, P. Alkylresorcinol content and homologue composition in durum wheat (Triticum durum) kernels and pasta products. J. Agric. Food Chem.54, 3012-3014 (2006). 
9. Bondia-Pons, I. et al. Rye phenolics in nutrition and health. J. Cereal Sci.49, 323$336(2009)$.

10. Ross, A. B. et al. Absorption of dietary alkylresorcinols in ileal-cannulated pigs and rats. Br. J. Nutr.90, 787-794 (2003).

11. Ross, A. B., Åman, P., Andersson, R. \& Kamal-Eldin, A. Chromatographic analysis of alkylresorcinols and their metabolites. J. Chromatogr. A1054, 157-164 (2004).

12. Seitz, L. M. Identification of 5-(2-oxoalkyl)resorcinols and 5-(2oxoalkenyl)resorcinols in wheat and rye grains. J. Agic. Food Chem.40, 1541$1546(1992)$.

13. McLeod, J. G. \& Gan, Y. Hazlet winter rye. Can. J. Plant Sci.88, 1-3 (2008).

14. Yu, D., Xu, F., Zeng, J. \& Zhan, J. Type III polyketide synthases in natural product biosynthesis. IUBMB life64, 285-295 (2012).

15. Funa, N., Ozawa, H., Hirata, A. \& Horinouchi, S. Phenolic lipid synthesis by type III polyketide synthases is essential for cyst formation in Azotobacter vinelandii. Proc. Natl. Acad. Sci. USA103, 6356-6361 (2006).

16. Suzuki, Y., Kurano, M., Esumi, Y., Yamaguchi, I. \& Doi, Y. Biosynthesis of 5alkylresorcinol in rice: incorporation of a putative fatty acid unit in the 5alkylresorcinol carbon chain. Bioorg. Chem.31, 437-452 (2003).

17. Baerson, S. R. et al. Alkylresorcinol biosynthesis in plants: new insights from an ancient enzyme family? Plant Signal. Behav.5, 1-4 (2010). 
18. Zarnowski, R., Kozubek, A. \& Pietr, S. J. Effect of rye 5-n-alkylresorcinols on in vitro growth of phytopathogenic fusarium and rhizoctonia fungi. B. Pol. Acad. SciBiol47, 231-235 (1999).

19. Reiss, J. Influence of alkylresorcinols from rye and related compounds on the growth of food-borne molds. Cereal Chem.66, 491-493 (1989).

20. Ross, A. B., Becker, W., Chen, Y., Kamal-Eldin, A. \& Åman, P. Intake of alkylresorcinols from wheat and rye in the United Kingdom and Sweden. Br. $J$. Nutr.94, 496-499 (2005).

21. Ross, A. B. et al. Cereal alkylrsorcinols are absorbed by humans. J. Nutr.133, $2222-2224(2003)$.

22. Ross, A. B., Åman, P. \& Kamal-Eldin, A. Identification of cereal alkylresorcinol metabolites in human urine - potential biomarkers of wholegrain wheat and rye intake. J. Chromatogr. B Analyt. Technol. Biomed. Life Sci.809, 125-130 (2004).

23. Marklund, M., Landberg, R., Andersson, R., Åman, P. \& Kamal-Eldin, A. Alkylresorcinol metabolism in swedish adults is affected by factors other than intake of whole-grain wheat and rye. J. Nutr.142, 1479-1486 (2012).

24. Koskela, A., Samaletdin, A., Aubertin-Leheudre, M. \& Adlercreutz, H. Quantification of alkylresorcinol metabolites in plasma by high-performance liquid chromatography with coulometric electrode array detection. J. Agric. Food Chem.56, 7678-7681 (2008).

25. Andersson, U., Dey, E. S., Holm, C. \& Degerman, E. Rye bran alkylresorcinols suppress adipocyte lipolysis and hormone-sensitive lipase activity. Mol. Nutr. Food Res.55 Suppl 2, S290-293 (2011). 
26. Ross, A. B. et al. Cereal alkylresorcinols elevate $\gamma$-tocopherol levels in rats and inhibit $\gamma$-tocopherol metabolism in vitro. J. Nutr.134, 506-510 (2004).

27. Rejman, J. \& Kozubek, A. Inhibitory effect of natural phenolic lipids upon NADdependent dehydrogenases and on triglyceride accumulation in 3T3-L1 cells in culture. J. Agric. Food Chem.52, 246-250 (2004).

28. Zhu, Y., Conklin, D. R., Chen, H., Wang, L. \& Sang, S. 5-Alk(en)ylresorcinols as the major active components in wheat bran inhibit human colon cancer cell growth. Bioorg. Med. Chem.19, 3973-3982 (2011).

29. Sang, S. et al. Wheat bran oil and its fractions inhibit human colon cancer cell growth and intestinal tumorigenesis in Apc(min/+) mice. J. Agric. Food Chem.54, 9792-9797 (2006).

30. Liu, L., Winter, K. M., Stevenson, L., Morris, C. \& Leach, D. N. Wheat bran lipophilic compounds with in vitro anticancer effects. Food Chem.130, 156-164 (2012).

31. Bylund, A. et al. Rye bran and soy protein delay growth and increase apoptosis of human LNCaP prostate adenocarcinoma in nude mice. Prostate42, 304-314 (2000).

32. Lobo, V., Patil, A., Phatak, A. \& Chandra, N. Free radicals, antioxidants and functional foods: Impact on human health. Pharmacogn. Rev.4, 118-126 (2010).

33. Lee, J., Koo, N. \& Min, D. B. Reactive oxygen specie, aging, and antioxidative nutraceuticals. Comp. Rev. Food Sci. F.3, 21-33 (2004).

34. Barja, G. Free radicals and aging. Trends iNeurosci.27, 595-600 (2004). 
35. Halliwell, B. Free radicals and antioxidants - quo vadis? Trends Pharmacol. Sci.32, 125-130 (2011).

36. Winata, A. \& Lorenz, K. Antioxidant potential of 5-n-pentadecylresorciniol. $J$. Food Process. Pres. 20, 417-429 (1996).

37. Parikka, K., Rowland, I. R., Welch, R. W. \& Wähälä, K. In vitro antioxidant activity and antigenotoxicity of 5-n-alkylresrocinols. J. Agric. Food Chem.54, $1646-1650$ (2006).

38. Kamal-Eldin, A., Pouru, A., Eliasson, C. \& Åman, P. Alkylresorcinols as antioxidants : hydrogen donation and peroxyl radical-scavenging effects. J. Sci. Food Agr.81, 353-356 (2001).

39. Kozubek, A. The effect of 5-(n-alk(en)yl)resorcinols on membranes. I. Characterization of the permeability increase induced by 5 -(nheptadecenyl)resorcinol. Acta Biochim. Pol.34, 357-367 (1987).

40. Linko, A.-M. \& Adlercreutz, H. Whole-grain rye and wheat alkylresorcinols are incorporated into human erythrocyte membranes. Br. J. Nutr.93, 11-13 (2005).

41. Kozubek, A. \& Demel, R. A. The effect of 5-(n-alk(en)yl) resorcinols from rye on membrane structure. Biochim. Biophys. Acta.642, 242-251 (1981).

42. Kozubek, A. \& Nienartowicz, B. Cereal grain resorcinolic lipids inhibit H2O2induced peroxidation of biological membranes. Acta Biochim. Pol.42, 309-316 (1995).

43. Huang, D., Ou, B., Hampsch-Woodill, M., Flanagan, J. A. \& Prior, R. L. Highthroughput assay of oxygen radical absorbance capacity (ORAC) using a 
multichannel liquid handling system coupled with a microplate fluorescence reader in 96-well format. J. Agric. Food Chem.50, 4437-4444 (2002).

44. Jayaprakasha, G. K., Singh, R. P. \& Sakariah, K. K. Antioxidant activity of grape seed (Vitis vinifera) extracts on peroxidation models in vitro. Food Chem.73, 285290 (2001).

45. Monostori, P., Wittmann, G., Karg, E. \& Túri, S. Determination of glutathione and glutathione disulfide in biological samples: an in-depth review. J. Chromatogr. B Analyt. Technol. Biomed. Life Sci.877, 3331-3346 (2009).

46. Griffith, O. W. Biologic and pharmacologic regulation of mammalian glutathione synthesis. Free Radic. Biol. Med.27, 922-935 (1999).

47. Tietze, F. Enzymic method for quantitative determination of nanogram amounts of total and oxidized glutathione: applications to mammalian blood and other tissue. Anal. Biochem.27, 502-522 (1969).

48. Paoletti, F., Aldinucci, D., Mocali, A. \& Caparrini, A. A sensitive spectrophotometric method for the determination of superoxide dismutase activity in tissue extracts. Anal. Biochem.154, 536-541 (1986).

49. Huo, M. et al. Anti-inflammatory effects of linalool in RAW 264.7 macrophages and lipopolysaccharide-induced lung injury model. J. Surg. Res.180, E47-E54 (2013).

50. Coussens, L. M. \& Werb, Z. Inflammation and cancer. Nature420, 860-867 (2002). 
51. Southerland, J. H., Talor, G. W., Moss, K., Beck, J. D. \& Offenbacher, S. Commonality in chronic inflammatory diseases: periodontitis, diabetes, and coronary artery disease. Periodontol. 200040, 130-143 (2006).

52. Heo, S. et al. Evaluation of anti-inflammatory effect of fucoxanthin isolated from brown algae in lipopolysaccharide-stimulated RAW 264.7 macrophages. Food Chem. Toxicol.48, 2045-2051 (2010).

53. Won, J.-H. et al. Anti-inflammatory effect of buddlejasaponin IV through the inhibition of iNOS and COX-2 expression in RAW 264.7 macrophages via the NF-kappaB inactivation. Br. J. Pharmacol.148, 216-225 (2006).

54. Abramson, S. B., Attur, M., Amin, A. R. \& Clancy, R. Nitric oxide and inflammatory mediators in the perpetuation of osteoarthritis. Curr. Rheumatol. Rep.3, 535-541 (2001).

55. Torres, S. H., Sanctis, J. B. De, Briceño, M. D. L., Hernández, N. \& J, F. H. Inflammation and nitric oxide production in skeletal muscle of type 2 diabetic patients. J. Endocrinol.181, 419-427 (2004).

56. Tripathi, P., Tripathi, P., Kashyap, L. \& Singh, V. The role of nitric oxide in inflammatory reactions. FEMS iImmunol. Med. Microbiol.51, 443-452 (2007).

57. Zamora, R., Vodovotz, Y. \& Billiar, T. R. Inducible nitric oxide synthase and inflammatory diseases. Mol. Med.6, 347-373 (2000).

58. Blobaum, A. L. \& Marnett, L. J. Structural and functional basis of cyclooxygenase inhibition. L. Med. Chem.50, 1425-1441 (2007).

59. Ricciotti, E. \& FitzGerald, G. A. Prostaglandins and inflammation. Arterioscler. Thromb. Vasc. Biol.31, 986-1000 (2011). 
60. Raschke, W. C., Baird, S., Ralph, P. \& Nakoinz, I. Functional macrophage cell lines transformed by Abelson leukemia virus. Cell15, 261-267 (1978).

61. Ji, G. et al. Genistein suppresses LPS-induced inflammatory response through

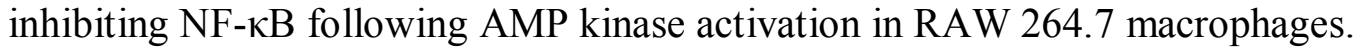
PloS One7, e53101 (2012).

62. Kamata, H. \& Hirata, H. Redox regulation of cellular signalling. Cell. Signal.11, $1-14$ (1999).

63. Pashkow, F. J. Oxidative stress and inflammation in heart disease: Do antioxidants have a role in treatment and/or prevention? Int. J. Inflam.2011, 1-9 (2011).

64. Adcock, I. M. \& Caramori, G. Cross-talk between pro-inflammatory transcription factors and glucocorticoids. Immunol. Cell Biol.79, 376-384 (2001).

65. Ma, Q., Kinneer, K., Ye, J. \& Chen, B. J. Inhibition of nuclear factor $\kappa$ B by phenolic antioxidants: interplay between antioxidant signaling and inflammatory cytokine expression. Mol. Pharmacol.64, 211-219 (2003).

66. Surh, Y., Kundu, J. K., Na, H. \& Lee, J. Redox-sensitive transcription factors as prime targets for chemoprevention with anti-inflammatory and antioxidative phytochemicals. J. Nutr.135, 2993S-3001S (2005).

67. Reuter, S., Gupta, S. C., Chaturvedi, M. M. \& Aggarwal, B. B. Oxidative stress, inflammation, and cancer: how are they linked? Free Radic. Biol. Med.49, 16031616 (2010).

68. Gliwa, J., Gunenc, A., Ames, N., Willmore, W. G. \& Hosseinian, F. S. Antioxidant activity of alkylresorcinols from rye bran and their protective effects on cell viability of PC-12 AC cells. J. Agric. Food Chem.59, 11473-11482 (2011). 
69. Prieto, M. A., Rodríguez-Amado, I., Vázquez, J. A. \& Murado, M. A. $\beta$-Carotene assay revisited. application to characterize and quantify antioxidant and prooxidant activities in a microplate. J. Agric. Food Chem.60, 8983-8993 (2012).

70. Çam, M., Hışıl, Y. \& Durmaz, G. Classification of eight pomegranate juices based on antioxidant capacity measured by four methods. Food Chem.112, 721-726 (2009).

71. Suzuki, Y. J. \& Packer, L. Inhibition of NF- $\mathrm{BB}$ activation by vitamin $\mathrm{E}$ derivatives. Biochem. Biophys. Res. Commun.193, 277-283 (1993).

72. Liu, S. et al. Relation between changes in intakes of dietary fiber and grain products and changes in weight and development of obesity among middle-aged women. Am. J. Clin. Nutr.78, 920-927 (2003).

73. De Munter, J. S. L., Hu, F. B., Spiegelman, D., Franz, M. \& van Dam, R. M. Whole grain, bran, and germ intake and risk of type 2 diabetes: a prospective cohort study and systematic review. PLoS Med.4, 1385-1395 (2007).

74. Lu, S. C. Regulation of glutathione synthesis. Mol. Aspects Med.30, 42-59 (2009).

75. Miao, L. \& St Clair, D. K. Regulation of superoxide dismutase genes: implications in disease. Free Radic. Biol. Med.47, 344-356 (2009).

76. Hermes-Lima, M. et al. Glutathione status and antioxidant enzymes in a crocodilian species from the swamps of the Brazilian Pantanal. Comp. Biochem. Physiol. A Mol. Integr. Physiol.163, 189-198 (2012).

77. Ross, A. B. Present status and perspectives on the use of alkylresorcinols as biomarkers of whole grain wheat and rye intake. J. Nutr. Metab.2012, 1-12 (2012). 
78. Andrikopoulos, S., Blair, A. R., Deluca, N., Fam, B. C. \& Proietto, J. Evaluating the glucose tolerance test in mice. Am. J. Physiol.-Endoc. M.295, E1323-32 (2008).

79. Winzell, M. S. \& Ahrén, B. The high-fat diet-fed mouse: a model for studying mechanisms and treatment of impaired glucose tolerance and type 2 diabetes. Diabetes53, S215-219 (2004).

80. Muthulakshmi, S. \& Saravanan, R. Protective effects of azelaic acid against highfat diet-induced oxidative stress in liver, kidney and heart of C57BL/6J mice. Mol. Cell Biochem.377, 23-33 (2013).

81. Cao, G., Alessio, H. M. \& Cutler, R. G. Oxygen-radical absorbance capacity assay for antioxidants. Free Radic. Biol. Med.14, 303-311 (1993).

82. Okarter, N. \& Liu, R. H. Health benefits of whole grain phytochemicals. Crit. Rev. Food Sci. Nutr.50, 193-208 (2010).

83. Jensen, M. K. et al. Intakes of whole grains, bran, and germ and the risk of coronary heart disease in men. Am. J. Clin. Nutr.80, 1492-1499 (2004).

84. Marklund, S. L. Extracellular superoxide dismutase in human tissues and human cell lines. J. Clin. Invest.74, 1398-1403 (1984). 